Florida International University FIU Digital Commons

$3-25-2016$

\title{
Consequences of Anthropogenic and Global Change on Orchids: An Emphasis on Biotic Interactions
}

Jason L. Downing

Florida International University, jdown003@fiu.edu

DOI: 10.25148 /etd.FIDC000276

Follow this and additional works at: https:// digitalcommons.fiu.edu/etd

Part of the Biology Commons, and the Ecology and Evolutionary Biology Commons

\section{Recommended Citation}

Downing, Jason L., "Consequences of Anthropogenic and Global Change on Orchids: An Emphasis on Biotic Interactions" (2016). FIU Electronic Theses and Dissertations. 2448.

https://digitalcommons.fiu.edu/etd/2448 


\title{
FLORIDA INTERNATIONAL UNIVERSITY
}

Miami, Florida

\section{CONSEQUENCES OF ANTHROPOGENIC AND GLOBAL CHANGE ON ORCHIDS:}

AN EMPHASIS ON BIOTIC INTERACTIONS

\author{
A dissertation submitted in partial fulfillment of the \\ requirements for the degree of \\ DOCTOR OF PHILOSOPHY \\ in \\ BIOLOGY \\ by \\ Jason Lamar Downing
}


To: Dean Michael Heithaus

College of Arts, Sciences and Education

This dissertation, written by Jason Lamar Downing, and entitled, Consequences of Anthropogenic and Global Change on Orchids: An Emphasis on Biotic Interactions, having been approved in respect to style and intellectual content, is referred to you for judgment.

We have read this dissertation and recommend that it be approved.

$\begin{array}{r}\hline \text { Suzanne Koptur } \\ \hline \text { Krish Jayachandran } \\ \hline \text { Javier Francisco-Ortega } \\ \hline \text { Melissa McCormick } \\ \hline \text { Hong Liu, Major Professor }\end{array}$

Date of Defense: March 25, 2016

The dissertation of Jason Lamar Downing is approved.

Dean Michael Heithaus College of Arts, Sciences and Education

Andrés G. Gil Vice President for Research and Economic Development and Dean of the University Graduate School

Florida International University, 2016 


\section{DEDICATION}

First and foremost I dedicate this achievement to my wife and boys, Elizabeth Anne Gingerich, Miles Lawrence Downing, and Landon (Fuji) Carter Downing. Without their backing this would not have been possible. To Dr. John Cozza, mentor and friend, thank you for introducing me to the world of tropical plants and for your guidance and support throughout my academic journey. To my parents Joyce Ann Smith, Gilbert Leroy Downing, William Smith, Sherri Jordan, Ralph (Doc) and Teddy Gingerich-- I finally finished! I thank you all for the reinforcement and encouragement. Most importantly a special dedication to my mother Joyce Ann, who is my biggest champion and has supported me in more ways than I can list right now, this achievement represents all of the hard work you put into me. 


\section{ACKNOWLEDGMENTS}

I would to thank my advisor and friend Dr. Hong Liu for her intense support, patience, and guidance. She has me an infinitely better scientist, through both rigor, and as a supreme example. She taught me perseverance in the face of many challenges. For these gifts I cannot thank her enough. To my fellow lab mates Melissa Abdo, Mario Cisneros, and Haydee Borrero, I thank you for your friendship and particularly the help in the field over the years. Thank you to my committee Drs. Suzanne Koptur, Krish Jayachandran, Javier Francisco-Ortega, and Melissa McCormick for their guidance and mentorship. Special thanks to Dr. McCormick for being a second mentor, and for introducing me to the field of orchid mycorrhiza. I also thank you for the generous support of the Smithsonian Environmental Research Center, for without this collaboration this dissertation would not have been possible. I am forever grateful for the support from Fairchild Tropical Botanic Garden, especially the Director Dr. Carl Lewis and the Director of Education Amy Padolf. I also thank the Fairchild Challenge Program staff; Sarah Vatland, Juan Rivera, Amanda Noble, Dr. Danielle Palow, Thad Foote, Barbara Martinez and Marion Litzinger. As a Fairchild Graduate Fellow, I have been able to enrich my dissertation research through outreach and education. Many thanks to the Fairchild garden nursery staff Marlon Rumble and Tiffany Lum, for assisting with my plant collections and helping the undergraduate research assistants. Sincere gratitude to Fakahatchee Strand Preserve Biologist Mike Owen, and Dennis Giardina of the Florida Fish and Wildlife Commission (FWC), Atlanta Botanical Garden Conservation Team, Dr. Jenny Cruse-Sanders, and Matt Richards, for their support of my research and providing rare access to some of the rarest orchids in the country. Also I would like to thank Miami-Dade County Parks and Recreation for 
providing the permits for the pine rockland sites in this study. Many thanks to my collaborator Dr. Gao Jiangyun from the Xishuangbanna Tropical Botanical Garden, and Chinese Academy of Sciences who kindly hosted my during my research in China. To my friends and field companions, Wang Xilong, and Jessie Han from the Chinese Academy of Sciences, I thank you for everything during our adventures in Guangxi. I would like to recognize, the exceptional undergraduate researchers that have helped me with over the years Carlos Quintero, Christine Beck, Erin Praver, Maria Barrios, Jay Arce, Jorge LopezPerez, Dailen Alonso, Shan Wong, Josh Wells, Kevin Gallagher, and Roman Caceres. During my dissertation, Funding was provided by the Fairchild Graduate Fellowship Grant, Kelly Foundation Tropical Botany Grant, Tinker Foundation Grant, the McKnight Dissertation Fellowship Program, and the National Science Foundation's East Asian Pacific Islands Summer Institute Grant. 


\title{
ABSTRACT OF THE DISSERTATION \\ CONSEQUENCES OF ANTHROPOGENIC AND GLOBLAL CHANGE ON \\ ORCHIDS: EMPHASIS ON BIOTIC INTERACTIONS
}

\author{
by \\ Jason Lamar Downing \\ Florida International University, 2016 \\ Miami, Florida \\ Professor Hong Liu, Major Professor
}

Evidence suggests that human-driven changes to the earth are having clear and profound effects on many species, as well as the species with which they associate. Disruptions in the interactions between species can change the community structure, in turn changing the dynamics of entire ecosystems. The following dissertation examines how the impacts of climate change related events and invasive species may influence biotic interactions and impact orchid populations and range distributions. Here I quantify how orchid pollinators and mycorrhiza vary between species with different life histories, and between and within habitats. The results showed that orchids with wide range distributions (i.e. geographic or elevational) were more generalized in their mycorrhizal fungi requirements than co-occurring rare and/or narrow ranging species; the rarer species were also more likely to be affected by antagonistic fungal interactions. This dissertation makes a critical contribution to understanding plant and orchid ecology, to assisting ongoing orchid recovery efforts worldwide, and ultimately to developing more comprehensive management plans to mitigate future biodiversity losses. 
TABLE OF CONTENTS

CHAPTER

PAGE

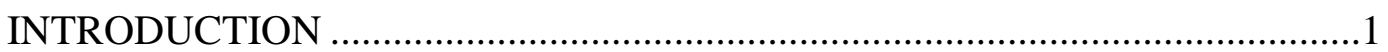

CHAPTERS OVERVIEW …………………………....................................

I SPECIES RESPONSES TO GLOBAL CHANGE: A FOCUS ON ORCHID MYCORRHIZAL ASSOCIATIONS ..........................................................

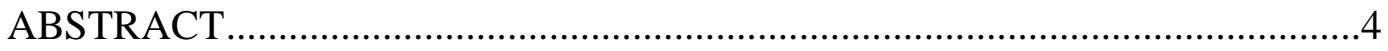

INTRODUCTION .....................................................................................

SPECIES RESPONSES TO GLOBAL CHANGE …......................................

INVASIVE SPECIES AND THEIR ABILITY FOR RANGE EXPANSION ......6 ORCHIDS: A MODEL SYSTEM FOR UNDERSTANDING HOW BIOTIC

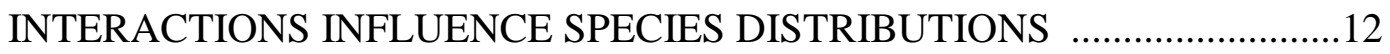

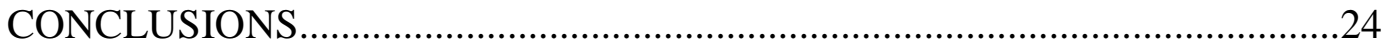

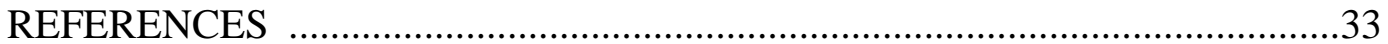

II DIFFERENTIAL IMPACTS FROM AN EXTREME COLD SPELL ON SUBTROPICAL VS. TROPICAL SPECIALIST BEES IN SOUTHERN

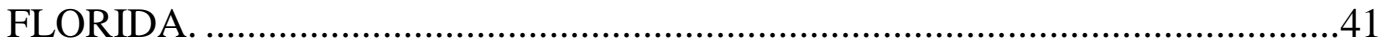

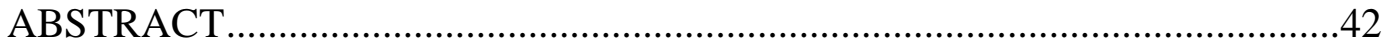

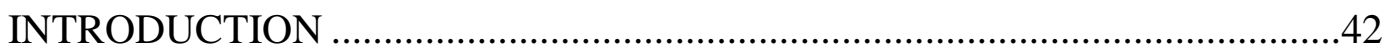

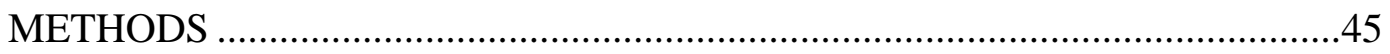

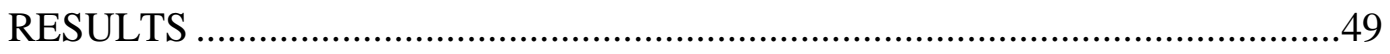

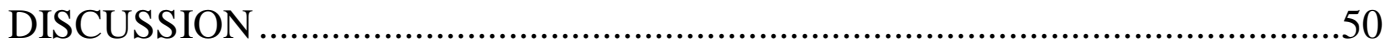

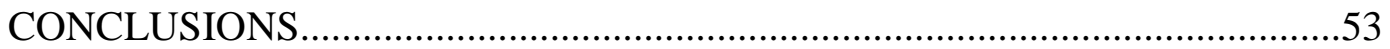

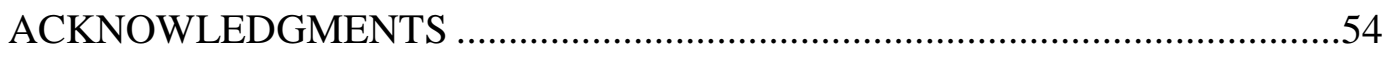

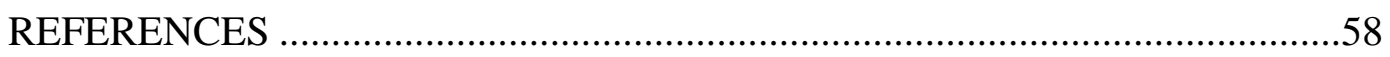

III MYCORRHIZAL ASSOCIATIONS OF NATIVE VERSUS INVASIVE

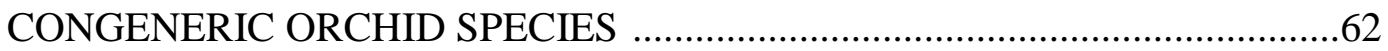

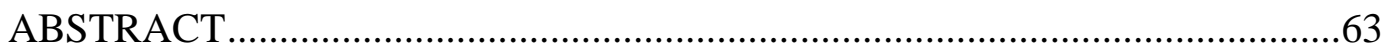

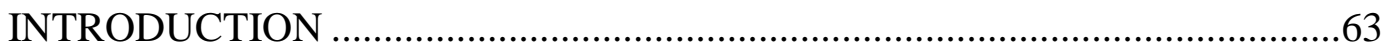

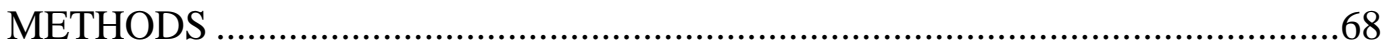

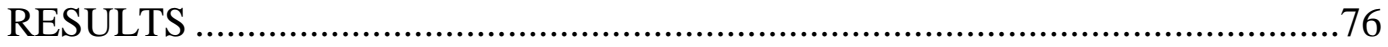

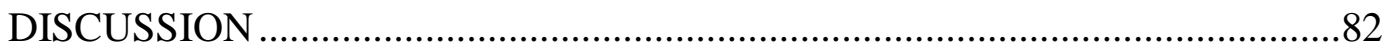

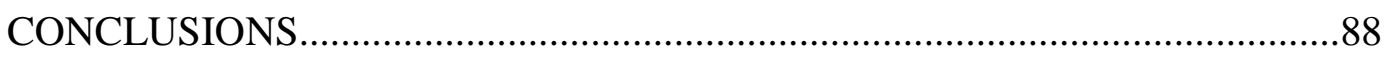

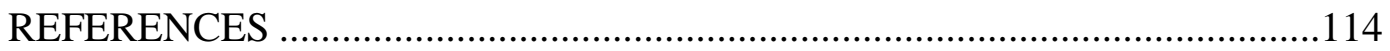

IV MYCORRHIZAL INTERACTIONS: A NEW FACTOR TO CONSIDER IN THE ASSISTED COLONIZATION OF ORCHIDS ....................................120

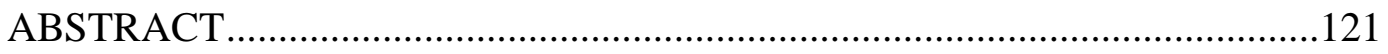

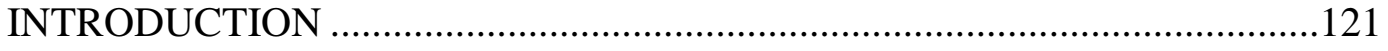

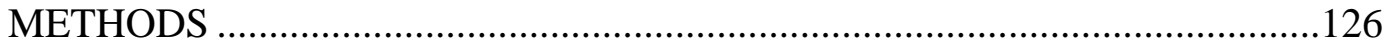




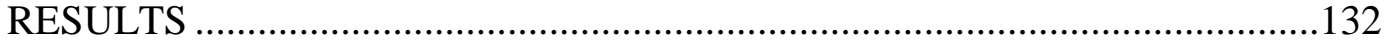

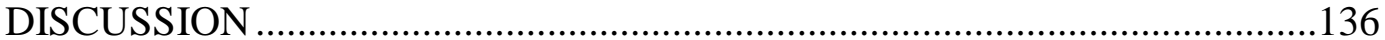

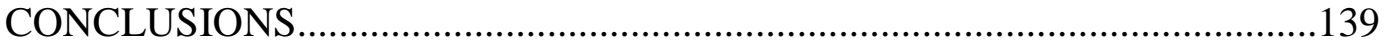

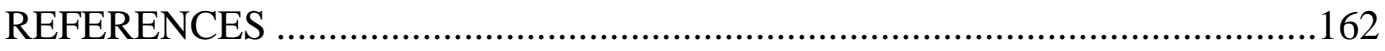

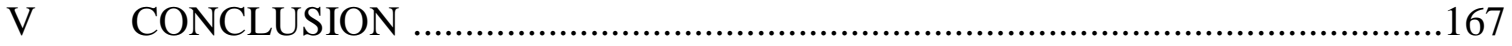

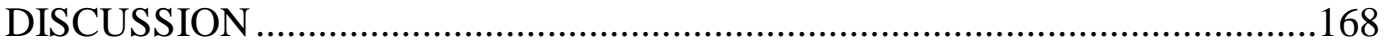

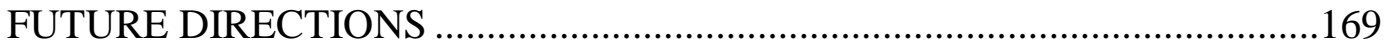

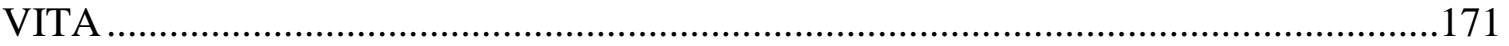




\section{LIST OF TABLES}

TABLE

PAGE

\section{CHAPTER II}

2.1 Visitations by the subtropical bee Centris errans and the tropical bee Centris nitida to Byrsonima lucida and Cyrtopodium punctatum plants.

\section{CHAPTER III}

3.1 Information about the fungal ITS sequences obtained for each orchid species. Included in this table: site, habitat, life stage, sequence length (bp), closest related taxa and their GenBank accession numbers. $(*)=$ seedlings with protocorm

3.2 Number of Rhizoctonia OTUs identified in non-Tulasnellaceae basidiomycete (NTB) and Tulasnellaceae groups from native orchids at three sites (FTBG, FSS, CSS), and from invasive orchids at three sites (FTBG, ZOO, BT). $H^{\prime}=$ Shannon-Weiner diversity index and $J^{\prime}=$ the evenness index, $\operatorname{SE}(x)=$ standard error. Numbers in bold represent mean diversity indices for each group. $*=$ statistically significant difference

3.3 Number of Ascomycetes OTUs identified from native and invasive orchids at three native sites in southern Florida and one native site in Yunnan Province China (XTBG), and four invasive sites in Miami-Dade County, Florida. $\mathrm{H}^{\prime}=$ Shannon-Weiner diversity index and J' = the evenness index, $\mathrm{SE}\left(\mathrm{x}^{\prime}\right)=$ standard error. Numbers in bold represent mean diversity indices for each group

3.4 Mean pairwise distances (MPD) were calculated based on ML consensus trees for NTB and Tualsnellaceae sequences obtained from native and invasive orchid species. Numbers shown in bold represent total breadth of associates for each $\mathrm{f}$ ungal type.

\section{CHAPTER IV}

4.1 Information about the fungal ITS sequences obtained for each orchid species. Included in this table: site, species range type (wide range or narrow (high and low ranges), sequence length (bp), two closest related taxa and their GenBank accession numbers, and percent identity. 
4.2 Number of OM sequences identified in from narrow and wide range elevational orchid species at six sites. $H^{\prime}$ = Shannon-Weiner diversity index and $J^{\prime}=$ the evenness index. Numbers in bold represent mean $\left(\mathrm{H}^{\prime}\right)$ and $(\mathrm{J}$ ') values.

4.3 Number of OM sequences identified from four orchid species at seven natural and one translocated sites. $\mathrm{H}^{\prime}$ = Shannon-Weiner diversity index and J' = the evenness index. Numbers in bold represent mean $\left(\mathrm{H}^{\prime}\right)$ and $\left(\mathrm{J}^{\prime}\right)$ values................145 


\section{LIST OF FIGURES}

FIGURES

PAGE

\section{CHAPTER I}

1.1 Conceptual model showing the invasion process and documented impacts. Species are assisted by humans across geographical barriers. Many species are introduced but must overcome novel environmental barriers that impede or prevent establishment and spread, resulting in relatively few species becoming invasive. However these species can have a disproportionate amount of negative impacts that are inter-related.

1.2 Photos show specialist oil-bees visiting the oil-rewarding plant Byrsonima lucida. Plate (a) shows Centris errans a subtropical oil bee native to southeast Florida. Plate (b) shows Centris nitida introduced oil-bee from Central America. Photos courtesy of Hong Liu and Haydee Borrero.

1.3 Plates showing the fruit and dust seeds of Cyrtopodium punctatum. (a) shows $C$. punctatum fruit which can produce $>2$ million seeds. (b) seeds of Eulophia alta (c) dark field photo showing desiccant resistant seed coat.

1.4 Rapid growth of the invasive orchid Cyrtopodium flavum protocorm germinated in situ on mulch in Miami-Dade County, Florida. (a) shows 6 week old protocorm with fungal penetration (arrow). (b) 8 week old protocorm with early root formation (double arrows). (c) early seedling stage at 12 weeks with early leaf development (arrow) and root formation ..................................................28

1.5 Diagram showing the Cyrtopodium punctatum life cycle

1.6 Table describing different types of mycorrhiza and major features of each group. * limited evidence for carbon acquisition by fungi (Cameron et al. 1997)

1.7 Plate showing different in situ fungi baiting techniques. (a) shows direct application of orchids seeds onto appropriate host tree bark, (b) close up of seeds on bark surface. (c) Photo showing nylon mesh seed packets; each compartment contains 50 seeds applied on sterile filer paper. In situ seed packets we placed in different microhabitat types including (d) humic spaces, (e) directly on back surface, and (f) near recruits

1.8 Fungal pelotons (a) isolated from root cells of Cyrtopodium flavum. Single pelton after 24 hours growing on Basal Salts Media (Caldwell et al. 1999) with a 
broad spectrum antibiotic and showing early hyphal extensions (arrow). (b) Pelton after 48 hours showing complex branching of the hyphal extensions (arrows). (c) Four fungal isolates after 1 week of growth. (d) Indvidual fungal isolate 3 weeks after sub-culturing forming a well-defined hyphal mat; isolate was identified as a member of the Order Polyporales

\section{CHAPTER II}

2.1 Visitation rates (no. of visits per minute) to Byrsonima lucida. The light line represents the native bee $C$. errans, and the dark line represents the introduced bee $C$. nitida, error bars represent +/- 1 standard error. Dashed lines represent the overall trajectory between years 2012-2014.

2.2 Visitation rates (no. of visits per minute) by each bee species to Cyrtopodium punctatum. The light line represents the native bee $C$. errans, and the dark line represents the introduced bee $C$. nitida. Error bars represent +/- 1 standard error.

Dashed lines represent the overall trajectory between years 2012-2014.

\section{CHAPTER III}

3.1 Plate showing Cyrtopodium punactatum (a) flower, (b) seedling with protocorm body, and (c) adult at Fakahatchee Strand State Park, in southwest Florida.

3.2 Plate showing the invasive Cyrtopodium flavum (a) flower, (b) adult plant at Boystown Pineland, Miami-Dade County, Florida, and (c) small adult plant illustrating the prolific flowering abilities in this species.

3.3 Plate showing Eulophia alta (a) flower (photo courtesy of Christine Cook), (b) seedling, (c) adult plant, and (d) adult plant with fruits. All plants were located at Corkscrew Swamp Sactuary in southwest Florida.

3.4 Plate showing the invasive Eulophia graminae (a) flowers (photos courtesy of Christine Cook), (b) adult plant at Xishuangbanna Tropical Botanic Garden, Yunnan Province, China (c) adult plant growing alongside C. flavum at Boystown Pineland, Miami- Dade County, Florida and (d) seedling growing epiphytically on Pinus elliotti at Fairchild Tropical Botanic Garden, Coral Gables, Florida. All plants were located at Corkscrew Swamp Sanctuary in southwest Florida.

3.5 Plates showing symbiotic seed germination for invasive orchid species; (a) shows protocorm of Cyrtopodium flavum recovered from fungal baits at the invaded Boystown Pineland site, (b) protocorms of $C$. flavum showing hyphal penetration 
recovered in situ in mulch near ZOOMiami, Miami-Dade County, Florida, and (c) a protocorm of E. graminae recovered in situ at Fairchild Garden site. .....102

3.6 Plates showing (a) Cyrtopodium punctatum seedling with apical meristem and protocorm body, and (b) C. punctatum roots with fungal hyphae at Fakahatchee Strand State Park (photo courtesy of Dennis Giardina).

3.7 Plates showing fungal baits; (a) nylon mesh compartments with sterile filter paper each containing 50 seeds, (b) fungal bait deployed beneath organic debris at the base of a bald cypress trunk at Fakahatchee Strand State Preserve site, (c) bait deployed in a crevice of buttonwood at Fairchild Garden site, and (d) fungal baits containing invasive orchid seeds were placed in metal cages filled with pine needle litter and decomposing organic debris

3.8 Pie charts showing the number and diversity of fungal OTUs identified in four congeneric orchid species in southern Florida; (a) and (c) are native species, (b) and (d) are invasive species. NTB = non-Tulasnellaceae basidiomycete; $\mathrm{N}=$ number of sequences included; $n=$ total number of OTUs detected

3.9 Pie charts showing the breakdown of the total number of different fungal OTUs identified between the (a) native species, and (b) invasive species. NTB = nonTulasnellaceae basidiomycete.

3.10 Comparison of mycorrhizal communities associating with native and invasive orchid congeners. Native orchids sites included FTBG, FSS, and CSS. Invasive orchid sites included FTBG, BT, ZOO, and CSS. n= total no. of OTUs.

3.11 Maximum-likelihood trees (500 bootsraps) of ITS sequences of Ascomycete fungi isolated from the congeneric pairs, Cyrtopodium punctatum and Eulophia alta (natives), and Cyrtopodium flavum and Eulophia graminae (invasives) in southern Florida. Topology shows the relationships between native and invasive species and their relative associations with putative orchid mycorrhizal groups (OTU1), and plant pathogens (OTU2). Numbers indicate bootstrapping percentage supporting the branches

3.12 Maximum-likelihood trees (500 bootsraps) of ITS sequences of nonTulasnellaceae basidiomycete (NTB) fungi isolated from the congeneric pairs, Cyrtopodium punctatum and Eulophia alta (natives), and Cyrtopodium flavum and Eulophia graminae (invasives) in southern Florida.

3.13 Maximum-likelihood trees (500 bootsraps) of ITS sequences of nonTulasnellaceae basidiomycete (NTB) fungi isolated from the congeneric pairs, 
Cyrtopodium punctatum and Eulophia alta (natives), and Cyrtopodium flavum and Eulophia graminae (invasives) at FTBG, FSS, CSS, BT, and ZOO sites in southern Florida. The branches support two Clades, clade A and clade B, and

OTUs 1-6

3.14 Graph showing the mean percent germination rates for native and invasive orchid species as a result of in situ bating techniques over five study sites (FTBG, ZOO, BT, FSS, and CSS). Different letters symbolize statistically significant differences; based on Tukey HSD posthoc comparisons.

\section{CHAPTER IV}

4.1 Plates showing Cymbidium bicolor flower (a), and plate (b) shows a large plant growing epiphytically at Mulun Nature Reserve in Guangxi Province.

4.2 Plates showing Geodorum eulophioides flowers (a) and translocated plant at Yachang Reserve (b).

4.3 Plates showing the flowers of Paphiopedilum hirsutissimum (a) and Paphiopedilum dianthum (b)

4.4 Map showing studies site in Guangxi Province, China. Star show the Yachang National Reserve which includes the orchid garden and Laya cliffs natural sites, and the translocated site. Black dots show three low elevation natural sites sampled in the region.

4.5 Plate showing the limestone mountains and subtropical forests in Guangxi Province, China. Photo shows the Huanjiang Karst cluster which is part of the South China Karst formation 150

4.6 Plate showing a village near Yachang National Nature Reserve in Leye County, Guangxi Province, China.

4.7 Plate showing the Karst Formations in Guangxi Province, China; a world Karst Heritage Site 
4.8 Plate showing the limestone cliffs at the Laya site at Yachang National Nature Reserve.

4.9 Maximum- likelihood trees (500 bootstraps) of ITS sequences of Ascomycete fungi isolated from four translocated orchid species, Geodorum eulophioides and Cymbidium bicolor (narrow elevational ranges), and Paphiopedilum dianthum and Paphiopedilum hirsutissimum (wide elevational ranges) in Guangxi Province. Topology shows the fungal relationships between these species and their relative associations with putative orchid mycorrhizal groups (OTUH). Sequences in bold an italics represent translocated plants. Numbers indicate bootstrapping percentage supporting the branches.

4.10 Maximum- likelihood trees (500 bootstraps) of ITS sequences of Rhizoctonia fungi isolated from four translocated orchid species, Geodorum eulophiodes and Cymbidium bicolor (narrow elevational ranges), and Paphiopedilum dianthum and Paphiopedilum hirsutissimum (wide elevational ranges) in Guangxi Province. Topology shows the fungal relationships between these species and their relative associations with putative orchid mycorrhizal groups Tremellaceae, Ceratobasidiaceae, Thelephoraceae, and Tulasnellaceae (OTUs A, B, and C). Sequences in bold an italics represent translocated plants. Numbers indicate bootstrapping percentage supporting the branches

4.11 Pie charts showing fungal sequences breakdowns for all natural (a, c, e, and g) and translocated (b, d, f, and h) populations. Species included Geodorum eulophioides ( $\mathrm{a}$ and b) and Cymbidium bicolor (c and d), Paphiopedilum dianthum (e and f) and Paphiopedilum hirsutissimum (g and h). N= number of plants samples, and $\mathrm{n}=$ total number of sequences

4.12 Pie charts showing fungal sequences breakdowns for narrow elevational species ( $a$ and $b$ ) and translocated (c and d) populations. $\mathrm{N}=$ number of plants samples, and $n=$ total number of sequences.

4.13 Venn diagrams showing the total number of unique mycorrhizal OTUs detected for wide elevational species (large ovals) and narrow elevational species (small ovals). Blue-green ovals represent translocated site, and the lighter green ovals represents all natural sites combined. Numbers on y-axis represent elevational ranges for each of the population types 


\section{INTRODUCTION}

DISSERTATION CHAPTERS OVERVIEW 


\section{CHAPTERS OVERVIEW}

The dissertation chapters have been written up as separate manuscripts that have been or will be submitted for publication: Chapter one- Species responses to global change: a focus on orchid mycorrhizal associations, is intended for publication in Issues in Ecology; Chapter two- Differential impacts from an extreme cold spell on subtropical vs. tropical specialist bees in southern Florida, has been accepted for publication in the journal Ecosphere; Chapter three- Mycorrhizal associations of native versus invasive congeneric orchid species, is intended for publication in Ecology; Chapter fourMycorrhizal interactions: a new factor to consider in the assisted colonization of Chinese orchids, is intended for publication in Conservation Biology. Chapter five- Conclusions and future directions. 


\section{CHAPTER I}

SPECIES RESPONSES TO GLOBAL CHANGE: A FOCUS ON ORCHID MYCORRHIZAL ASSOCIATIONS 


\section{ABSTRACT}

This introduction examines how current anthropogenic pressures can affect biotic interactions in orchids, and how orchid species range distributions and abundances may respond. First, I review how other species have responded to climate change through range expansions, shifts in phenology, and alterations in their biotic interactions. Then I focus on species invasions as an important component of current anthropogenic change, and the potential mechanisms that enable invasions; such as acquisition of novel beneficial interactions, and/or the loss of antagonistic partners from the incipient ranges (enemy release hypothesis; ERH). Because of their substantial dependence on pollinators and mycorrhizal fungi, orchids are a model system for understanding how these changes in biotic interactions shape species distributions. Throughout the introduction I examine in detail the role of specialization in pollination and mycorrhizal associations and their influence on orchid diversity, distributions, and population dynamics. Finally, I preview the subsequent research chapters, which apply comparisons of specialized congeneric species that have been subject to range expansions, both intentionally (assisted colonization) and unintentionally (introduced species). In summary, this dissertation research directly addresses some of the gaps regarding orchid populations, especially in the sub-tropics and tropics. It will also help determine how orchid pollinators and mycorrhiza may vary between species, and between and within habitats, both of which are critical to understanding orchid ecology, and to assisting ongoing orchid recovery efforts worldwide. 


\section{INTRODUCTION}

Anthropogenic impacts are one of the most urgent and challenging issues facing our planet, affecting every landmass, ocean, and all major taxonomic groups of organisms (IPCC 2014, Root et al. 2003, Parmesan 2006). Human impacts on natural systems have been broadly summarized into three interlinked processes: land and ocean transformation, alteration of global biogeochemical cycles, and biotic additions and losses (Vitousek 1997). Changes to these processes can in turn have profound effects on ecosystem function and biodiversity. However, detecting causation and/or a relationship between specific human activities and discernable trends remains challenging. Accordingly, research that can help quantify the ecological responses to human activities is necessary, both to explain globally emergent patterns and to inform conservation actions.

This research focuses on how current anthropogenic pressures affect biotic interactions in orchids, and how orchid species distributions and abundances may respond. Orchids provide an ideal study system to understand how biotic interactions may affect plant populations and diversity, because of their extreme dependence on pollinators and mycorrhizal fungi. Understanding the flexibility in these specialized interactions in orchids is urgent, because climate change related phenomena are expected to disproportionately affect those species that depend heavily on other species (Fitter et al. 2000, Compant et al. 2010). 


\section{SPECIES RESPONSES TO GLOBAL CHANGE}

\section{Range Expansions}

Human-caused global warming has already negatively affected ecosystems and biota (Walther et al. 2009, IPCC 2014), and has led to changes in species distributions (Parmesan \& Yohe 2003, Feeley et al. 2011, 2014). Range shifts, both poleward in latitude and higher in elevation, are predicted as species respond to gradual temperature increases (Root et al. 2003, Parmesan et al. 2006). A meta-analysis conducted by Parmesan and Yohe (2003) estimated that Northern Hemisphere species will move on average $6.1 \mathrm{~km}$ farther north or $6.1 \mathrm{~m}$ upward in elevation per decade. Species ranges are also strongly affected by stochastic events such as extreme weather. Many studies have documented species' responses to extreme climate, including changes in physiological tolerances and phenology (Menzel et al. 2011, Liu et al. 2014), and species abundance and distributions (Parmesan et al. 2000, Wang et al. 2015). For example, range contractions and expansions have been observed for several butterfly (Lepidoptera) species in Finland, in response to seasons with "harsh" versus "favorable" weather conditions (Kaisila 1962, Dennis 1993). Most of these studies, however, have taken place in the temperate zones; while relatively little is known about climate- and weathermediated responses of species in the sub-tropics and tropics, (but see Feeley et al. 2011, 2013).

\section{Phenological Shifts}

While causing species distributions to change spatially, climate change can also cause phenological changes in species life histories and can be used as indicators of the 
species level impacts of climate change (Menzel et al. 2006, 2011, Schwartz et al. 2006, Miller-Rushing and Primack 2008, Liu et al. 2014). Phenotypic plasticity and rapid adaptive evolution of the affected species will be mechanisms in which future community assemblages and ecosystem services will be determined (Anderson et al. 2012). When

examining Northern Hemisphere species, quantitative analyses of phenological responses gave estimates of an advancement of 2.3 days per decade across all species (Parmesan \& Yohe 2003). Changes in phenologies have been documented best in temperate plants, insects, and birds; likely because the changes in seasons are often cues for leaf flush and flowering in plants, date of first emergence after diapause in insects, and migration in birds (Parmesan 2006, Richardson et al. 2013). In tropical forests, community level differences in phenology tend to be driven by the duration of the dry season (Reich 1995), or by seasonal variation in insolation (Calle et al. 2010), but exceptions exist (Liu et al. 2014). Yet, once again, relatively little is known. There is a lack of long term, multi- species studies, over a variety of habitats that show shifts in phenologies related to climate change in the tropics (Richardson et al. 2013, Liu et al. 2014).

\section{Alteration of Biotic Interactions}

Since different life forms use different cues for phenology, climate change will have direct and/or indirect impacts on species interactions, especially when interactions are specialized, or involve only a few interacting taxa. Biotic interactions are key drivers of community structure and thus, if they remain intact, could ameliorate species responses to climate change (Blois et al. 2013). On the other hand, disrupting the interactions between species, particularly primary producers and their mutualistic 
partners, could have a strong influence on community structure and dynamics, which in turn would change the dynamics of entire ecosystems. Evidence suggests that continued changes in climate will harm or remove mutualistic partners of plants, such as pollinators and mycorrhizal fungi (Fitter et al. 2000, Memmot et al. 2007, Compant et al. 2010, Gillman et al. 2010, Potts et al. 2010). However, so far most studies have focused only on the direct effects of climate change on individual species (Gillman et al. 2010). Studies that include changes in the interactions of species within the community will provide the most realistic assessment of the potential impacts of climate change, and will be necessary for developing viable management plans to mitigate biodiversity losses.

\section{INVASIVE SPECIES AND THEIR ABILITY FOR RANGE EXPANSION}

Understanding what traits and life histories enable invasive species to expand beyond their natural ranges can provide invaluable insights into how native species may respond to global change. Ecologists have long sought to discover a comprehensive list of traits that different invasive species may share (Ehrlich 1986, Roy 1990, and Rejmanek and Richardson 1996). A goal of compiling such lists is to construct predictive tools to screen potential invaders or eliminate dispersal vectors. However, with few exceptions (Pheloung et al.1999), the predictive traits for invasiveness have varied among taxonomic groups (Rejmanek and Richardson 1996, Mack et al. 2000). In order to control for confounding phylogenetic effects, it is most effective to study the invasive potential of closely related taxa, especially congeners in their incipient and recipient locations, and to conduct comparative studies that can help identify which combinations of traits lead to successful invasions. Linking these traits, once found, to specific genetic markers using 
modern molecular techniques is a burgeoning area of invasion biology research (Prentis et al. 2008, Le Roux and Wieczorek 2009).

In addition to inherent traits that can enhance invasion success, evidence suggests that a species' ability to establish and spread is also correlated to the number of beneficial or novel biotic interactions they can acquire in their new ranges (Richardson et al. 2000, Mitchell et al. 2006, Bonnardeaux et al. 2007, Pringle et al. 2009, Wood et al. 2015). These critical interactions can have a strong influence on how species respond to change, and whether they become invasive. One could then assume that this would favor either generalist strategies or usage of widespread mutualists, since the chances of finding a highly specialized or endemic partner in a novel range are unlikely. However, invasions may not necessarily be dependent on frequent encounters with highly diverse mutualists. In Chile, the recent introduction of a single ectomycorrhizal fungal species (ECM) has enabled the rapid spread of the highly invasive tree Pinus contorta (Hayward et al. 2015). Reports of this highly specialized co-invasion between Pinus and ECM fungus, have been widely reported throughout the southern hemisphere (Chu-Chou and Grace 1988, Chapela et al. 2001, and Wood et al. 2015). Interactions with novel partners can also affect the extent of invasiveness of a species trait. When the invasive plant Microstegium vimineum (Japanese Stiltgrass) associated with an arbuscular mycorrhiza (AM) native to temperate North America, it had a positive effect on growth and changed its functional morphology to promote dispersal (Lee et al. 2014). Conversely, a lack of beneficial interactions may also limit the spread of introduced species. In general plant species that are non-autogamous, capable of apomixis, and/or those plants whose pollinators are lacking in a new range tend not to become invasive (Pheloung 1999). 


\section{Ecological release as a mechanism for range expansion}

Although there is some support for a suite of traits, and certain beneficial interactions, that might enable invasiveness, an alternative explanation is the enemy release hypothesis (hereafter ERH; Crawley 1987, Keane and Crawley 2002, Wolfe 2002, Liu and Stiling 2006). According to the ERH, some species are able to successfully invade, after introduction, because they have been ecologically released from their natural enemies (i.e. competitors, predators, and pathogens) in their introduced ranges. For plants, these natural enemies could attack from above ground, as many insect herbivores do, or from belowground, as many fungal pathogens do, in their incipient range, these antagonistic interactions would suppress individual growth and vigor, and may help regulate population sizes. However, all enemies are not created equal. Accordingly, to adequately test the ERH, it is necessary to distinguish between compensatory versus regulatory enemy release, and generalist and specialist enemies.

Compensatory enemy release occurs when the introduced species loses enemies that it is well defended against; these are often considered generalist enemies (Wolfe 2002). In the native range, these interactions can be viewed as common and inevitable, making adaptions for defense necessary. If there is a substantial cost to these defenses, then a loss of the enemies could allow resources to be re-allocated to growth and reproduction (Blossey and Nötzold 1995, Koricheva 2002, Joshi and Vrieling 2005). In view of that, compensatory release assumes that defense traits are genetically driven, phenotypically plastic, and able to be rapidly lost through selection.

In contrast, regulatory enemy release is the loss of an enemy that the host species has little defense against. Such enemies can be specialized for the host species, and are 
likely to be strong regulators of populations. When released from these enemies, the introduced species are likely to experience immediate increases in survivorship, fecundity, and overall fitness in the introduced range. Although the compensatory and regulatory scenarios are not mutually exclusive, in plants specialist enemy species such as fungal pathogens and specialist frugivores have a disproportionate effect on fitness, in comparison to more generalist enemies such as leaf herbivores and aphids (Keane and Crawley 2002 and Wolfe 2002). Thus, regulatory release would be expected to produce a greater potential for invasiveness than compensatory release would.

However attractive the ERH can be in its simplicity, research testing it has been largely inconclusive (Willis et al. 2000, Vila et al. 2003, Liu and Stiling 2006, Liu et al. 2007). In a review paper, Colautti et al. (2004) reported that 25 studies conducted at the biogeographic and community levels showed mixed results. Furthermore, at the community level, studies showed that introduced host species were affected by (their new) enemies just as much as native host species, and thus experienced no enemy release (Colautti et al. 2004). In translocation experiments conducted by Willis and Blossey (1999) increased vigor in Lythrum salicaria (Lythraceae) plants was significantly related to genotype differences rather than location differences, and thus the ERH hypothesis alone was not sufficient to explain increased vigor.

Even when enemy release has been demonstrated, relatively few studies have compared the effects of host enemies in native and introduced ranges (Willis et al. 1999, Memmot et al. 2000, Maron et al. 2004). Wolfe (2002) quantified the damage incurred from different enemies to Silene latifolia (Caryophyllaceae), a dioecious perennial plant accidently introduced from Europe, and considered to be invasive in North America. The 
study found that plants were more likely to be damaged and encountered a greater variety of enemies in their native range than in the introduced range. In general, it is likely that introduced plants will be affected to some degree in their new ranges by new host enemies, thus somewhat counteracting the loss of their (previous) natural enemies, on the biogeographical scale. Although more work is needed, one simple relationship between host and enemy is probably insufficient to fully explain species invasions.

\section{ORCHIDS: A MODEL SYSTEM FOR UNDERSTANDING HOW BIOTIC INTERACTIONS INFLUENCE SPECIES DISTRIBUTIONS}

An ideal system for studying global change on species distributions should allow simultaneous testing of the kinds of species interactions likely to be affected. Such a system should thus be dependent on specialized mutualistic interactions, and feature closely-related native and introduced species. All of these criteria are to be found in orchids. Orchidaceae is a hyper-diverse plant family, with an estimated 880 genera and 27,800 species (Stephens 2015) (Angiosperm Phylogeny Website; hereafter APGIII). This monocot family is strongly supported as a monophyletic group, and is sister to all other groups within the Asparagales (Givinish et al. 2015). Orchids as a group have an enormous distribution and occupy a wide range of habitats. They are found on all the continents except Antarctica, and in all habitat types except the driest deserts and the arctic (APGIII). Darwin thought that the orchid family’s great distribution and diversity was a result of coevolved adaptations to their specialized pollinators. However, more recently, it has been shown that orchids also depend on specialized associations with mycorrhizal fungi for seed germination and seedling survival, and for optimal growth in 
later life stages (Rasmussen 1995, Taylor et al. 2003, McCormick et al. 2006, Otero and Flanagan 2006, Shefferson et al. 2007, Rasmussen et al. 2015). About 170 species of orchid have taken this to an extreme and produce no chlorophyll at all, thus remaining totally dependent on fungi throughout their life cycle (Leake 1994). Because of their central roles in reproduction and recruitment, it is likely that both adaptations to novel pollinators and to mycorrhizal fungi are driving orchid diversity and distributions.

Orchids represent a full spectrum of biotic interactions and population abundances, from rare to dominant, and specialist to generalist. This allows exploration of the life history traits that might lead to differences in relative abundance and distribution in plants. One hypothesis is that rare orchid species may have more specialized or narrower requirements for their biotic interactions than their more abundant relatives. Specialization in both pollination and mycorrhizal interactions has been shown to influence orchid species abundance and distribution (Tremblay et al. 2005, Swart and Dixon 2009), and so the lack of these associations would likely impede the establishment of some orchids outside their native ranges (Daehler 1998). However, some orchid species have nonetheless established in non-native ranges and habitats. Approximately 90 orchid species are listed as weedy (Ackerman 2012, Liu and Pemberton 2010, Jonathan et al. 2012).

\section{Orchid pollination, specialization, and range expansions}

Orchids have specialized pollination systems and are well known for their complex floral designs and chemical attractants to lure specific pollinators (Darwin 1862, Dodson 1975, Cozzolino and Widmer 2005). However, other plant families with far less 
diversity also have evolved specialist pollination systems; some well-studied examples being Cactaceae, Malpighiaceae, Clusiaceae, Moraceae, and Scrophulariaceae (Judd et al. 1999, Johnson and Steiner 2000). Nearly one-third of all orchid species are 'cheaters' that provide no nutritional reward to the pollinator (Ackerman 1986, Nilsson 1992). Some non-rewarding orchids even demonstrate sexual deception, in which the flowers mimic the mating cues of insects (Cozzolino and Widmer 2005, Schiestl 2005). These cheater interactions are highly specialized, and exploit the pollination services of a limited clientele that can be genus- or species-specific. For example, Ophrys orchids mimic the appearance and pheromones of sexually receptive females of a single species of Andrena bee. The orchid's visual and olfactory cues induce copulation behavior in male bees, during which pollinia are transferred (Schiestl et al. 1999). Throughout the neotropics, Cyrtopodium or "cowhorn" orchids commonly exploit the services of oil-collecting bees in the genus Centris (Pansarin et al. 2008, Pemberton and Liu 2008, Liu and Pemberton 2010, Downing et al. 2016). Centris bees are part of a specialized oil-reward pollination system with oil plant species in the family Malpighiaceae (Fig 3; Anderson 1979, Buchmann 1987, Downing and Liu 2012, Downing et al. 2016). In the case of Cyrtopodium orchids, it is thought that the primary floral attractant is morphological mimicry of co-occurring rewarding species (Luer 1972), but further research is needed to identify the specific floral cues. Although specialist pollination can be a major reproductive limitation, some introduced orchid species are able to take advantage of specialist pollinators even within their new ranges (Pemberton and Liu 2010). Stouffer et al. (2014) found that specialist pollinators despite being weak contributors to community nestedness were more likely to interact with introduced plant species. 
Once the pollination barrier has been overcome, orchids can have great potential for range expansion and invasion. They produce thousands of minute dust-like seeds adapted for wind dispersal, and are so small that the seed coat (testa) of these tiny seeds appears transparent, and the embryo can be observed using a dissecting microscope (Fig 4). These seeds are so easily dispersed by wind, that there is evidence of some species' seeds crossing oceans (Renner 2004). Orchids' ability for long distance dispersal has led to the formation of many widely separated populations in various species (Vasquez et al. 2003), and give orchids the amazing capacity to expand to new habits and beyond native ranges. However, fewer than expected orchid taxa have become established outside their native ranges (Pemberton and Liu 2009, Ackerman 2008), and the tradeoff for this great dispersal potential is that the seeds contain no nutritional reserves (endosperm) to initiate germination (Arditti \& Ghani 2000).

Thus, as previously mentioned, orchid seeds germinate only after coming into contact with appropriate mycorrhizal fungi in the environment. Once germinated, seeds grow into a mass of differentiated achlorophyllous cells called a protocorm. The protocorm phase may extend for a variable period of time until chlorophyll and the first leaves are produced. Depending on the species, the protocorm stage may be very short, or it may extend up to several years (Fig 5; Leake 1994). Since the crucial mycorrhizal fungi are temporally and spatially variable in their distribution, orchid recruitment might also vary, and thus the fungi ultimately determine orchid population abundances and distributions. If not inoculated, at least some orchid seeds can remain dormant for long periods, in some cases $>10$ years (Whigham et al. 2006). The spatial and temporal constraints on orchid recruitment are similar in effect to the specialized and infrequent 
pollination events they experience. This creates another bottleneck in the life history of orchids and can restrict range expansions (Fig 6).

\section{Mycorrhizae: A brief overview}

The most prevalent and beneficial organisms associated with plants are mycorrhizal fungi, obligate mutualists that interact with plant roots. Mycorrhizal associations form in nearly all terrestrial habitats on the planet (Smith and Read 2010). There is considerable variation in the morphology and function of mycorrhizae, but in all cases, the plants obtain essential plants nutrients from the fungi (Fig 7). The two fundamental differences between plant interactions with mycorrhizal fungi and with other types of plant associated fungi are: 1) mycorrhizal fungi interact with plant roots, and 2) root colonization by mycorrhizal fungi does not cause disease; it is the normal state for most plants in natural settings.

Two broad categories of mycorrhizae are ecto- and endomycorrhiza. ECM fungi are the most ecologically prevalent type of mycorrhizal association, because they are characteristic of dominant trees in biomes such as taiga, oak savanna, and eucalyptus woodland. ECM fungi do not produce intracellular hyphae, and are instead characterized by the formation of the mantle sheath and Hartig net around the roots of perennial trees species (Smith and Read 2008). The endomycorrhizal (EM) fungi are more diverse and variable than ECM, and include arbuscular (AM), Ericoid, and orchid (OM) mycorrhizal fungi. These fungi are characterized by intracellular penetration and the development of specialized hyphal structures within the cortical cells of roots. The developmental differences and morphology of these intracellular structures are key diagnostic features of 
the various endomycorrhizae. For example, the defining characteristic of $\mathrm{OM}$ is the fungal coils called 'pelotons' that are confined to the root cortical cells (Peterson et al. 1998). Unlike in AM and ECM, the root interface structures produced by the fungus are not stable; the OM pelotons are consumed by the host root, and their nutrients absorbed, allowing for colonization by a new fungus. However, there remains a debate about the true mutualistic nature of $\mathrm{OM}$ and there have been some suggestions that in certain conditions OM may be more mutualistic than was previously assumed (Cameron et al. 2006, 2008, Rasmussen and Rasmussen 2009).

\section{Orchid mycorrhizal associations}

The fungi that form OM are a polyphyletic group (Rasmussen 1995) and include both Ascomycota (Helotiales) and Basidiomycota (the most common group being the form genus Rhizoctonia; see Fig 7). These fungi are difficult to classify morphologically due to that lack of complex fruiting bodies. Rhizoctonia species are also difficult to identify morphologically from living cultures, and as a result molecular methods have become the standard for the identification of OM taxa. Major advances in the detection of OM were facilitated by the development of OM specific PCR primers (Taylor and McCormick 2008), in situ and ex situ seed sowing techniques (Fig 8; Rasmussen 2002, Brundett et al. 2003), and improved fungal isolation methods (Caldwell et al. 1991). There are two approaches to isolating OM: direct isolation and culturing of individual pelotons (Fig 9), and isolation from entire root sections. The first is the preferred method to obtain definitively OM isolates, whereas the latter method will also detect fungi that 
are not producing pelotons within the roots; these isolates are likely to include plant pathogens. Although fungal isolation is a valuable technique for a number of reasons, including morphological taxonomy, metabolic studies, and seed germination trials, molecular approaches, such as bar-coding and next generation sequencing, are currently regarded as the most efficient way to detect and survey mycorrhizal fungi (Bergerow et al. 2010).

By far the most common OM partners are Basidiomycetes within the form genus Rhizoctonia (Rasmussen 1995). The Rhizoctonia group is non-monophyletic, comprising three genera with similar anamorphic life stages: Ceratobasidium, Sebacina, and Tulasnella (Rasmussen 2002, Smith and Read 2008). Phylogenetic analysis has shown that the three Rhizoctonia genera are closely related and yet highly diverse, suggesting rapid evolutionary change and adaptation (Wells 1994, Weiss \& Oberwinkler 2001, Taylor and McCormick 2008). In nature these fungi can be saprophytic and/or pathogens. In contrast to the fungi that form AM and ECM, OM fungi are not obligately mycorrhizal, and their distributions within the environment are independent of the host plant's (Brundrett et al. 2003). The most commonly encountered fungal associates of orchids are in the Rhizoctonia genus Tulasnella. However, until recently they have been difficult to isolate and identify: some are notoriously difficult to culture axenically, and the entire genus has shown accelerated evolution of the ribosomal operon, making standard internal transcribed spacer (ITS) primers, as well as many of the large and small ribosomal subunit primers (LSU and SSU), largely ineffective as a means of detection (Binder et al. 2005; Moncalvo et al. 2006). The recent development of Tulasnellaspecific PCR primers (Taylor and McCormick 2008), in conjunction with broader 
spectrum ITS primers, have allowed for more comprehensive identification of OM, and represent a major breakthrough in the study of OM ecology and evolution.

Ascomycete fungi that associate with orchids are generally considered to be either endophytic (root-colonizing symbionts) or pathogens, with the latter being the more common relationship (Queloz et al 2011, Grelet et al. 2009). These fungi are rarely considered mycorrhizal, and are commonly detected as intercellular hyphae within the root (Těšitelová et al. 2012). One rare confirmed mutualist in the Ascomycetes is the order Helotiales, which has been detected in terrestrial orchids roots (Těšitelová et al. 2012), and is known to enhance plant performance (Tedersoo et al. 2011).

Orchids can form mycorrhizal associations with more than one fungal species at the same time (Otero et al. 2002, McCormick et al. 2004, Barrett et al. 2010, Xing et al. 2013). Orchid-mycorrhizal associations can be interpreted in two ways: OM specificity and OM preference. Mycorrhizal specificity is basically a species-richness measure, and can be defined as either the number of different fungal taxa associated with an orchid species (Rasmussen and Whigham 1994, McCormick et al. 2004), or as the phylogenetic breadth of the associates (Shefferson et al. 2007 Jacquemyn et al. 2010, 2014). Mycorrhizal preference also considers relative abundance, for example the fungal taxa that are most often associated with a particular orchid species, or a bias by the host plant to associate with certain fungus species.

Mycorrhizal specificity is dynamic, and can vary between orchid species and populations, across life histories, and among habitat types. Fungal specificity is thought to be narrow for most non-photosynthetic orchid species (Taylor et al. 2003, Barrett et al. 2010), while many photosynthetic orchids have broader mycorrhizal specificity 
(Rasmussen 2002, Bidartando et al. 2004, Otero et al. 2007, Smith and Read 2008). Yet there are a few exceptions to this expected pattern (McCormick et al. 2006, Shefferson et al. 2007). Within these broad trends there is a lot of variability. Recently, Xing et al. (2013) observed that two co-occurring species of Dendrobium utilized different OM taxa and had opposite levels of specificity, with $D$. officianale showing broad range of fungal partners, associating with up to five different fungal taxa at the same time, and $D$.

fimbriatum having very narrow specificity and only associating with one fungus taxon at a time. Although their specificity strategies were divergent, both Dendrobium species showed a preference for members of the fungal group Tulasnella (Xing et al. 2013). These findings suggest that co-occurring plant species may use different fungal partners to reduce competition, while their similar fungal preference may help explain orchid invasions and the coexistence of some orchid species (Waterman et al. 2011, Jacquemyn et al. 2012).

Additional studies of mycorrhizal preference in other species of orchids have given similar results. Otero et al. (2004) conducted cross germination trials using OM isolates from co-occurring and closely-related orchid species: Tolumnia variegata and Ionopsis utricularioides. Results showed that I. utricularioides germinated better with, and showed preference for, its own isolates. While $T$. variegata, germinated equally well on both T. variegata and I. utricularioides, and showed no preference for its own fungi. Jacquemyn et al. (2011) examined the relationship between OM networks and orchid phylogenies and found that closely related orchid species did show preferences toward similar sets of fungal partners. Thus, homology of fungal preferences may maintain sympatric distributions of sister orchid taxa. 
While orchid species in close proximity can share similar broad fungal associations (McCormick et al. 2004, McKendrick et al. 2002, Xing et al. 2013), finescale orchid diversity may be driven by microhabitat adaptation of appropriate host fungi. In nature, the mosaic-like distribution of closely related compatible fungal taxa within the environmental landscape could create ecological niches that may promote adaptive radiation in orchids, and may increase species diversity. Patchy distributions of fungi and high fungal specificity may lead to reproductive isolation and small effective population sizes that promote orchid speciation (Waterman and Bidartondo 2008).

Comparisons of terrestrial and epiphytic orchid mycorrhizae provide valuable insights into how different fungal communities can influence orchid diversity. Suarez et al. (2006) determined that epiphytic orchids in the Andes utilized a distinct group of Tulasnella fungi from those used by many tropical terrestrial orchids. These results suggest that these epiphytic orchid groups may have evolved to exploit a novel group of tulasnselloid fungi in the trees. Martos et al. (2012) used network analysis to show that, although terrestrial and epiphytic orchids utilize fungi in closely related taxa (Rhizoctonia), there were major ecological barriers between the below-ground and aboveground communities of fungi. As in the celebrated Anolis lizards (Losos 1990), orchid radiations may represent rapid adaptation to different terrestrial and arboreal microhabitats. In the case of the orchids, disruptive selection may be fueled not just by differences in substrate (e.g. trunk vs. fine branch tips) and light availability (Gravendeel et al. 2004), but also by the multitude of opportunities that arise from the great diversity of closely related Rhizoctonia fungi across different habitat types. 
Alternatively, orchid diversity, and potential range expansions, could be driven not just by differences in the fungal community, but by rapid changes in the fungal specificity of orchids. Mycoheterotrophic orchids lack chlorophyll and thus function unambiguously as parasites, and show considerable variation in fungal specificity (Taylor et al. 2003, Smith and read 2008, McCormick 2009). Taylor et al. (2003) found that two sympatric varieties of Hexalectris spicata var. spicata associated with different strains of Sebacina fungi. This suggests that, at least for some mycoheterotrophic orchids, speciation may be may be a result of rapidly evolving specificity. These findings were supported by Shefferson et al. (2007), who found that sympatric species of non-parasitic Cypripedium orchids were associated with different mycorrhizal fungus species. They showed fungal specificity had narrowed over time compared to basal taxa in the genus, suggesting that specificity as an evolving trait could promote speciation.

In addition to the effects of spatial and temporal variation in fungal specificity, the distribution of orchids may also be dependent on abundance of host fungi (McCormick et al. 2012). Several key studies have shown that the presence and abundance of appropriate mycorrhizal fungi can determine where orchids occur (Rasmussen and Whigham 1998, Suarez et al. 2006, McCormick et al. 2012, McCormick et al. 2016). McCormick et al. (2009) found the highest densities of flowering Corallorhiza odontorhiza in areas that supported high densities of its host fungi (Tomentella spp.), which in turn were typically associated with the roots of ECM trees. Similarly, McCormick et al. (2012) found that the distribution of three terrestrial orchid species depended not just on the presence, but also a threshold abundance of the appropriate host fungi. Both studies also showed that edaphic conditions can greatly influence the abundance of different host fungi, and may 
ultimately determine the distributions of the orchid (also see Diez 2007). Fewer studies have surveyed the abundance and distribution of epiphytic OM on host trees (Martos et al. 2010, Jacquemyn et al. 2011).

Fungi associated with different orchid species may respond differently to changes in edaphic conditions, thus causing orchid distributions and ranges to fluctuate. Furthermore, edaphic conditions are likely to be influenced by changes in temperature and precipitation associated with climate change. Changes in the abundance and distribution of the terrestrial orchid Corallorhiza odontorhiza was found to be related to both inter-annual climatic conditions and the abundance of host fungi (McCormick et al. 2009). For epiphytic orchids, constraints on water, light, and nutrient availability are stronger than in the soil rhizosphere (Zotz and Hietz 2011), and have likely driven tighter co-evolution between orchids and mycorrhizal networks (Martos et al. 2012). The fungi associated with orchids have specific environmental requirements, whether above or below ground, and in a rapidly changing world those orchid species that have more flexible fungal host requirements may have the greatest chances of survival.

In orchids, rarity may be the result of high host fungal specificity that limits recruitment (Rasmussen and Whigham 1998, Waterman and Bidartondo 2008), while wide distribution (and even invasiveness) may be aided by low fungal specificity and thus greater opportunities for recruitment. Bonnardeaux et al. (2007) examined the effect of orchid-fungus specificity on distribution by contrasting the mycorrhizal diversity associated with the invasive South African orchid (Disa bracteata), with that of a widespread, native Australian orchid (Pyrorchis nigricans). They found that both the invasive and widespread species utilized a broad range of similar Rhizoctonia fungi, 
regardless of whether the habitat was disturbed or not. Interestingly, the fungal relationships formed by the invasive $D$. bracteata were shorter-lived than those with the native orchids, yet they remained successful invaders. These results suggest that orchids that have a broader range of compatible fungi can increase dispersal ranges, and enhance recruitment, all of which can widen distribution.

\section{CONCLUSIONS}

As discussed in this chapter, orchids are inordinately affected by their biotic interactions. We recognize this by the strong relationship between interaction specificity and orchid diversity and distributions. Yet in the face of anthropogenic-driven change this heavy dependence on other organisms may put orchids at more risk than generalist plant species. The following dissertation research directly addresses some of the gaps regarding orchid populations, especially in the sub-tropics and tropics. Chapter three addresses the central hypothesis that periodic extreme cold weather events limit the expansion of tropical species into the sub-tropical zone; and a reduction in the frequency of these events due to global warming trends can facilitate the northern range expansion of some tropical species. The study compares the differential impacts of the introduced tropical specialist bee Centris nitida, and the native sub-tropical specialist bee Centris errans, following the 2010 cold spell in south Florida. We have taken advantage of preand post-impact observational data on Brysonima lucida (Malpighiaceae) and Cyrtopodium punctatum (Orchidaceae), specialized host plants, at Fairchild Garden to infer the relative abundance and recovery patterns of each bee. Our research approach 
also provided a rare opportunity to examine these impacts on multiple interacting species, which provides a more realistic assessment of the potential impacts of climate change. In chapter four, we used a comparative approach to address the role of mycorrhizal specificity in the spread of two recently introduced orchids in southern Florida. These findings will advance the study of ecology, specifically invasions, range expansions, and species responses to environmental change, by addressing the role of mycorrhizal symbioses (i.e. specialist versus generalist strategies) in governing plant distribution in both native and introduced geographic ranges; and so provide an explicit factor to assess invasive potential and rarity in plants. Chapter five directly addresses how biotic interactions can be influenced by elevation range expansions, and how this may factor into the decision-making framework of assisted colonization for tropical orchids. This study examines the mycorrhizal associations of four rare orchid species with different elevational ranges that have been translocated uphill at Yachang National Orchid Reserve, Guangxi, China. The project will help determine how mycorrhizae may vary between orchid species, and between and within habitats, both of which are critical to understanding orchid ecology, and to assisting ongoing orchid recovery efforts in southwest China. In the conclusion chapter, I briefly summarize the significance of my dissertation findings, future directions in the research, and the importance of orchids as symbols for outreach and conservation. 


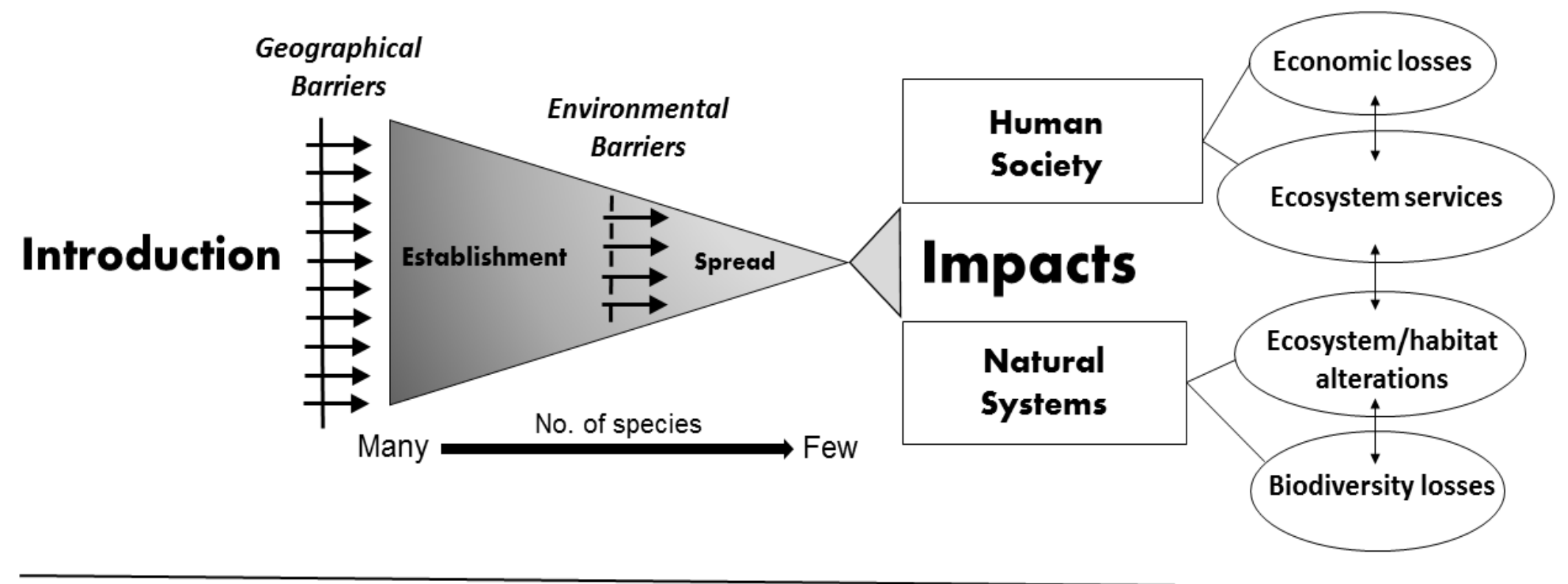

Fig. 1.1 Conceptual model showing the invasion process and documented impacts. Species are assisted by humans across geographical barriers. Many species are introduced but must overcome novel environmental barriers that impede or prevent establishment and spread, resulting in relatively few species becoming invasive. However these species can have a disproportionate amount of negative impacts that are inter-related. 

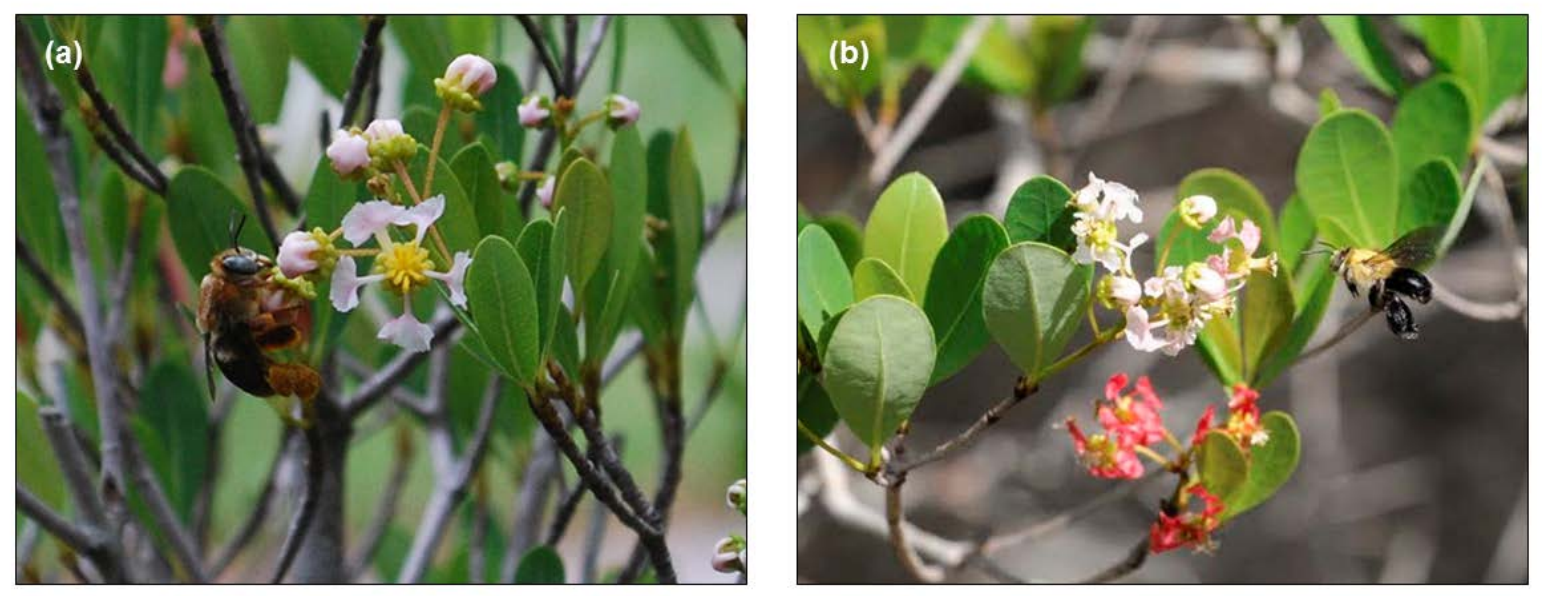

Fig. 1.2 Photos show specialist oil-bees visiting the oil-rewarding plant Byrsonima lucida. Plate (a) shows Centris errans a subtropical oil bee native to southeast Florida. Plate (b) shows Centris nitida introduced oil-bee from Central America. Photos courtesy of Hong Liu and Haydee Borrero.
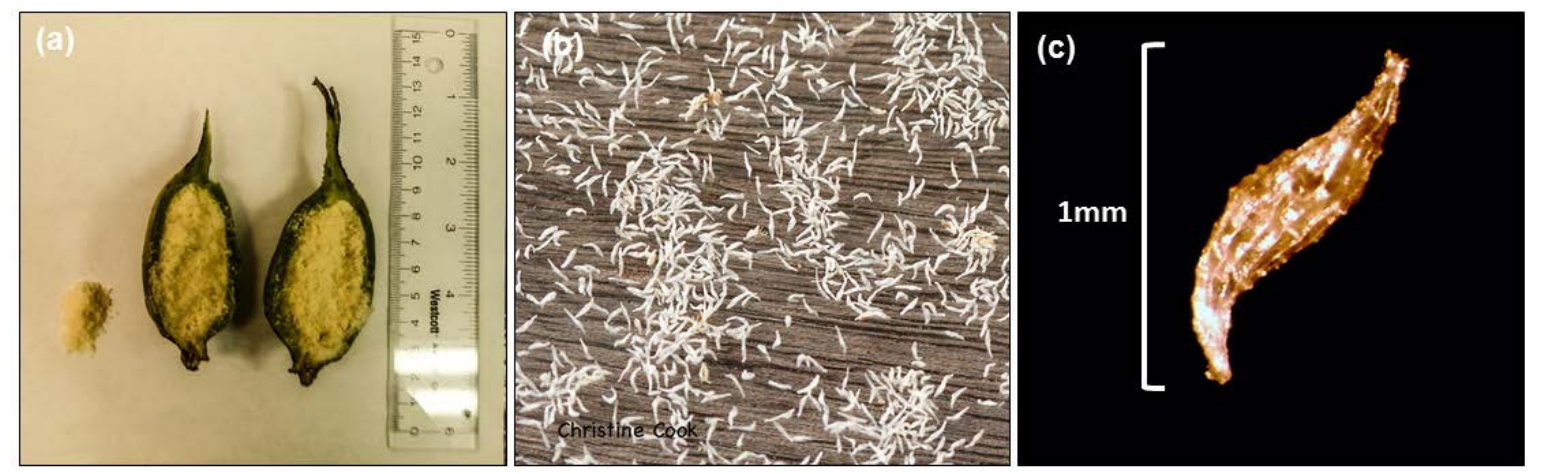

Fig. 1.3 Plates showing the fruit and dust seeds of Cyrtopodium punctatum. (a) shows $C$. punctatum fruit which can produce $>2$ million seeds. (b) seeds of Eulophia alta (c) dark field photo showing desiccant resistant seed coat (testa). 


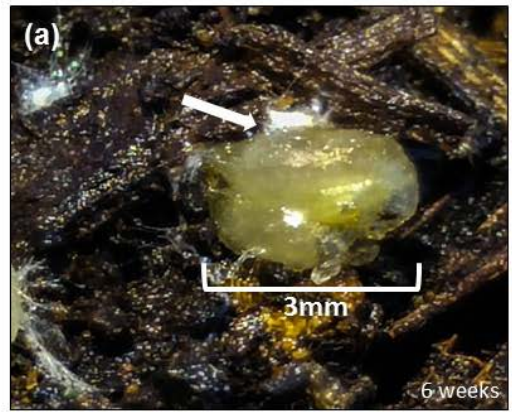

\section{(b)}

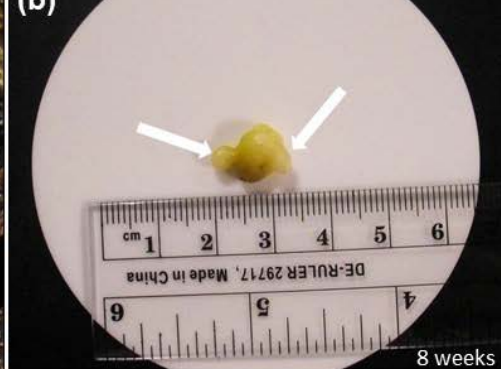

(c)

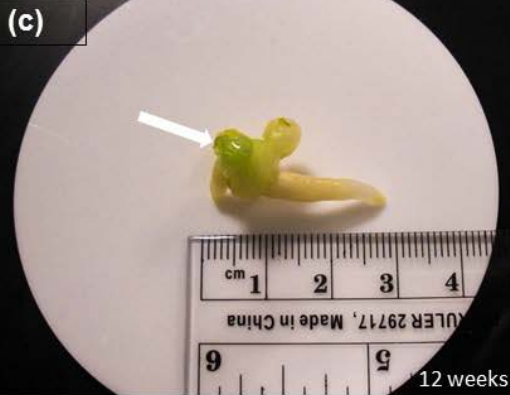

Fig. 1.4 Rapid growth of the invasive orchid Cyrtopodium flavum protocorm germinated in situ on mulch in Miami-Dade County, Florida. (a) shows 6 week old protocorm with fungal penetration (arrow). (b) 8 week old protocorm with early root formation (double arrows). (c) early seedling stage at 12 weeks with early leaf development (arrow) and root formation. 


\section{Orchid Life Cycle}

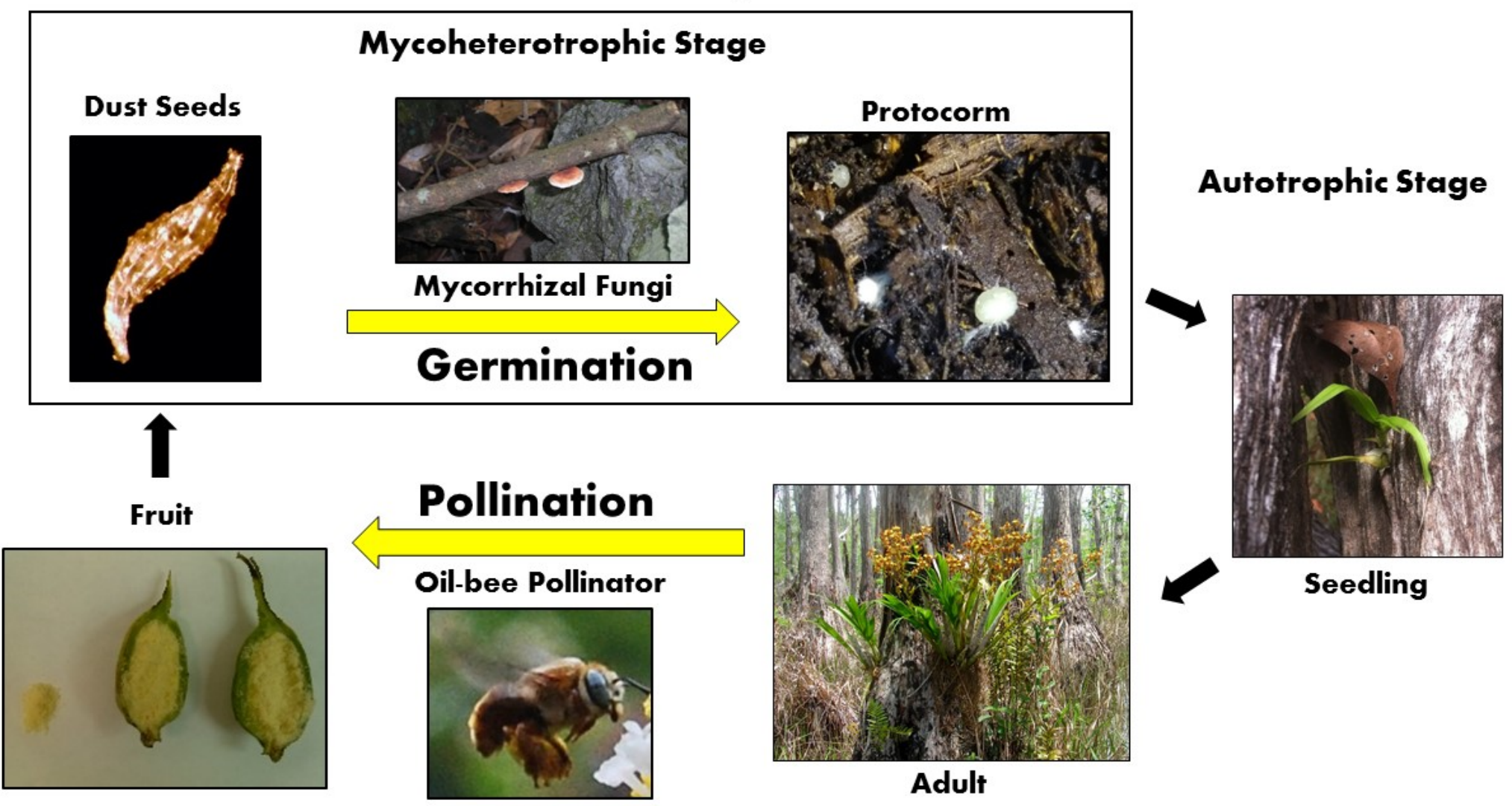

Fig 1.5 Diagram showing the Cyrtopodium punctatum life cycle. 


\begin{tabular}{|c|c|c|c|c|c|c|c|}
\hline Mycorrhiza Type & Fungal clades & $\begin{array}{c}\text { Plant } \\
\text { Associations }\end{array}$ & $\begin{array}{c}\text { Anatomical } \\
\text { Features }\end{array}$ & $\begin{array}{l}\text { Intracellular } \\
\text { Structure }\end{array}$ & $\begin{array}{l}\text { Nutrients } \\
\text { (Fungi to plant) }\end{array}$ & $\begin{array}{c}\text { Nutrients } \\
\text { (Plant to fungi) }\end{array}$ & $\begin{array}{l}\text { Environmental } \\
\text { Distribution }\end{array}$ \\
\hline Arbuscular (AM) & $\begin{array}{l}\text { Glomeromycota: } \\
\text { Glomerales } \\
\text { Archaeosporales } \\
\text { Paraglomerales }\end{array}$ & $\begin{array}{c}\sim 80 \% \text { of all vascularplants } \\
\text { some non-vascular; ferns }\end{array}$ & \begin{tabular}{|l|} 
Arbucscular; Arum \& \\
Paris-types, vesicles
\end{tabular} & Yes & $\begin{array}{c}\mathrm{P}\left(\mathrm{PO}_{4}\right), \mathrm{N}\left(\mathrm{NO}_{3}\right), \mathrm{K}, \mathrm{Ca} \\
\mathrm{Zn}, \mathrm{Cu}\end{array}$ & $\begin{array}{l}\text { Carbon compounds } \\
\text { (only source) }\end{array}$ & $\begin{array}{l}\text { All habitats, limited in } \\
\text { coniferous forest and } \\
\text { tundra }\end{array}$ \\
\hline Ectomycorrhizal (ECM) & $\begin{array}{l}\text { Basidiomycetes } \\
\text { some Ascomycetes }\end{array}$ & $\begin{array}{l}\text { Perennial trees species, } \\
\text { some herbs }\end{array}$ & $\begin{array}{l}\text { Mantle, Hartig net, } \\
\text { dichotomous } \\
\text { branching roots }\end{array}$ & No & $\mathrm{P}\left(\mathrm{PO}_{4}\right), \mathrm{N}\left(\mathrm{NH}_{4}, \mathrm{NO}_{3}\right), \mathrm{K}$ & $\begin{array}{l}\text { Carbon compounds } \\
\text { (glucose, fructose) }\end{array}$ & $\begin{array}{l}\text { Boreal, temperate, } \\
\text { tropical forests, some } \\
\text { savannahs }\end{array}$ \\
\hline Ericoid (EM) & $\begin{array}{c}\text { Hymenoscyphus ercicae } \\
\text { Anamorphs: } \\
\text { Scytalidium } \\
\text { Oidiodendron }\end{array}$ & $\begin{array}{l}\text { Ericales: } \\
\text { Ericaceae } \\
\text { Epacridaceae } \\
\text { Empetraceae }\end{array}$ & $\begin{array}{c}\text { Hair roots in plants, } \\
\text { intracellular hyphal } \\
\text { complex (epidermal } \\
\text { cells only) }\end{array}$ & Yes & $\begin{array}{c}\mathrm{P}\left(\mathrm{PO}_{4}\right), \mathrm{N}\left(\mathrm{NH}_{4}, \mathrm{NO}_{3}\right. \\
\text { amino acids, peptides, } \\
\text { proteins) }\end{array}$ & Carbon compounds & $\begin{array}{l}\text { Arctic tundra, } \\
\text { Mediterranean habitats }\end{array}$ \\
\hline Orchid (OM) & $\begin{array}{l}\text { Ascomycetes: } \\
\text { Order Hypocreales } \\
\text { Basidiomycetes: } \\
\text { Rhizoctonia; } \\
\text { Tulansella } \\
\text { Sebacina } \\
\text { Ceratobasidium } \\
\text { Other genera: } \\
\text { Russula } \\
\text { Thelephora } \\
\text { Tomentella }\end{array}$ & Orchidaceae & $\begin{array}{c}\text { Pelotons (modified } \\
\text { hyphal coils), reduced } \\
\text { extra radical } \\
\text { mycelium }\end{array}$ & Yes & $\begin{array}{c}\mathrm{P}\left(\mathrm{PO}_{4}\right), \mathrm{N}\left(\mathrm{NH}_{4}, \mathrm{NO}_{3}\right) \\
\text { carbon compounds, } \\
\text { minerals }\end{array}$ & None* & $\begin{array}{c}\text { All habitats, except } \\
\text { driest deserts and } \\
\text { tundra }\end{array}$ \\
\hline
\end{tabular}

Fig. 1.6 Table describing different types of mycorrhiza and major features of each group; * limited evidence for carbon acquisition by fungi (Cameron et al. 1997). 


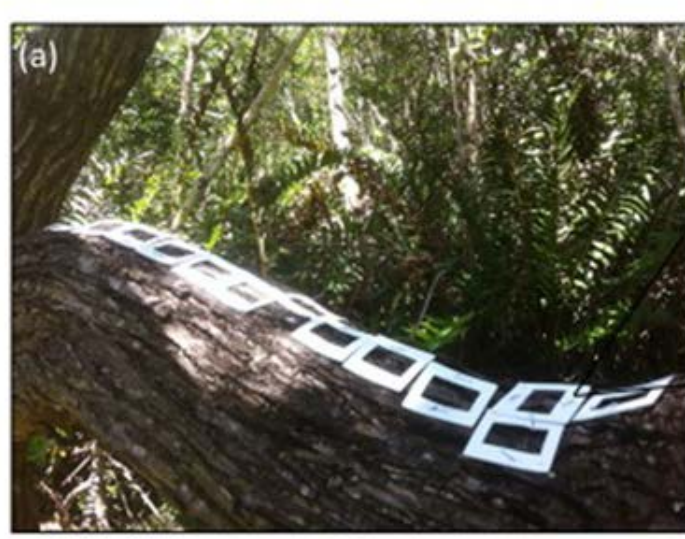

(c)
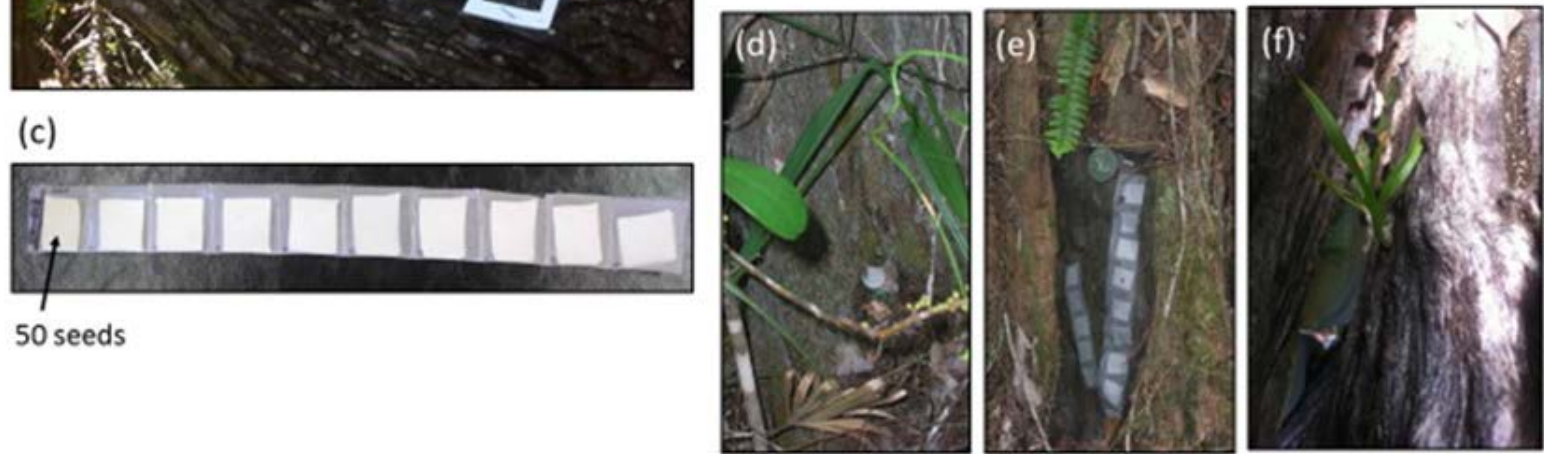

Fig. 1.7 Plate showing different in situ fungi baiting techniques. (a) shows direct application of orchids seeds onto appropriate host tree bark, (b) close up of seeds on bark surface. (c) Photo showing nylon mesh seed packets; each compartment contains 50 seeds applied on sterile filer paper. In situ seed packets we placed in different microhabitat types including (d) humic spaces, (e) directly on back surface, and (f) near recruits. 

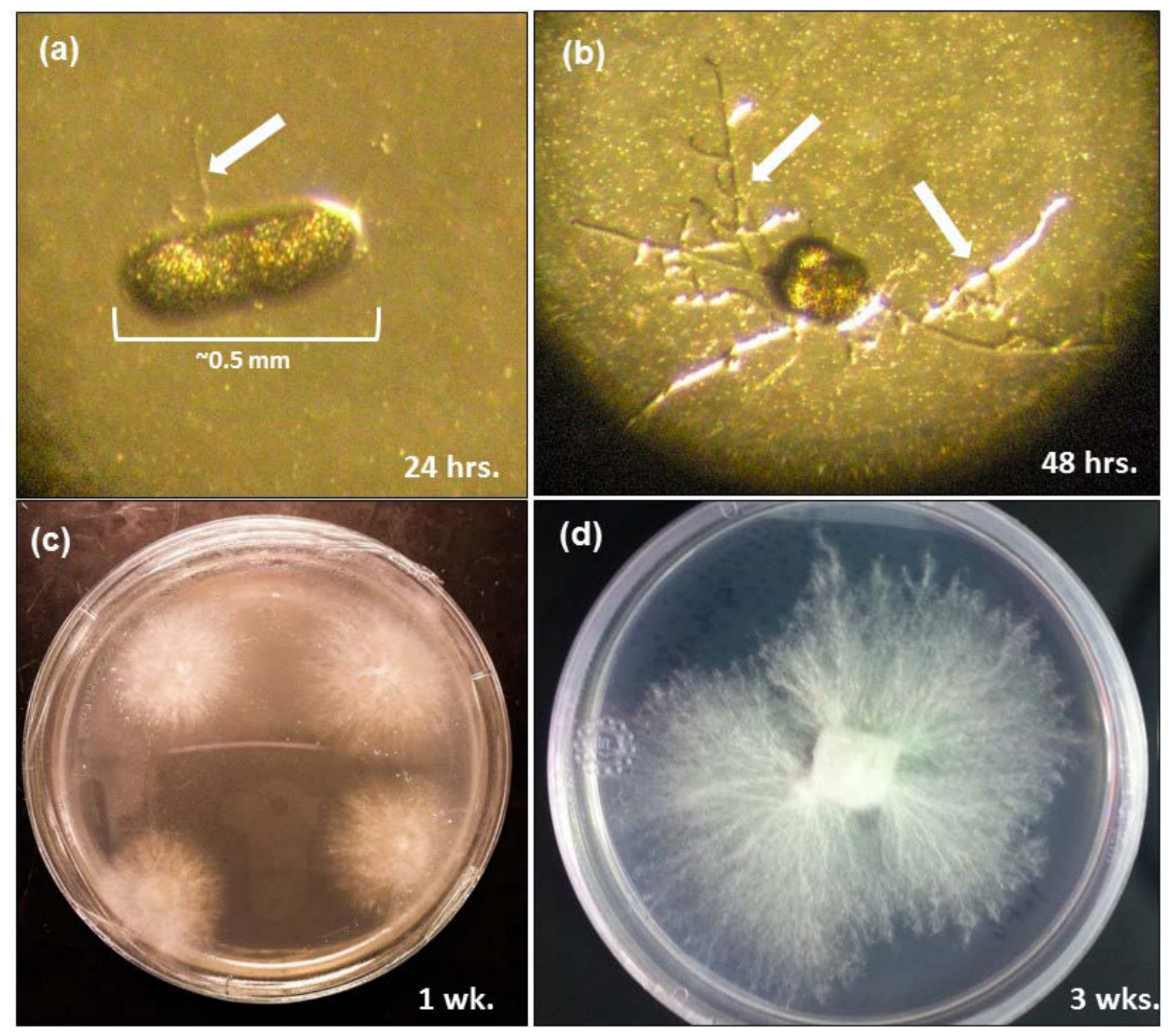

Fig. 1.8 (a) fungal pelotons isolated from root cells of Cyrtopodium flavum. Single peloton after 24 hours growing on E-medium (Caldwell et al. 1999) with a broad spectrum antibiotic and showing early hyphal extensions (arrow). (b) Pelton after 48 hours showing complex branching of the hyphal extensions (arrows). (c) Four fungal isolates after 1 week of growth. (d) Individual fungal isolate 3 weeks after sub-culturing forming a well-defined hyphal mat; isolate was identified as a member of the Order Polyporales. 


\section{REFERENCES}

Ackerman, J. D. (1986). Coping with the epiphytic existence: pollination strategies. Selbyana, 52-60.

Ackerman, J. (2012). Orchids gone wild. Orchids, 81(2), 88-93.

Anderson, J. T., Inouye, D. W., McKinney, A. M., Colautti, R. I., \& Mitchell-Olds, T. (2012). Phenotypic plasticity and adaptive evolution contribute to advancing flowering phenology in response to climate change. Proceedings of the Royal Society of London B: Biological Sciences, rspb20121051.

Anderson, W. R. (1979). Floral conservatism in neotropical Malpighiaceae. Biotropica, 219-223.

Blois, J. L., Zarnetske, P. L., Fitzpatrick, M. C., \& Finnegan, S. (2013). Climate change and the past, present, and future of biotic interactions. Science, 341 (6145):499504.

Blossey, B., \& Notzold, R. (1995). Evolution of increased competitive ability in invasive nonindigenous plants: a hypothesis. Journal of Ecology, 83 (5):887-889.

Bonnardeaux, Y., Brundrett, M., Batty, A., Dixon, K., Koch, J., \& Sivasithamparam, K. (2007). Diversity of mycorrhizal fungi of terrestrial orchids: compatibility webs, brief encounters, lasting relationships and alien invasions. Mycological research, 111 (1):51-61.

Buchmann, S. L. (1987). The ecology of oil flowers and their bees. Annual Review of Ecology and Systematics, 18:343-369.

Calle, Z., Schlumpberger, B. O., Piedrahita, L., Leftin, A., Hammer, S. A., Tye, A., \& Borchert, R. (2010). Seasonal variation in daily insolation induces synchronous bud break and flowering in the tropics. Trees, 24 (5):865-877.

Center for Biology Diversity. (2016). Retrieved February 19, 2016. http://www.biologicaldiversity.org/

Clavero, M., \& Garcia-Berthou, E. (2005). Invasive species are a leading cause of animal extinctions. TRENDS in Ecology and Evolution, 20 (3):110-110.

Colautti, R. I., Ricciardi, A., Grigorovich, I. A., \& MacIsaac, H. J. (2004). Is invasion success explained by the enemy release hypothesis? Ecology Letters, 7 (8):721733. 
Compant, S., Van Der Heijden, M. G., \& Sessitsch, A. (2010). Climate change effects on beneficial plant-microorganism interactions. FEMS microbiology ecology, 73 (2):197-214.

Cozzolino, S., \& Widmer, A. (2005). Orchid diversity: an evolutionary consequence of deception? Trends in Ecology \& Evolution, 20 (9):487-494.

Crawley, M. J. (1987). What makes a community invasible? In Symposium of the British Ecological Society.

Daehler, C. C. (1998). The taxonomic distribution of invasive angiosperm plants: ecological insights and comparison to agricultural weeds. Biological Conservation, 84 (2):167-180.

Darwin, C. (1862). On the Two Forms, or Dimorphic Condition, in the Species of Primula, and on their remarkable Sexual Relations. Journal of the Proceedings of the Linnean Society of London. Botany, 6 (22):77-96.

Dodson, C. H. (1975). Coevolution of orchids and bees. Coevolution of animals and plants, 91:99

Downing, J.D., Borrero, H., Liu, H. (2016). Differential impacts from an extreme cold spell on subtropical vs. tropical specialist bees in southern Florida. Ecosphere; accepted for publication.

Downing, J. L., \& Liu, H. (2012). Friend or foe? Impacts of the introduced tropical oil bee Centris nitida on a threatened and specialized native mutualism in Southern Florida. Biological Invasions: 14 (10):2175-2185

De Long, Jonathan, R., Swarts, N. D., Dixon, K. W., \& Egerton-Warburton, L. M. (2012). Mycorrhizal preference promotes habitat invasion by a native Australian orchid: Microtis media. Annals of botany, mcs294

Dennis, R. L. (1993). Butterflies and climate change. Manchester University Press.

Ehrlich, P. R. (1986). Which animal will invade?. In Ecology of biological invasions of North America and Hawaii, Springer New York, 70-95.

Feeley, K. J., Hurtado, J., Saatchi, S., Silman, M. R., \& Clark, D. B. (2013). Compositional shifts in Costa Rican forests due to climate-driven species migrations. Global change biology, 19 (11):3472-3480.

Feeley, K. J., Silman, M. R., Bush, M. B., Farfan, W., Cabrera, K. G., Malhi, Y., Meir, P., Salinas Revilla, N., Raurau Quisiyupanqui, M.N., \& Saatchi, S. (2011). Upslope migration of Andean trees. Journal of Biogeography, 38 (4):783-791. 
Fitter, A. H., Heinemeyer, A., \& Staddon, P. L. (2000). The impact of elevated CO2 and global climate change on arbuscular mycorrhizas: a mycocentric approach. New Phytologist, 147 (1):179-187.

Gilman, S. E., Urban, M. C., Tewksbury, J., Gilchrist, G. W., \& Holt, R. D. (2010). A framework for community interactions under climate change. Trends in Ecology \& Evolution, 25 (6):325-331.

Givnish, T. J., Pires, J. C., Graham, S. W., McPherson, M. A., Prince, L. M., Patterson, T. B., \& Millam, K. C. (2006). Phylogenetic relationships of monocots based on the highly informative plastid gene ndhF: evidence for widespread concerted convergence. Aliso, 22:28-51.

Hellmann, J. J., Byers, J. E., Bierwagen, B. G., \& Dukes, J. S. (2008). Five potential consequences of climate change for invasive species. Conservation biology, 22 (3):534-543.

Hoegh-Guldberg, O., Hughes, L., McIntyre, S., Lindenmayer, D. B., Parmesan, C., Possingham, H. P., \& Thomas, C. D. (2008). Assisted colonization and rapid climate change. Science (Washington), 321 (5887):345-346.

Hunter, M. L. (2007). Climate change and moving species: furthering the debate on assisted colonization. Conservation Biology, 21 (5):1356-1358.

Johnson, S. D., \& Steiner, K. E. (2000). Generalization versus specialization in plant pollination systems. Trends in Ecology \& Evolution, 15 (4):140-143.

Jonathan, R., Swarts, N. D., Dixon, K. W., \& Egerton-Warburton, L. M. (2012). Mycorrhizal preference promotes habitat invasion by a native Australian orchid: Microtis media. Annals of botany, mcs294.

Joshi, J., \& Vrieling, K. (2005). The enemy release and EICA hypothesis revisited: incorporating the fundamental difference between specialist and generalist herbivores. Ecology Letters, 8 (7):704-714.

Judd, W. S., Campbell, C. S., Kellogg, E. A., Stevens, P. F., \& Donoghue, M. J. (1999). Plant systematics: a phylogenetic approach. Ecologia Mediterranea, 25 (2):215.

Kaisila, J. (1962). Immigration und Expansion der Lepidopteren in Finnland in den Jahren 1869-1960. Acta Entomol. Fenn. 18 (1):452.

Keane, R. M., \& Crawley, M. J. (2002). Exotic plant invasions and the enemy release hypothesis. Trends in Ecology \& Evolution, 17 (4):164-170.

Koricheva, J. (2002). Meta-analysis of sources of variation in fitness costs of plant antiherbivore defenses. Ecology, 83 (1):176-190. 
Le Roux, J., \& Wieczorek, A. M. (2009). Molecular systematics and population genetics of biological invasions: towards a better understanding of invasive species management. Annals of Applied Biology, 154 (1):1-17.

Leake, J. R. (1994). The biology of myco-heterotrophic (saprophytic) plants. New Phytologist, 127 (2):171-216.

Liu, H., Feng, C., Chen, B., Wang, Z, Xie, X., Deng, Z., Wei, X., Liu, S., Zhang, Z., \& Luo, Y. (2012). Overcoming extreme weather challenges: Successful but variable assisted colonization of wild orchids in southwestern china. Biological Conservation. 150 (1):68-75.

Liu, H., Feng, C., Xie, X., Lin, W., Deng, Z., Wei, X., Liu, S., \& Luo, Y. (2014). Impacts of extreme weather on flowering phenology of wild orchids in southwestern China. In Darwin's Orchids—Now and then, Bernhardt, P. and R. Meier (Eds.) University of Chicago, Chicago. 311-327.

Liu, H., \& Stiling, P. (2006). Testing the enemy release hypothesis: a review and metaanalysis. Biological Invasions, 8 (7):1535-1545.

Liu, H., Stiling, P., \& Pemberton, R. W. (2007). Does enemy release matter for invasive plants? Evidence from a comparison of insect herbivore damage among invasive, non-invasive and native congeners. Biological Invasions, 9 (7):773-781.

Liu, H., \& Pemberton, R. (2010). Pollination of an invasive orchid, Cyrtopodium polyphyllum (Orchidaceae), by an invasive oil-collecting bee, Centris nitida, in southern Florida. Botany, 88 (3):290-295.

Luer, C. A. (1972). The native orchids of Florida. New York: Botanical Garden 293p..

Mack, R. N., Simberloff, D., Mark Lonsdale, W., Evans, H., Clout, M., \& Bazzaz, F. A. (2000). Biotic invasions: causes, epidemiology, global consequences, and control. Ecological applications, 10 (3):689-710.

Maron, J. L., Vilà, M., \& Arnason, J. (2004). Loss of enemy resistance among introduced populations of St. John's wort (Hypericum perforatum). Ecology, 85 (12):32433253.

McCormick, M. K., Whigham, D. F., Sloan, D., O'Malley, K., \& Hodkinson, B. (2006). Orchid-fungus fidelity: a marriage meant to last? Ecology, 87 (4):903-911.

McCormick, M. K., Taylor, D. L., Juhaszova, K., Burnett, R. K., Jr., Whigham, D. F., \& O'Neill, J. P. (2012). Limitations on orchid recruitment: Not a simple picture. Molecular Ecology, 21(6), 1511-1523. 
McCormick, M.K., D.L. Taylor, D.F. Whigham, R.K. Burnett Jr. 2016. Germination patterns in three terrestrial orchids relate to abundance of mycorrhizal fungi. Journal of Ecology DOI: 10.1111/1365-2745.12556.)

Memmott, J., Craze, P. G., Waser, N. M., \& Price, M. V. (2007). Global warming and the disruption of plant-pollinator interactions. Ecology letters, 10 (8):710-717.

Memmott, J., Fowler, S. V., Paynter, Q., Sheppard, A. W., \& Syrett, P. (2000). The invertebrate fauna on broom, Cytisus scoparius, in two native and two exotic habitats. Acta Oecologica, 21 (3):213-222.

Menzel, A., Seifert, H., \& Estrella, N. (2011). Effects of recent warm and cold spells on European plant phenology. International journal of biometeorology, 55 (6):921932.

Menzel, A., Sparks, T. H., Estrella, N., Koch, E., Aasa, A., Ahas, R., \& Chmielewski, F. M. (2006). European phenological response to climate change matches the warming pattern. Global change biology, 12 (10):1969-1976.

Miller-Rushing, A. J., \& Primack, R. B. (2008). Global warming and flowering times in Thoreau's Concord: a community perspective. Ecology, 89 (2):332-341.

Mitchell, C. E., Agrawal, A. A., Bever, J. D., Gilbert, G. S., Hufbauer, R. A., Klironomos, J. N., \& Seabloom, E. W. (2006). Biotic interactions and plant invasions. Ecology Letters, 9 (6):726-740.

Mooney, H. A., \& Hobbs, R. J. (2000). Global change and invasive species: where do we go from here. Invasive species in a changing world. Island Press, Washington, DC, 425-434.

Nilsson, L. A. (1992). Orchid pollination biology. Trends in Ecology \& Evolution, 7 (8):255-259.

Otero, J. T., \& Flanagan, N. S. (2006). Orchid diversity-beyond deception. Trends in Ecology \& Evolution, 21:64-65.

Pansarin, L. M., Pansarin, E. R., \& Sazima, M. (2008). Reproductive biology of Cyrtopodium polyphyllum (Orchidaceae): a Cyrtopodiinae pollinated by deceit. Plant Biology, 10 (5):650-659.

Parmesan, C. (2006). Ecological and evolutionary responses to recent climate change. Annual Review of Ecology, Evolution, and Systematics, 637-669.

Parmesan, C., \& Yohe, G. (2003). A globally coherent fingerprint of climate change impacts across natural systems. Nature, 421 (6918):37-42.

Peakall, R., \& Beattie, A. J. (1991). The genetic consequences of worker ant pollination in a self-compatible, clonal orchid. Evolution, 1837-1848. 
Pemberton, R. W., \& Liu, H. (2008). Potential of invasive and native solitary specialist bee pollinators to help restore the rare cowhorn orchid (Cyrtopodium punctatum) in Florida. Biological conservation, 141 (7):1758-1764.

Pheloung, P. C., Williams, P. A., \& Halloy, S. R. (1999). A weed risk assessment model for use as a biosecurity tool evaluating plant introductions. Journal of Environmental Management, 57 (4):239-251.

Pimentel, D., Zuniga, R., \& Morrison, D. (2005). Update on the environmental and economic costs associated with alien-invasive species in the United States. Ecological economics, 52 (3):273-288.

Potts, S. G., Biesmeijer, J. C., Kremen, C., Neumann, P., Schweiger, O., \& Kunin, W. E. (2010). Global pollinator declines: trends, impacts and drivers. Trends in ecology \& evolution, 25 (6):345-353.

Prentis, P. J., Wilson, J. R., Dormontt, E. E., Richardson, D. M., \& Lowe, A. J. (2008). Adaptive evolution in invasive species. Trends in plant science, 13 (6):288-294.

Pringle, A., Bever, J. D., Gardes, M., Parrent, J. L., Rillig, M. C., \& Klironomos, J. N. (2009). Mycorrhizal symbioses and plant invasions. Annual Review of Ecology, Evolution, and Systematics, 40:699-715.

Queloz, V., Sieber, T. N., Holdenrieder, O., McDonald, B. A., \& Grünig, C. R. (2011). No biogeographical pattern for a root-associated fungal species complex. Global Ecology and Biogeography, 20 (1):160-169.

Rasmussen, H. N. (1995). Terrestrial orchids: from seed to mycotrophic plant. Cambridge University Press.

Rasmussen, H. N., Dixon, K. W., Jersáková, J., \& Těšitelová, T. (2015). Germination and seedling establishment in orchids: a complex of requirements. Annals of Botany, mcv087.

Reich, P. B. (1995). Phenology of tropical forests: patterns, causes, and consequences. Canadian Journal of Botany, 73 (2):164-174.

Reichard, S., H. Liu, and C. Husby. (2012). Is managed Relocation another pathway of biological invasion? In Managing Eden: Plant Reintroduction’s Promises, Perils, and Uses in a Changing Climate. J. Maschinski and K. E. Haskins (editors) Island Press, Washington D.C. pp243-262.

Rejmánek, M., \& Randall, J. M. (1994). Invasive alien plants in California: 1993 summary and comparison with other areas in North America. Madrono, 161-177.

Rejmánek, M., \& Richardson, D. M. (1996). What attributes make some plant species more invasive? Ecology, 77 (6):1655-1661. 
Renner, S. (2004). Plant dispersal across the tropical Atlantic by wind and sea currents. International Journal of Plant Sciences, 165 (S4):S23-S33.

Ricciardi, A., \& Simberloff, D. (2009). Assisted colonization is not a viable conservation strategy. Trends in ecology \& evolution, 24 (5):248-253.

Richardson, A. D., Keenan, T. F., Migliavacca, M., Ryu, Y., Sonnentag, O., \& Toomey, M. (2013). Climate change, phenology, and phenological control of vegetation feedbacks to the climate system. Agricultural and Forest Meteorology, 169:156173.

Richardson, D. M., Pyšek, P., Rejmánek, M., Barbour, M. G., Panetta, F. D., \& West, C. J. (2000). Naturalization and invasion of alien plants: concepts and definitions. Diversity and distributions, 6 (2):93-107.

Root, T. L., Price, J. T., Hall, K. R., Schneider, S. H., Rosenzweig, C., \& Pounds, J. A. (2003). Fingerprints of global warming on wild animals and plants. Nature, 421 (6918):57-60.

Roy, J. (1990). In search of the characteristics of plant invaders. In Biological invasions in Europe and the Mediterranean Basin, Springer Netherlands, 335-352.

Schiestl, F. P. (2005). On the success of a swindle: pollination by deception in orchids. Naturwissenschaften, 92 (6):255-264.

Schiestl, F. P., Ayasse, M., Paulus, H. F., Löfstedt, C., Hansson, B. S., Ibarra, F., \& Francke, W. (1999). Orchid pollination by sexual swindle. Nature, 399 (6735):421-421.

Schwartz, M. D., Ahas, R., \& Aasa, A. (2006). Onset of spring starting earlier across the Northern Hemisphere. Global Change Biology, 12 (2):343-351.

Shefferson, Richard P., D. Lee Taylor, Michael Weiß, Sigisfredo Garnica, Melissa K. McCormick, Seth Adams, Hope M. Gray et al. "The evolutionary history of mycorrhizal specificity among lady's slipper orchids." Evolution 61, no. 6 (2007): 1380-1390.

Smith, S. E., \& Read, D. J. (2010). Mycorrhizal symbiosis. Academic press.

Soliva, M., \& Widmer, A. (2003). Gene flow across species boundaries in sympatric, sexually deceptive Ophrys (Orchidaceae) species. Evolution, 57 (10):2252-2261.

Stevens, P. F. (2016 onwards). Angiosperm Phylogeny Website. Version February 19, 2016. http://www.mobot.org/MOBOT/research/APweb/.

Swarts, N. D., \& Dixon, K. W. (2009). Terrestrial orchid conservation in the age of extinction. Annals of Botany, 104 (3):543-556. 
Taylor, D. L., Bruns, T. D., Szaro, T. M., \& Hodges, S. A. (2003). Divergence in mycorrhizal specialization within Hexalectris spicata (Orchidaceae), a nonphotosynthetic desert orchid. American Journal of Botany, 90 (8):1168-1179.

Tremblay, R. L., Ackerman, J. D., Zimmerman, J. K., \& Calvo, R. N. (2005). Variation in sexual reproduction in orchids and its evolutionary consequences: a spasmodic journey to diversification. Biological Journal of the Linnean Society, 84 (1):1-54.

Vilà, M., Gómez, A., \& Maron, J. L. (2003). Are alien plants more competitive than their native conspecifics? A test using Hypericum perforatum L. Oecologia, 137 (2):211-215.

Vitousek, P. M., Mooney, H. A., Lubchenco, J., \& Melillo, J. M. (1997). Human domination of Earth's ecosystems. Science, 277(5325), 494-499.

Walther, G. R., Roques, A., Hulme, P. E., Sykes, M. T., Pyšek, P., Kühn, I., \& Czucz, B. (2009). Alien species in a warmer world: risks and opportunities. Trends in ecology \& evolution, 24 (12):686-693.

Wang X., Liu H., Gu M., Boucek R., Wu Z., Zhou G. (2015). Greater impacts from an extreme cold spell on tropical than wide ranging butterflies in southern China. Ecosphere.

Waterman, R. J., \& Bidartondo, M. I. (2008). Deception above, deception below: linking pollination and mycorrhizal biology of orchids. Journal of Experimental Botany, 59 (5):1085-1096.

Willis, A. J., \& Blossey, B. (1999). Benign environments do not explain the increased vigour of non-indigenous plants: a cross-continental transplant experiment. Biocontrol Science and Technology, 9 (4):567-577.

Willis, A. J., Memmott, J., \& Forrester, R. I. (2000). Is there evidence for the postinvasion evolution of increased size among invasive plant species?. Ecology Letters, 3 (4):275-283.

Willis, A. J., Thomas, M. B., \& Lawton, J. H. (1999). Is the increased vigour of invasive weeds explained by a trade-off between growth and herbivore resistance? Oecologia, 120 (4):632-640.

Willis, S. G., Hill, J. K., Thomas, C. D., Roy, D. B., Fox, R., Blakeley, D. S., \& Huntley, B. (2009). Assisted colonization in a changing climate: a test-study using two UK butterflies. Conservation Letters, 2 (1):46-52.

Wolfe, L. M. (2002). Why alien invaders succeed: support for the escape-from-enemy hypothesis. The American Naturalist, 160 (6):705-711. 
CHAPTER II

DIFFERENTIAL IMPACTS FROM AN EXTREME COLD SPELL ON SUBTROPICAL VS. TROPICAL SPECIALIST BEES IN SOUTHERN FLORIDA.

Downing, JL, Borrero, H, and Liu, H (2016). Differential impacts from an extreme cold spell on subtropical vs. tropical specialist bees in southern Florida. Ecosphere, accepted for publication, (MS\#: ES15-00340R1). 


\begin{abstract}
Gradual warming and changes in extreme weather patterns associated with human induced climate change are altering the range distributions of species. However, species responses to climate change are predicted to be more strongly affected by extreme events than by changes in mean values. As a result, measuring species' responses to extreme events in addition to the mean changes in climate are necessary to predict species range limits under future conditions. This study examines the impacts of a cold spell in southern Florida on native and an introduced oil collecting bees by examining the bees’ interactions with two native plants species. Our results provide evidence of differential impacts from an extreme cold event on a native, subtropical bee vs. an introduced, tropical bee. Specifically, the cold spell had little impact on the abundance of the native bee, while the abundance of the introduced, tropical bee was negatively impacted. Our findings demonstrate that extreme cold spells are important climate change-related phenomena that can have strong impacts on tropical species distributions and abundances, especially at the threshold of their thermal tolerances. Our approach also provided a rare opportunity to examine these impacts on multiple interacting species, which provides a more realistic assessment of the potential impacts of climate change.

Keywords: climate change, cold spell, ecological release, extreme weather, specialist bees, subtropics
\end{abstract}

\title{
INTRODUCTION
}

During the recent warming trend species have been shifting their threshold ranges poleward, either naturally or mediated by humans (Walther et al. 2002, Parmesan \& Yohe 
2003, Hill et al. 2011). At the same time, risks from extreme cold spells are predicted to persist as gradual warming trends continue (IPCC 2014). These weather events can have strong impacts on species’ population dynamics and distributions (Easterling et al. 2000, Parmesan et al. 2000, Thibault et al. 2008). Over the long-term, extreme cold spells contribute to the physiological threshold ranges for native species, and in theory can limit the range expansions of some introduced species. With cold tolerances being one of the main determinants for a species distributional range, there is a chance for the population decline of a non-native species in the event of an extreme climatic event, such as a cold spell (Kreyling et al. 2015, Rehage et al. 2015). As a result, measuring species’ responses to extreme events in addition to the mean changes in climate is necessary to predict species range limits under future conditions (Zimmerman et al. 2009). In the northern hemisphere, species at the northern margin of their distribution are expected to be more impacted by extreme cold spells (Hoffman and Parsons 1997, Parmesan et al. 2000). Understanding how species respond to extreme cold events at the leading and trailing edges of range expansions provides the best insights into the likelihood of species adapting to the ongoing climate change.

Climate change will also have direct and/or indirect impacts on species interactions, especially when interactions are specialized, involving only a few interacting taxa. For example, changes in climate may harm or remove mutualistic partners of plants, such as pollinators and mycorrhizal fungi (Fitter et al. 2000, Compant et al. 2010, Gillman et al. 2010, Potts et al. 2010). Nevertheless, most current studies focus on the direct effects of climate change on individual species (Gillman et al. 2010). Disruptions in the interactions between species can alter community structure and dynamics, in turn 
changing the dynamics of entire ecosystems. Therefore, understanding how climate change influences biotic relationships is urgent, and will be necessary for developing management plans that mitigate biodiversity losses.

Relatively few studies have examined the impacts of extreme cold weather on sub-tropical and tropical species' distributions (Mazzotti et al. 2011, Cavanaugh et al. 2014, Wang et al. 2015), and even fewer on the impacts to species interactions. Reduction in the frequency of extreme and prolonged cold spells in sub-tropical regions will likely permit the movement of some tropical species polewards; as shown by the northward expansion of mangrove forests in Florida (Cavanaugh et al. 2014). Conversely, the existence of prolonged and unusual extreme cold events may have the potential to dictate the extent of poleward migration by tropical species.

A rare extreme cold spell struck southern Florida during January 2-11, 2010. This cold spell was considered "extreme" because of the combination of lower than average air temperatures, record lows, and unusually long duration (NOAA 2010). On January 10, an all-time record low of $1.6^{\circ} \mathrm{C}$ was recorded in Miami, and air temperatures remained at or below $10^{\circ} \mathrm{C}$ for at least 48 hours (NOAA 2010). This resulted in sudden mortality and reductions in the abundance of many non-native tropical species, such as iguanas, parrots, pythons, and fishes (Fantz 2010, Mazzotti et al. 2011, Quinlan 2010). The cold weather also caused notable and well documented mortality of several tropical native species, such as snook, tarpon, corals, manatees, and crocodiles for example (Hallac et al. 2010, Lirman et al. 2011, Boucek and Rehage 2014, personal observations).

Following the above mentioned cold spell, we noticed a reduction in the activities of the introduced tropical oil-collecting bee, Centris nitida, which had recently 
naturalized in southern Florida (Pemberton and Liu, 2008a). This casual observation suggested that the extreme cold may have impacted the population abundance of this introduced tropical species, and its interactions with native oil-producing or mimic plant species. In this study we examined the impacts of the 2010 cold spell in south Florida on both the native and introduced oil collecting bees through examining the bees' interactions with the two native plants with specialized floral offer (oil) or oil mimic. We addressed the following questions:

1) Are there differential impacts from the extreme cold spell on the relative abundance of the native, subtropical bee versus that of the recently introduced, tropical bee?

2) Are there differences in the recovery patterns for each pollinator species in the years following the impact year?

\section{METHODS}

\section{Study System}

Although they can be diverse in the tropics, in southern Florida there are only two oil-collecting bees, Centris errans which is native to southeast Florida, and Centris nitida which has recently naturalized from Mexico and Central America (Pemberton and Liu 2008a). Throughout the neotropics, Centris bees form specialized oil-reward pollination systems with oil-plant species in the Family Malpighiaceae, as well as orchid species that mimic oil plants. The orchids are thought to have evolved a food deception pollination strategy that exploits oil-collecting bees. Female Centris bees require floral oil resources to construct the brood nest and provision their larvae (Frankie et al. 1988, Michener 2000). 
In southeast Florida, both Centris bees are the main pollinators for the only native oil-reward plant in the region, Byrsonima lucida (Malpighiaceae), as well as several other introduced Malpighiaceae species (Downing and Liu 2012). These Centris bees are also the primary pollinators of Cyrtopodium punctatum (cigar or Florida cowhorn orchid) in southeastern Florida (Pemberton and Liu 2008b). The Florida cowhorn was thought to be historically abundant throughout southern Florida before over-collection in the early 1900's (Luer 1972). Currently, natural populations of the Florida cowhorn remain small, and are primarily found in cypress sloughs throughout southwestern Florida. The species is now listed as endangered by the State of Florida, and it is still subject to sporadic illegal poaching in National and State protected areas (Dennis Giardina, personal communications). A combination of natural and cultivated plants of B. lucida and Florida cowhorns occurs at Fairchild Tropical Botanic Garden in Miami-Dade County, where there are also naturally-established populations of both Centris bee species. We specifically chose these focal plant species based on preliminary observational data that showed during the flowering period of B. lucida and C. punctatum, both bee species more frequently visited B. lucida plants over other non-native Malphigaceae species flowering in the garden.

\section{Pollinator Observations}

We used floral visitation frequencies as an indicator of bee-plant interaction intensity and also of the abundance of each bee species, and carried out timed floral watches to determine the visitations of C. nitida, and C. errans to flowers of B. lucida and C. punctatum at Fairchild Tropical Botanic Garden. Watches were conducted from February through April each year during the peak flowering of both plant species. The 
flowering phenologies of B. lucida and C. punctatum and the foraging period of native $C$. errans tightly coincide (March-May), while the recently naturalized C. nitida forages year-round. The highest forager activity was observed throughout the daylight hours, therefore watches were conducted throughout the day (08:30-15:30). Each watch was at least fifteen minutes long. Watches on B. lucida plants started three months after the cold spell in 2010 (impact year), and in the post impact years of 2011, 2012, and 2014 (Table 1). The watches for C. punctatum plants were conducted in 2006 (4 years pre-impact), and in the post impact years of 2011, 2012, and 2014 (Table 1). During 2011 and 2012, watches were conducted simultaneously for B. lucida and C. punctatum plants. Since we could not anticipate the extreme weather event we did not collect data for years 20072009. For each species, we quantified visitation frequency by each bee species. We did so by recording the type and number of visitors present on the flower patches during each watch period.

Timed watches were conducted on five large individuals of $B$. lucida. At any given sampling, display sizes for the plants were often greater than 100 inflorescences, each comprising 8-12 small flowers. The B. lucida plants in the garden setting are much larger than wild individuals because they have been allowed to grow beyond a small shrub (their predominant form in natural areas due to frequent fire) and into small trees. Before timed watches were performed, the total display size (total number of inflorescences on each plant) was quantified. If the plant had more than approximately 50 inflorescences, a portion of the plant was selected for observation. Watches were also conducted on at least five adult C. punctatum plants at a time within the garden. All of these individuals regularly set fruit and had display sizes ranging from 30-200 flowers. 
The tropical C. nitida is readily distinguished from the native bee by its smaller size and it distinct bright yellow thorax and jet black abdomen. Voucher specimens were collected for C. errans and C. nitida, and specimens were deposited at Fairchild Tropical Botanic Garden.

\section{Statistical Analyses}

To test for the interaction of time and population abundance we converted our temporal observation data into the proportion (\%) of the total visits observed by each bee species, and by calculating a visitation frequency variable. The proportion (\%) of the total number of observed visits by each bee species was calculated as: (no. of visits by each species/ total number of observed visits * 100); with the sum of the two species proportions equaling 100 percent. On a per plant basis, the no. of visits during each watch varied greatly, likely due to differences in display sizes for each individual plant on any given sampling day, and differences in the no. of flowers watched by each observer. Visitation frequency was calculated as: (no. of visits by each species/ amount of watch time in minutes) and was completed for each species interaction. Prior to statistical analysis, visitation variables were square root transformed. Any differences in the mean visitation frequencies between years were determined using one-way ANOVA in SPSS 7.0. Significant differences in opposite directions would indicate different temporal trajectories for individuals within that year, similar to a repeated measures analysis (Gotelli and Ellison 2004). We could not use a repeated measures analysis because the data violated the assumption of "circularity”; i.e. variances of the differences in observations between years were significantly different (Gotelli and Ellison 2004). 


\section{RESULTS}

\section{Observations on B. lucida}

During the impact year (2010) and in the year (2011) following the cold spell, the proportions of visits and mean visitation frequencies by the exotic $C$. nitida were much lower than those two and three years post-impact (Table 1 \& Fig 1). In contrast, visitations by the native $C$. errans were proportionally much greater during the impact year and the first year following the impact (Table 1 \& Fig 1). Two and four years following the impact (in 2012 and 2014, respectively), visitations by the two bees trended in the reverse directions, with $C$. errans visits to $B$. lucida dramatically decreasing and $C$. nitida increasing proportionally.

Mean visitation frequencies for both bees to $B$. lucida plants varied between years $\left(\mathrm{F}_{3,139}=13.235, \mathrm{P}<0.0001\right.$ for $C$. errans, and $\mathrm{F}_{3,139}=6.353, \mathrm{P}<0.0001$ for $C$. nitida $)$. Mean visitation frequencies to $B$. lucida by $C$. errans increased significantly in the first season following the cold spell (Tukey HSD post hoc; $\mathrm{P}=0.007$ ) and followed by a significant decrease in visitation frequencies in 2012 (Tukey HSD post hoc; $\mathrm{P}<0.0001$ ). The tropical $C$. nitida responded differently than its native subtropical congener: it showed a much slower recovery pattern, with no increase in mean visitation frequencies to B. lucida until 2014, four flowering seasons post impact (Tukey HSD post hoc; $\mathrm{P}=$ $0.008)$.

\section{Observation on C. punctatum}

In pre-impact watches conducted on C. punctatum in 2006, both bees were observed roughly the same number of times and relative to $B$. lucida, both bees were similarly infrequent visitors to C. punctatum (Table 1). The visitation frequencies of both 
bee species to C. punctatum were the highest in the pre-impact year (2006). During the pre-impact year and final observation year, both bee species had similar mean visitation frequencies (Fig. 2). The mean visitation frequency of C. errans to C. punctatum were not significantly different between pre-impact and post impact years $\left(\mathrm{F}_{3,45}=2.479, \mathrm{P}=\right.$

0.074 ). However, four years post impact (2014), visitations by C. errans to C. punctatum decreased compared to previous years (Fig. 2). In contrast, C. nitida had significantly different mean visitation frequencies across years $\left(\mathrm{F}_{3,45}=5.649, \mathrm{P}=0.002\right)$, and each visitation frequency in post-impact years was significantly lower than the pre-impact frequency (posthoc Tukey HSD; P < 0.003). Unlike C. errans, four years post impact (2014), the visitations by C. nitida remained constant (Fig. 2). For C. punctatum that year, only one visit by each bee was observed.

\section{DISCUSSION}

Our results and analyses suggested differential impacts from the extreme cold event on the native, subtropical vs. the introduced, tropical bees. Specifically, the cold spell seemed to have no or low impact on the abundance of the native bee. In contrast, the visitation intensity and abundance of the introduced, tropical bee showed a pattern consistent with that of a negative impact. The native bee, C. errans, showed a marked increase in the proportion of total number of visits and visitation frequency to both plant species in the flowering season immediately following the impact year, indicating minimal impacts and/or rapid population recovery. Either way, the findings strongly suggests no long-term impacts from this extreme cold spell. The more tropical bee $C$. nitida showed opposite effects from the extreme cold event, taking at least three to four 
years to recover. The rate at which each population recovered may have been determined by the different life histories of the two species, and the number of surviving reproductive individuals (Gotelli 2008). We saw no evidence that B. lucida or C. punctatum were adversely effected by the cold spell (i.e. mortality, extensive tissue damage, or marked decrease in floral displays between years).

The differences in the visitation frequencies of the two bees may reflect interactions between the two species. On both focal plants, we observed opposite trajectories in the visitation frequencies one and two years after the cold event, suggesting potential competition between the bees during the recovery of the introduced C. nitida. However, these findings are in contrast to findings in Downing and Liu (2012) which observed no evidence of direct competition, or indirect competition associated with resource limitations. It was also found that there was no evidence of decreased fruit set or pollination limitations associated with the presence of the novel introduced pollinator, and that in sites where both bee species co-occurred fruit set was significantly higher (Downing and Liu 2012). Yet this study was conducted over a shorter two-year sampling period and included natural areas with more B. lucida plants. Regardless, if competition may have contributed to the decline in the visitation frequency of C. errans in 2012 at the garden site, this would then support "ecological release” hypotheses that suggest the impacts of extreme climate events can create short term situations where the native species has increased fitness caused by a greater setback to interacting introduced species. Although the tropical bee was affected by the extreme event more severely, 2014 visitation frequencies suggest that both bee species have recovered fully. 
These results also support the hypothesis that extreme cold spells can retard and/or limit the population abundances and distributions of newly arrived tropical species at the sub-tropical edges of their ranges, at least in the short-term. Consequently, a reduction in the frequency of these cold events in Florida would likely enhance the poleward migration of this and other tropical species. It has been hypothesized that extreme climatic events facilitate the expansion and/or migration of non-native species by either physically moving the species' or by reducing the "biotic resistance" that native communities may have towards invaders (Diez et al. 2012). In southern Florida, climate change models predict an increase in annual mean temperature between $1-4^{\circ} \mathrm{C}$ over the next 100 years (IPCC 2014). Theoretical models predict that increases in mean annual temperature, even by small amounts, will increase the number of extreme hot days and a decrease in the number of extreme cold days (Meehl et al 2000). The continued but rarer occurrence of cold events could also select for hardier and more cold-tolerant individuals, increasing the probability of tropical species' long-term persistence and continued poleward expansion. The native subtropical C. errans is probably adapted to occasional extreme cold. Its heavier body type may afford some thermal inertia, along with the long dormancy period of this species, which spans the winter months and included the cold spell. For C. errans these cold tolerant life history traits have likely evolved in response to the cooler subtropical climate of southern Florida.

Although both bee species are known to utilize non-native Malphigiaceae plants we do not believe that the changes in visitation frequencies following the impact reflect a shift to other non-native host plant species within the foraging range. As mentioned in the methods section, preliminary observational data showed that both bee species are 
infrequent visitors to non-native Malphigiaceae during the flowering period of B. lucida and C. punctatum. For that reason the rate of visitations to these focal plant species best represent the overall population abundance.

Our findings also shed some light on the hypothesis that obligate mutualists will be strongly affected, either positively or negatively, by predicted climate change trends. In the case of the introduced tropical species, with gradual warming we expect an overall increase in the level of interaction in the new range, but occasionally dampened by extreme cold weather. By definition, naturalized species have already adapted to novel environments and/or ranges; this flexibility will also assist its poleward migration. In contrast, the native C. errans may respond more negatively to the overall impacts of climate change because of its more specialized life history: the tightly coevolved, extremely short flight period and heavy dependence on B. lucida plants. As a result, even minor mismatches with the phenology of B. lucida as a likely consequence of changes in climate may have large impacts on C. errans populations.

\section{CONCLUSIONS}

Studies that can predict the impacts of climate change are one of the greatest and most urgent challenges faced by ecologists. The pattern of our findings support the hypothesis that extreme cold spells are important climate change-related phenomena that can have impacts on tropical species distributions and abundances, especially at the threshold of their thermal tolerances. Our approach also provided a rare opportunity to examine these impacts on multiple interacting species, which provides a more realistic assessment of the potential impacts of climate change. Although this study was brief and 
limited in scope, it was suggestive of the major potential for tropical species to extend their ranges and interactions with sub-tropical species as climate change continues. A combination of more sampling years and a comprehensive examination into gradual changes in the life histories and physiologies for these species will be necessary to better predict the impacts of extreme cold spells.

\section{ACKNOWLEDGMENTS}

We thank the students from Florida International University Restoration Ecology classes of 2010, 2011, and 2014 for their assistance in field work. This is contribution number 312 from the Tropical Biology Program of Florida International University. 
Table 2.1

Table1. Visitations by the subtropical bee Centris errans and tropical bee Centris nitida to Byrsonima lucida and Cyrtopodium punctatum plants.

\begin{tabular}{|c|c|c|c|c|c|c|c|c|}
\cline { 2 - 9 } \multicolumn{1}{c|}{} & \multicolumn{4}{c|}{ B. lucida } & \multicolumn{4}{c|}{ C. punctatum } \\
\cline { 2 - 10 } & Impact Year & \multicolumn{2}{|c|}{ Post-Impact Years } & Pre-Impact Year & \multicolumn{3}{c|}{ Post-Impact Years } \\
\cline { 2 - 10 } & $\mathbf{2 0 1 0}$ & $\mathbf{2 0 1 1}$ & $\mathbf{2 0 1 2}$ & $\mathbf{2 0 1 4}$ & $\mathbf{2 0 0 6}$ & $\mathbf{2 0 1 1}$ & $\mathbf{2 0 1 2}$ & $\mathbf{2 0 1 4}$ \\
\cline { 2 - 10 } & $301 \mathrm{~min}$. & $1042 \mathrm{~min}$. & $1511 \mathrm{~min}$. & $521 \mathrm{~min}$. & $635 \mathrm{~min}$. & $1246 \mathrm{~min}$. & $624 \mathrm{~min}$. & $196 \mathrm{~min}$. \\
\hline \multirow{2}{*}{ C. errans } & $91.5(86)$ & $96.2(584)$ & $75.6(289)$ & $72.5(247)$ & $48(12)$ & $76.9(30)$ & $76.5(13)$ & $50(1)$ \\
\hline \multirow{2}{*}{ C. nitida } & $8.5(8)$ & $3.8(23)$ & $24.4(93)$ & $27.6(94)$ & $52(13)$ & $23.1(9)$ & $23.1(4)$ & $50(1)$ \\
\hline
\end{tabular}

Note: Numbers below years represent the total observation time and percentage of the total visits (total no. of visits) observed for each bee species.

Table 2.1 Visitations by the subtropical bee Centris errans and the tropical bee Centris nitida to Byrsonima lucida and Cyrtopodium punctatum plants. 
Fig. 2.1 Visitation rates (no. of visits per minute) to Byrsonima lucida. The light line represents the native bee $C$. errans, and the dark line represents the introduced bee $C$. nitida, error bars represent $+/-1$ standard error. Dashed lines represent the overall trajectory between years 2012-2014.

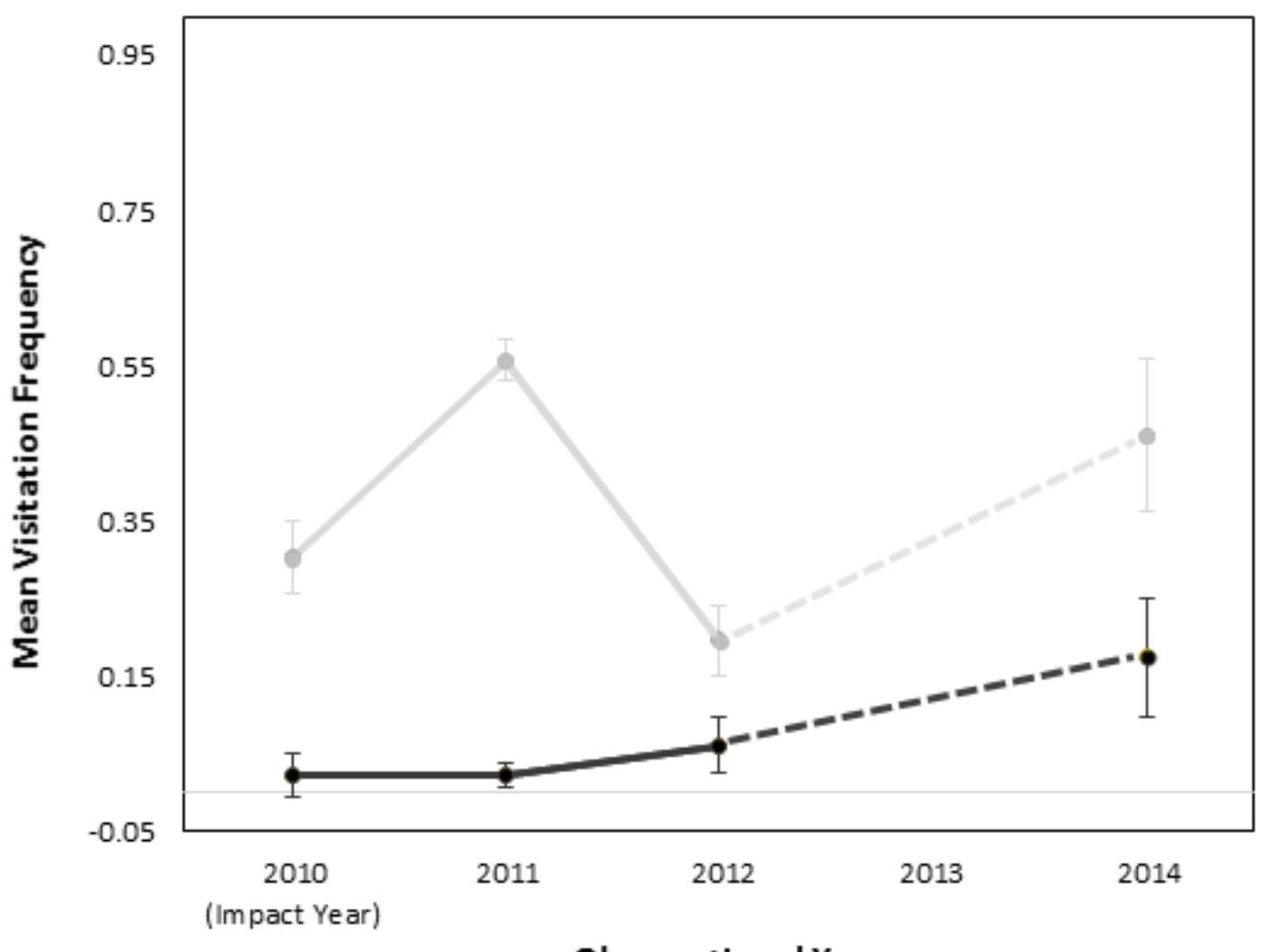

Observational Year 
Fig. 2.2 Visitation rates (no. of visits per minute) by each bee species to Cyrtopodium punctatum. The light line represents the native bee $C$. errans, and the dark line represents the introduced bee $C$. nitida. Error bars represent $+/-1$ standard error. Dashed lines represent the overall trajectory between years 2012-2014.

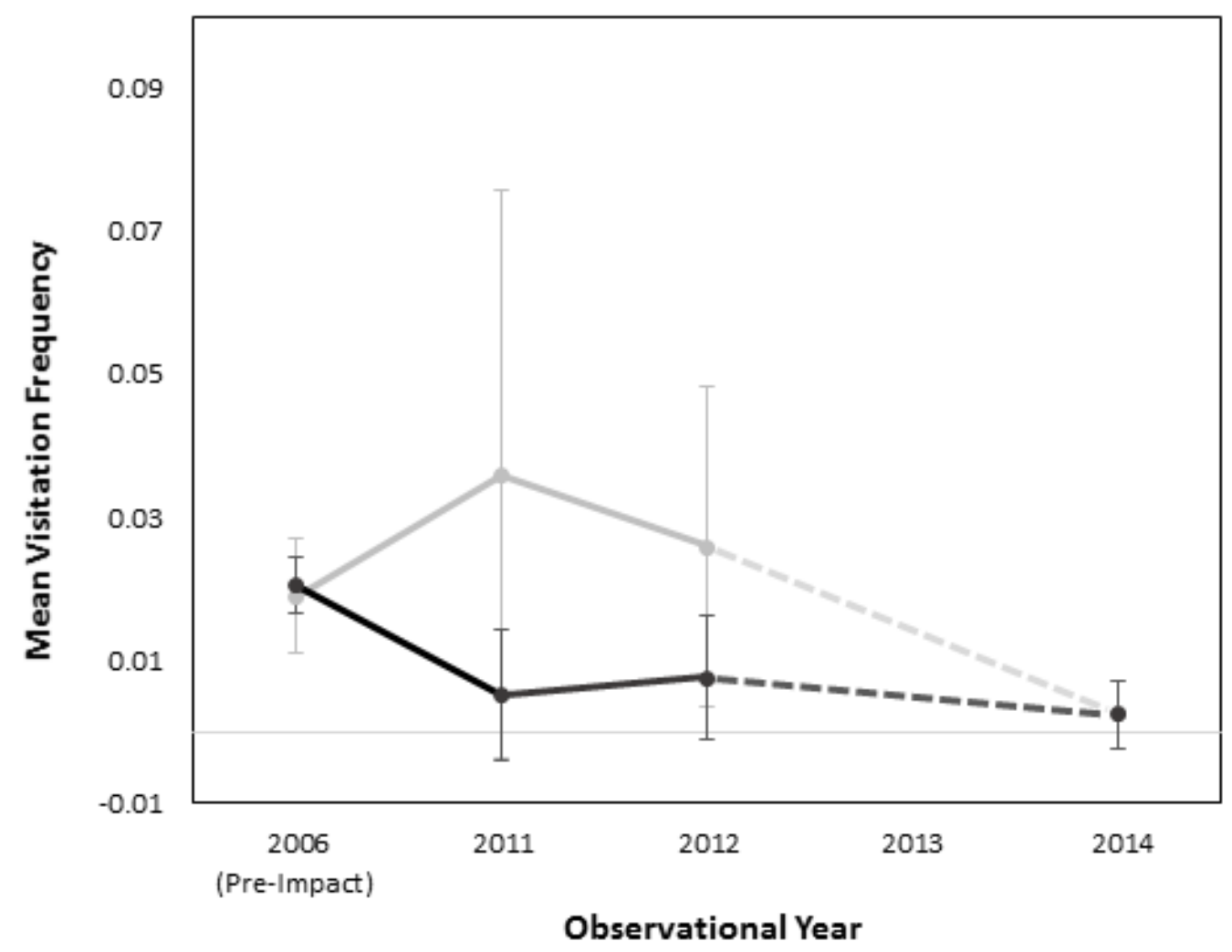




\section{REFERENCES}

Avery, M. L., R. M. Engeman, K. L. Keacher, J. S. Humphrey, W. E. Bruce, T. C. Mathies, \& R. E. Mauldin. 2010. Cold weather and the potential range of invasive Burmese pythons. Biological Invasions 12(11): 3649-3652.

Boucek, R. E., \& J. S. Rehage. 2014. Climate extremes drive changes in functional community structure. Global Change Biology 20(6): 1821-1831.

Compant, S., M. G.Van Der Heijden, and A. Sessitsch. 2010. Climate change effects on beneficial plant-microorganism interactions. FEMS Microbiology Ecology: 73(2), 197-214.

Cox, G. W., and R.E. Ricklefs. 1977. Species diversity and ecological release in Caribbean land bird faunas. Oikos: 113-122.

Diez, M. J., C. M. D’Antonio, J. S. Dukes, E. D. Grosholz, J. D. Olden, C. J. Sorte, D. M. Blumenthal, B. A. Bradley, R. Early, I. Ibáñez, S. J. Jones, J. J. Lawler and L. P. Miller. 2012. Will Extreme Climatic Events Facilitate Biological Invasions? Ecological Society of America: 10(5), 249-257.

Downing, J. L. and H. Liu. 2012. Friend or foe? Impacts of the introduced tropical oil bee Centris nitida on a threatened and specialized native mutualism in Southern Florida. Biological Invasions: 14(10): 2175-2185

Easterling, D. R., G. A. Meehl, C. Parmesan, S. A. Changnon, T. R. Karl, \& L. O. Mearns. 2000. Climate extremes: Observations, modeling, and impacts. Science: 289(5487), 2068-2074.

Field, C. B., V. R. Barros, D. J. Dokken, K. J. Mach, M.D. Mastrandrea, T. E. Bilir, and L. L. White. 2014. IPCC, 2014: Climate Change 2014: Impacts, Adaptation, and Vulnerability. Part A: Global and Sectoral Aspects. Contribution of Working Group II to the Fifth Assessment Report of the Intergovernmental Panel on Climate Change.

Gotelli, N. J. 2008. A primer of ecology. Fourth Edition. Sinauer Associates Incorporated, Sunderland, Massachusetts, USA.

Gotelli, N. J. and G. N. Ellison. 2004. A primer of ecological statistics. Sinauer Associates Incorporated, Sunderland, Massachusetts, USA.

Fantz, A. 2010. Pythons and citrus and iguanas, oh my! Frigid Florida copes. CNN US. http://www.cnn.com/2010/US/weather/01/10/us.cold.weather/index.html 
Fitter, A. H., A. Heinemeyer, and P. L. Staddon. 2000. The impact of elevated CO2 and global climate change on arbuscular mycorrhizas: a mycocentric approach. New Phytologist: 147(1), 179-187.

Frankie, G W, S. B. Vinson, E. Newstrom, J. F. Barthell. 1988. Nest site and habitat preferences of Centris bees in the Costa Rican Dry Forest. Biotropica: 20, 301310.

Gilman, S. E., M. C. Urban, J. Tewksbury, G. W. Gilchrist, \& R. D. Holt. 2010. A framework for community interactions under climate change. Trends in Ecology \& Evolution: 25(6), 325-331.

Hallac, D., J. Kline, J. Sadle, S. Bass, T. Ziegler and S. Snow. 2010. Preliminary effects of the January 2010 cold weather on flora and fauna in everglades national park. Biological Resources Branch, South Florida Natural Resources Center, Everglades and Dry Tortugas National Parks, Homestead, Florida.

Hill, J. K., H. M. Griffiths, and C. D. Thomas. 2011. Climate change and evolutionary adaptations at species' range margins. Annual review of entomology: 56, 143-159.

Hoffman, A. A. and P. A. Parsons. 1997. Extreme Environmental Change and Evolution. Cambridge University Press, Cambridge, UK.

Jentsch, A., and C, Beierkuhnlein. 2008. Research frontiers in climate change: Effects of extreme meteorological events on ecosystems. Comptes Rendus Geoscience: 340(9), 621-628.

Jentsch, A., J. Kreyling, and C. Beierkuhnlein. 2007. A new generation of climate-change experiments: Events, not trends. Frontiers in Ecology and the Environment: 5(7), 365-374.

Kearns, C. A., D. W. Inouye, and N. M. Waser. 1998. Endangered mutualisms: the conservation of plant-pollinator interactions. Annual review of ecology and systematics: $83-112$.

Kreyling, J., S. Schmid, and G. Aas. 2015. Cold tolerance of tree species is related to the climate of their native ranges. Journal of Biogeography, 42(1), 156-166.

Lirman, D., S. Schopmeyer, D. Manzello, L. J. Gramer, W. F. Precht, F. Muller-Karger, K. Banks, B. Barnes, E. Bartels, A. Bourque, J. Bryne, S. Donahue, J. Duquesnel, L. Fisher, D. Gilliams, J. Hendee, M. Johnson, K. Maxwell, E. McDevitt, J. Monty, D. Rueda, R. Ruzicka, S. Thanner. 2011. Severe 2010 cold-water event caused unprecedented mortality to corals of the Florida reef tract and reversed previous survivorship patterns. PLoS One: 6(8), 23047.

Liu, H., C. Feng, B. Chen, Z. Wang, X. Xie, Z. Deng, X. Wei, S. Liu, Z. Zhang, and Y. Luo. 2012. Overcoming extreme weather challenges: Successful but variable 
assisted colonization of wild orchids in southwestern china. Biological Conservation: 150(1), 68-75.

Losos, J. B., and K. De Queiroz. 1997. Evolutionary consequences of ecological release in Caribbean Anolis lizards. Biological Journal of the Linnean Society: 61(4), 459-483.

Luer, C. A. 1972. The native orchids of Florida. First Edition. The New York Botanical Garden. New York, New York, USA.

Mazzotti, F. J., M. S. Cherkiss, K. M. Hart, R. W. Snow, M. R. Rochford, M. E. Dorcas, and R. N. Reed. 2011. Cold-induced mortality of invasive Burmese pythons in south Florida. Biological Invasions: 13(1), 143-151.

Meehl, G. A., T. Karl, D. R. Easterling, S. Changnon, R. Pielke, D. Changon, J. Evans, P. Y. Groisman, T. R. Knutson, K. E. Kunkel, L. O .Mearns, C. Parmesan, R. Pulwarty, T. Root, R. T. Sylves, P. Wheton, and F. Zwiers 2000. An introduction to trends in extreme weather and climate events: Observations, socioeconomic impacts, terrestrial ecological impacts, and model projections. Bulletin of the American Meteorological Society, 81(3), 413-416.

Michener C. D. 2000. The Bees of the World. Johns Hopkins University Press, Baltimore, Maryland.

NOAA. 2010. Historic cold weekend in south Florida. NOAA, National Weather Service, Weather Forecast Office, Miami, Florida, USA.

Parmesan, C., T. L. Root, and M. R. Willig. 2000. Impacts of extreme weather and climate on terrestrial biota. Bulletin of the American Meteorological Society: 81(3), 443-450.

Parmesan, C., and G. Yohe. 2003. A globally coherent fingerprint of climate change impacts across natural systems. Nature: 421(6918), 37-42.

Pemberton R.W., H. Liu. 2008a. Potential of invasive and native solitary specialist bee pollinators to help restore the rare cowhorn orchid (Cyrtopodium punctatum) in Florida. Biological Conservation: 141, 1758-1764

Pemberton R. W., H. Liu .2008b. Naturalization of the Oil Collecting Bee Centris nitida (Hymenoptera, Apidae, Centrini), a potential pollinator of selected native, ornamental, and invasive plants in Florida. Florida Entomologist: 91, 101-109

Potts, S. G., J. C. Biesmeijer, C. Kremen, P. Neumann, O. Schweiger, and W. E. Kunin. 2010. Global pollinator declines: trends, impacts and drivers. Trends in ecology \& evolution: 25(6), 345-353. 
Quinlan P. 2010. Cold snap kills, injures Florida turtles, manatees, iguanas, fish. Palm Beach Post. http://www.palmbeachpost.com/news/cold-snap-kills-injures-floridaturtles-manatees-iguanas-177037.html.

Rehage J. S., Blanchard J. R., Boucek, R. E., Lorenz J. J., Robinson M. 2015. Knocking back invasions: variable resistance and resilience to multiple cold spells in native vs. nonnative fishes. Ecosphere.

Thibault, K. M., and J. H. Brown. 2008. Impact of an extreme climatic event on community assembly. Proceedings of the National Academy of Sciences: 105(9), 3410-3415.

Walther, G. R., E. Post, P. Convey, A. Menzel, C. Parmesan, T. J. Beebee, and F, Bairlein. 2002. Ecological responses to recent climate change. Nature: 416(6879), 389-395.

Wang X., Liu H., Gu M., Boucek R., Wu Z., Zhou G. 2015. Greater impacts from an extreme cold spell on tropical than wide ranging butterflies in southern China. Ecosphere.

Winfree, R., R. Aguilar, D. P. Vázquez, G. LeBuhn, and M. A. Aizen. 2009. A metaanalysis of bees' responses to anthropogenic disturbance. Ecology: 90(8), 20682076.

Zimmermann, N. E., N. G. Yoccoz, T. C. Edwards, E. S. Meier, W. Thuiller, A. Guisan, D. R. Schmatz, and P. B. Pearman. 2009. Climatic extremes improve predictions of spatial patterns of tree species. Proceedings of the National Academy of Sciences of the United States of America: 106(Supplement 2), 19723-19728. 


\section{CHAPTER III}

MYCORRHIZAL ASSOCIATIONS OF NATIVE VERSUS INVASIVE CONGENERIC ORCHID SPECIES 


\section{ABSTRACT}

A species' ability to establish and spread is often influenced by different types of biotic interactions encountered in the introduced range. Using a comparative approach we address the role of mycorrhizal specificity in the spread of two invasive orchids in southern Florida, Cyrtopodium flavum and Eulophia graminae, with that of two rarer native congeners, Cyrtopodium punctatum and Eulophia alta. We accomplished this by sampling and isolating fungi from the roots of each orchid species, and by placing packets containing seeds collected from wild individuals in the habitat for two years to obtain the fungi necessary for germination. Then using fungal specific DNA primers we identified the fungal taxa associated with each species. The degree of mycorrhizal specificity was defined as both the number of distinct fungal taxa (OTU) associated within each species, as well as the phylogenetic breadth between distinct fungal taxa. Our results showed that the invasive orchids are exploiting specific genera of basidiomycete fungi that are widely available in the invaded habitats and they are capable of utilizing diverse groups of fungi for seed germination as compared to their rare congeners. These findings will advance the study of ecology specifically invasions, range expansions, and species responses to environmental change by addressing the potentially strong role of mycorrhizal symbioses in governing plant distribution in both native and introduced ranges; and so provide an explicit factor to assess invasive potential and rarity in plants.

\section{INTRODUCTION}

We are just beginning to understand the factors that influence invasiveness in plants, let alone orchids. However, it has been shown that a species' ability to invade is 
heavily dependent on the number and types of biotic interactions it encounters upon introduction (Richardson et al. 2000, Liu and Stiling 2006, Pringle et al. 2009, Liu and Pemberton 2010). A major type of biotic interaction that can structure plant communities is the mycorrhizal associations, particularly in obligately mycorrhizal plant taxa such as orchids (Rasmussen 1995). Orchid mycorrhiza (OM) are a special type of endomycorrhiza that are evolutionarily distinct from the arbuscular mycorrhiza (AM) that are formed by Glomeromycota fungi with most taxa of land plants (Smith and Read 2008). OM fungi are polyphyletic and ecologically diverse: some are saprophytic basidiomycetes, others are tree mycorrhizal basidiomycetes that the orchids parasitize, and finally others are ascomycete endophytes. The saprophytic basidiomycetes belong to several teleomorph genera that make up the functional group called Rhizoctonia; well documented examples include Ceratobasidium, Tulasnella, and Sebacina, (Rasmussen 1995, Dearnaley et al. 2012). The mycorrhizal basidiomycetes form ectomycorrhiza with tree roots and are then exploited by mycoheterotrophic orchids such as Corallorhiza (McCormick et al. 2009). These fungal genera include Russula, Thelephora, and Tomentella. The Ascomycetes, some of which can act as ECM fungi and pathogens in other plants can also form mycorrhizae in orchids (Peterson et al. 2004). Most notably is the order Pezizales, which are ECM in temperate forests yet commonly associate with the terrestrial genus Epipactis; some prominent genera are Tuber, Genea, and Wilcoxina (Selosse et al. 2004, Bidartondo and Read 2008, Těšitelová et al. 2012).

Orchids are model organisms in which to explore mycorrhizal effects on plant community assembly. All species of orchids are dependent on their fungal associates for seed germination (Rasmussen 1995) and, at least at the outset, all exploit the fungus. 
However, in adult orchids, the relationships can be more complicated. Mature orchids encompass the full range of associations with their mycorrhizal fungi: from parasitic to mutualistic, and from generalist to specialist in their associations (Taylor 2004, McCormick et al. 2006). The type and degree of specificity of these interactions can regulate orchid species' abundance and distributions, and thus may play a role in both rarity and invasiveness (McCormick et al. 2009, 2012, Swarts et al. 2010, Jacquemyn et al. 2012 (a) and (b), Nomura et al. 2013; but see Panday et al. 2013 and Phillips et al. 2011 for exceptions). The variety of interactions allows the testing of two main hypotheses to explain fungal effects on orchid populations:1) Rare orchid species have specialized associations with one or just a few beneficial fungal partners, while invasive species have gained generalized associations with many or widespread new partners. 2) Conversely, rare orchid species have relatively many (or particularly harmful) antagonistic fungal associates, while invasive species have lost their former antagonistic partners (i.e. the enemy-release hypothesis or ERH; Keane and Crawley 2002).

The presence of compatible OM in the environment can determine where, and in what abundance, orchids occur (Rasmussen and Whigham 1998, Suarez et al. 2006, McCormick 2012). In particular, high OM specificity can restrict orchid distribution by limiting recruitment to new sites. Or if one or a few fungal species are suitable partners, a fungus might be only rarely available to support seed germination. As a result, orchid populations would remain restricted to sporadic patches in which their fungus occurs (Rasmussen and Whigham 1998, Waterman and Bidartondo 2008, Otero et al. 2007). Similarly, a lack of appropriate OM partners could prevent the establishment of some introduced orchids in non-native ranges all together. 
On the other hand, orchid species that are flexible in their fungal requirements, or have a broader range of compatible host fungi (i.e. generalists), will have enhanced recruitment success over a wider range of environmental conditions, and therefore be more likely to invade. Bonnardeaux et al. (2007) examined the effect of orchid-fungus specificity on the orchid partner's distribution by comparing the diversity of mycorrhizal fungi associated with the invasive South African orchid Disa bracteata to that of a widespread native Australian orchid (Pyrorchis nigricans), and to another weedy native Microtis media. They found that the invasive $D$. bracteata had the greatest breadth of mycorrhizal fungus diversity, while the native orchids utilized smaller sets of fungi. In a closer investigation into the role of mycorrhizae in the spread of the weedy native $M$. media, findings again supported the hypothesis that widespread terrestrial orchid species were associating with diverse fungal communities whose species were widespread and/ or common in the environmental matrix (De Long et al. 2012).

The enemy-release hypothesis (ERH) has been proposed as an alternative mechanism for the establishment and spread of non-indigenous species (Keane and Crawley 2002). According to the ERH, some species are able to successfully invade because they have been ecologically released, and their natural enemies (i.e. competitors, predators, and pathogens) have been left behind. Freed from the need for costly defense strategies, and provided that individuals can reallocate resources to growth and reproduction, the introduced species can realize a resource windfall and spread rapidly. Most studies of the ERH have addressed plant-herbivore interactions in non-orchid taxa. Few include comparisons in the native and introduced ranges (Agarwal et al. 2005, Liu et al 2006) or between congeneric introduced species with differing population abundances 
(Liu and Stiling 2007). In a meta-analysis by Liu and Stiling (2006), which included fifteen plant species, the total number of herbivore enemies was reduced in the introduced versus native ranges, and the reduction was skewed toward a loss of specialist enemies. Mitchell and Power (2003) examined 473 European plant species introduced to North America, and found that on average the naturalized plants were largely released from fungal and viral pathogens (i.e. $84 \%$ fewer fungi and 24\% fewer viruses). Conversely, introduced species can be susceptible to new enemies that they have not evolved defenses against (Russell and Louda 2005, Barbosa et al. 2009).

Although these studies have shown that either increased beneficial, or reduced antagonistic, fungal interactions may enable orchid species to invade new ranges, the ability to extrapolate the results to other orchid species is limited. Most of the studies to date compare only native species to each other, or invasive species to unrelated native species. Comparisons conducted within a phylogenetic context can limit confounding differences that may be intrinsic to taxonomic groups, providing greater power to distinguish characteristics specifically related to invasiveness. In this study we utilize congeneric pairs, comprising one native and one invasive species, within the Orchidaceae, subfamily Epidendroideae, and tribe Cymbidieae (Cameron et al., 1999). To explore the relationships between invasiveness and mycorrhizal specificity and ERH, we employ two natural experiments: the recent naturalization of Cyrtopodium flavum and Eulophia graminae in Florida, and compare the mycorrhizal associations of these invasive species with their less abundant native congeners, C. punctatum and E. alta, both of which are also found in the region. These closely related species represent extremes of the population abundance spectrum, and provide a fortuitous opportunity to 
better understand how mycorrhizal interactions may drive orchid population dynamics. Using phylogenetic analyses, in situ fungi baiting, and germination experiments, we determined the level of specificity in relationships of different types of root-associated fungi for each species. Specifically, we address the following research hypotheses: 1) Invasive orchids are more generalized in their OM associations than less abundant native congeners; 2) Invasive orchids will be more commonly infected with pathogenic fungi than their native congeners; 3) Germination rates will differ between native and exotic congeners.

\section{METHODS}

\section{Study Species}

The Florida cowhorn orchid (C. punctatum) is an epiphytic orchid that was thought to be abundant throughout southern Florida (Luer 1972) (Fig 1a-c), but due to habitat loss and extensive poaching, it is now legally endangered in the state of Florida (Wunderlin and Hansen 2012). Currently it is restricted to a small number of cypress domes in Everglades National Park, Big Cypress National Preserve, Fakahatchee Strand Preserve State Park (FSS), and the Florida Panther National Wildlife Refuge in southwest

Florida. In addition, in southeastern Florida a semi-natural population occurs at Fairchild Tropical Botanic Garden (FTBG). Cyrtopodium punctatum is an obligately outcrossing species (Pemberton and Liu 2008), and in the natural populations fruit set is extremely low (personal communications Mike Owen \& Dennis Giardina), likely due to the low population densities that can hamper pollination services. Contrastingly, in the garden setting, there are two specialist pollinators (Centris errans and Centris nitida), and 
mature $C$. punctatum individuals consistently produce fruit. Each year new volunteers are found on the surrounding trunks of palms, oaks, and buttonwoods (personal observations).

The yellow cowhorn C. flavum (formerly C. polyphyllum) is a showy terrestrial orchid that occurs in rocky and sandy soil as part of the restinga vegetation along the southeastern coast of Brazil (Pansarin et al. 2008) (Fig 2a-d). This non-rewarding species is self-compatible and has demonstrated a high-fruit set in both manual self- and outcross-pollinated individuals (Pansarin et al. 2008, Liu and Pemberton 2010). Since the 1970's it has volunteered in mulched areas and residential yards, throughout central and southern Florida, and has invaded at least three pine rockland forests in Miami-Dade County, Florida (Liu and Pemberton 2010). In one of the most heavily infested forests, a 76 acre fragment, Camp Matecumbe/Boystown Pineland (BT site), population estimates place the number of reproducing plants at 6,000 (unpublished data).

Eulophia alta (L.) Fawc. \& Rendle is a terrestrial orchid that produces large tuber-like corms from which a long inflorescence is borne (Fig 3a-d). Although now uncommon in southern Florida, this species has a large natural distribution that spans North, Central, and South America, as well as West Africa (Luer 1972). In Florida, E. alta can be found as far north as Collier County, but is patchy in its distribution (Stewart \& Richardson, 2008). Breeding studies demonstrated that this species is capable of spontaneous autogamy, but is most productive when outcrossed by pollinators (Johnson et al. 2009). In Florida, it occupies a range of habitats from damp and semi-aquatic swamps and roadside ditches, to well sunlit pastures. 
Eulophia graminae Lindl. is a terrestrial corm-forming species that is native to Southeast Asia where it is considered endangered (Li et al. 2002) (Fig 4a-c). This widespread species has been found on three continents, Asia, Australia, and North America. Currently the orchid is commonly found as far north as Central Florida. It is thought that this orchid was introduced in the soil of plants imported for cultivation. Pemberton et al. (2008) first reported this species in the Miami area in 2007, sporadically appearing in residential mulch piles throughout Miami-Dade County of Florida. Now it can be readily found throughout the urban and disturbed habitats, including grasslands and even beaches. Volunteers have even been seen growing epiphytically at FTBG (Fig 4d) and can reproduce vegetatively through corms. This species displays a complex breeding system, Chang et al. (2010) demonstrated autogamous selfing capabilities, yet it depends on pollinator-driven outcrossing in the populations in Florida and Hong Kong (Sun 1997, Pemberton et al. 2008, Chang et a. 2010). Despite possible breeding system limitations, this orchid exhibits the weedy characteristics of rapid protocorm and seedling development, and moves quickly through the flowering and early fruit set stages (Chang et al. 2010, personal observations).

\section{Protocorm and Root Collection}

We obtained protocorms from seed baits, as well as in situ, for both C. flavum and E. graminae (FIG 5a, b, c). We did not obtain viable protocorms for the native species from seed baiting. Although, we did observe evidence of germinated seeds in the baits for both native species, they had either aborted or were too small to extract DNA. However, we collected four young seedlings that still had protocorm bodies (Fig 6a; see samples R- 
1, R-2, R-3, R-4). For each study species we collected at least five root sections $(>5 \mathrm{~cm})$ from each individual sampled. We only selected roots that were in direct contact with the substrate (Fig 6b). Roots were removed using a clean razor blade, and immediately rinsed with sterile water to remove any excess organic debris. Root cuttings were covered in moist paper towel and stored in a sterile plastic bag for transport. Tissue samples were stored at $4^{\circ} \mathrm{C}$ for up to one week before fungal isolation and DNA extraction. We collected roots from fourteen accessible adults, and six seedlings of $C$. punctatum at the FTBG site. At the FSS site, we sampled twelve adults and one seedling of $C$. punctatum; only two seedlings were observed at this site, and due to the vulnerability of this population we chose to collect only one root sample. For $C$. flavum we sampled a total of 31 individuals. At the newly invaded ZOO site, all seven adult plants were sampled, and nine seedlings. At the heavily infested BT site, roots were randomly sampled from seven adults and five seedlings. We sampled 26 plants of E. graminae at three introduced sites in Florida (FTBG, BT, \& CSS), and two adult plants in the native range in Guangxi, China; sites included: Xishuangbanna Tropical Botanic Garden (XTBG) and a schoolyard in Nanning, Guangxi, China.

\section{Fungi Baiting}

We used in situ seed baiting to determine mycorrhizal distribution in a variety of favorable microhabitats at each study site. Nylon mesh fungus baits containing fresh orchid seeds were deployed to sample the fungi necessary for germination. Fungus baits were constructed using protocols adapted from Brundrett et al. (2003). Baits consisted of fifteen, $2.5 \mathrm{~cm}$ X $2.5 \mathrm{~cm}$ square, heat sealed compartments. Fifty fresh seeds were placed 
in each compartment on a $1.5 \mathrm{~cm} \mathrm{X} 1.5 \mathrm{~cm}$ square of sterile moistened filter paper with a small painting brush (Fig 7a). For C. punctatum, a total of 30 fungus baits were deployed at the FTBG and FSS sites (2 sites X 30 baits X 15 packets X 50 seeds $=45,000$ seeds total; Fig 7b \& c). The first 15 baits were put out at each site in May of 2013 and were scored for the first time in November 2013. For the second deployment, 15 more baits were placed out in March of 2014. Fifteen fungus baits for C. flavum were deployed in November-December of 2013, and in February of 2014, at the ZOO and BT sites (2 sites X 30 baits X 15 packets X 50 seeds $=45,000$ seeds total; Fig 7d). After the first year of baiting, we observed very little germination, so for the remaining baits we added $0.5 \mathrm{~g}$ of lean wood that had been ground and sterilized. For both E. alta and E. graminae we deployed one set of fungus baits at each site. The E. alta fungus baits were deployed once in March of 2014 at CSS (1 sites X 15 baits X 15 packets X 50 seeds = 22,500 seeds total), and E. graminae once in February of 2014 (1 sites X 15 baits X 15 packets X 50 seeds $=22,500$ seeds total). Fungus baits were scored for protocorm development every six months for up to two years. Baits for C. punctatum and C. flavum were retrieved in December of 2015.

\section{Isolation of mycorrhizal pelotons}

We obtained pure fungal cultures from a subset of root samples for DNA identification and seed germination trials. Using sterile technique, fungal pelotons (coils of fungal hyphae within orchid cells) were removed from the cortical cells of protocorms, and the roots of seedlings and adult plants. Sampling all life stages is necessary because some orchids associate with different fungal taxa during different life history stages 
(McCormick et al. 2004, Bidartondo and Read 2008). To remove surface contaminants, tissues were washed with a small brush in tap water and dish soap, and then rinsed several times in sterile deionized water. Under a laminar flow cabinet, roots were scraped with a sterile scalpel to excise pelotons from the cortical cells. Each was then rinsed five times in sterile deionized water, and initially plated on E-medium nutritive agar containing 50 mg Novobiocin antibiotic (Caldwell et al. 1991). Plates were sealed with plastic wrap and stored in a cool dark place for one to two weeks. Growing hyphal tips were then subcultured onto new agar media without antibiotic for two weeks. For each sample, the remnant pieces of the roots were collected and stored in $1 \mathrm{XTAE}$ at $-20^{\circ} \mathrm{C}$ for DNA identification. Later we used nutritive broth subcultures of the isolates for DNA identification and to conduct germination assays to determine whether these fungi a functional mycorrhiza (i.e. capable of germination).

\section{DNA Extraction, PCR, and Sequencing}

Genomic DNA was extracted from the lyophilized plant tissues, and fungal isolates grown in liquid media, using the DNeasy Mini Plant kit (QIAGEN, Venlo Limburg, Netherlands) at FTBG laboratories. Amplification of nuclear DNA from the first and second internal transcribed spacers and the 5.8s subunit of the ribosome gene (hereafter ITS) was accomplished using the universal fungal primer pairs ITS 1F/4, ITS1OF/4OF, and the Tulasnella specific primer pair ITS 5/ITS4-Tul, because they are expected to work very well for amplifying DNA of orchid fungi from tissue and culture (Gardes and Bruns 1993, Taylor and McCormick 2008). The different primer pairs were manufactured at Applied Biosystems (Foster City, CA, USA). The PCR reactions were 
performed using Redmix HI fidelity TAQ (Applied Biosystems, Waltham, Massachusetts, USA) and the following program: $96^{\circ} \mathrm{C}$ for $1 \mathrm{~min}$; 35 cycles of $94^{\circ} \mathrm{C}$ for $30 \mathrm{~s}, 54^{\circ} \mathrm{C}$ (ITS $1 \mathrm{~F} / 4$ and $5 / 4 \mathrm{Tul}$ ) or $60^{\circ} \mathrm{C}$ (ITS $1 \mathrm{~F} / 4$ ) for 30 s, $72^{\circ} \mathrm{C}$ for $30 \mathrm{~s}$; and $72^{\circ} \mathrm{C}$ for 10min. PCR reactions were conducted at FTBG and the Smithsonian Environmental Research Center (SERC; Edgewater, Maryland). Prior to sequencing, each PCR product was cleaned using ExoSAP-IT PCR Cleanup (Affymetrix, Santa Clara, California), and/or Sephadex G-50 (fine) Centri-Sep spin columns (Princeton Separations, Adelphia, New Jersey, USA). Sequencing reactions were completed using BigDye Terminator v3.1 Cycle Sequencing Kit (Applied Biosystems). Samples were sent to Florida International University, Core DNA Facility (Miami, FL, USA), and to Smithsonian Institution’s Laboratory of Analytical Biology (Suitland, Maryland, USA) for Sanger sequencing. All sequences were aligned using the MAFFT alignment plugin implemented in Geneious version 8.1.5 (Kearse et al., 2012; Biomatters, Auckland, New Zealand). Any misalignments were visually examined and then manually trimmed and optimized. All new ITS sequences from this study will be deposited in GenBank.

\section{Molecular Analysis}

Resulting sequences were compared to known sequences in GenBank through a nucleotide BLAST search. Estimations of phylogenies, and comparisons of taxonomic breadth, were done by generating consensus trees using neighbor-joining, and maximum likelihood (ML), with 500 random addition replicates, also implemented in Geneious. Tree topologies were qualitatively similar for both estimations. We decide to designate all OTUs as belonging either the Ascomycetes, non-Tulasnellaceae basidiomycetes, or 
the core Tulasnellaceae, and generated separate consensus trees were for each taxonomic grouping. Operational taxonomic units (OTUs) were grouped by calculating the pairwise sequence distances from ML consensus trees, and are represented as the tips of the phylogenetic trees. We considered the sequences with greater than $97 \%$ similarity for the Ascomycetes and non-Tulasnellaceae basidiomycetes to be the same fungal taxa. Because of the rapid evolution in Tulasnellaceae, we set the cut off value at $95 \%$ similarity for these taxa. For each orchid species, the total number of OTUs, the minimum and maximum, and the average number of OTUs were calculated for each population (site). To compare the diversity of each fungal group for each orchid species, the Shannon-Weiner Index $\left(H^{\prime}\right)$ was calculated using counts of distinct OTUs detected at each site. The indices were then compared using Student's $t$-tests.

To reveal any differences in phylogenetic breadth between the two orchid types (native and invasive) we calculated Mean Pairwise Distance (MPD) and phylogenetic diversity (Faith’s PD; hereafter PD) (Faith 1992). These methods have been shown to be useful ways to determine whether orchids are utilizing groups of closely related fungi (specialized association) or genetically distant fungi (generalized associations) (Taylor et al. 2003, Bailarote et al. 2012, Jacquemyn et al. 2014). Using the picante Package of the R program (Kembel et al. 2010), we calculated the MPD and PD, for all species, and among all sampling sites. To correct for small sampling sizes we also calculated the standardized effect sizes (SES) for each site. A $t$-test was performed to determine if the number of OTUs and MPD and PD values differed significantly between each native and invasive orchid species. Mean germination rates were calculated as the no. of protocorms/ total number of seeds in each fungal bait. Differences in mean germination rates were 
arcsine transformed to normalize the residuals. We used one-way ANOVAs to compare mean differences, and post hoc pairwise treatment comparisons were carried out using Tukey-Kramer. All statistical tests were performed in SPSS 17.0 for Windows.

\section{RESULTS}

A total of 88 fungal ITS sequences were obtained for all of the study species and were compared based on each orchid's putative ecology (Table 1, sequence table). We identified 61 distinct OTUs from these sequences over all the sites. Among the four study species, FL native epiphyte $C$. punctatum $(\mathrm{N}=34)$ and invasive terrestrial $C$. flavum $(\mathrm{N}=$ 28) had the greatest number of OM fungal associates $(n=18)($ Fig $8 \mathbf{a} \& \mathbf{c})$. In contrast, FL native terrestrial E. alta $(\mathrm{N}=11)$ associated with the fewest OTUs $(\mathrm{n}=11)$, and invasive terrestrial E. graminae $(\mathrm{N}=24)$ yielded fourteen OTUs $(\mathbf{F i g} \mathbf{8 b} \mathbf{\&} \mathbf{d})$. Of the eighteen total OTUs detected from C. punctatum, half belonged to the Ascomycetes group, four OTUs were identified as putative or known OM taxa in the nonTulasnellaceae Basidiomycetes (NTB), and five OTUs belonged to the Tulasnellaceae group (Fig 8a). During fungal isolations, we noticed that many root samples from adult C. punctatum plants were devoid of viable pelotons, and showed signs of peloton digestion, as evidenced by the large number of starch granules within the cortical cells. The invasive congener $C$. flavum had the greatest number of OTUs within a single fungal group, associating with thirteen different OTUs within the NTB group, but it also formed the fewest associations with the core Tulasnellaceae (Fig 8c). For the native E. alta, we detected eleven OTUs that displayed a similar fungal composition to the epiphytic native C. punctatum, with nearly $50 \%$ of the OTUs comprising Ascomycete taxa, and similar 
proportions of OM (i.e. NTB and core Tulasnellaceae combined) OTUs (Fig 8b). Ascomycetes were not the dominant fungal group for any of the invasive orchids ( $C$. flavum with $18 \%$, and E. graminae with $36 \%$ of total OTUs); these species were associated with a greater proportion of OM OTUs (Fig $\mathbf{8 c} \boldsymbol{\&} \mathbf{d})$. For E. graminae, the greatest number OTUs belonged to the core Tulasnellaceae group, which made up 43\% of the total OTUs, followed by the Ascomycetes with 36\%. The least represented fungi were the NTB group with only three OTUs (21\%) identified (Fig 8d).

There were similar patterns of fungal community diversity on native versus invasive orchids, with the native species having a significantly greater proportion of Ascomycetes (fifteen OTUs) represented, and similar associations with both of the OM groups: eight OTUs belonging to the NTB group, and seven from the core Tulasnellaceae (Fig 9a). The dominant fungal group for the invasive orchids was NTB (sixteen OTUs), while invasive orchids associated the least often with the Ascomycete group (seven OTUs) (Fig 9b).

The native orchid species associated with fewer OM taxa than did the invasive orchids (fifteen and 24 OTUs, respectively, across six different sites; Fig 10). Orchid roots differed in their mycorrhizal communities as well, with the native species forming associations predominately with the core Tulasnellaceae group (seven OTUs, and $50 \%$ of the total OTUs); the native species shared only three of these OTUs with other species (Fig 10a). Other Basidiomycete groups made up 36\% of the total OTUs. We also detected one OTU identified as Russula sp. in one individual of E. alta, and one OTU identified as belonging to the Basidiomycete Order Polyporales (Fig 10a). The invasive orchids associated more evenly with four different OM groups, with the highest number 
of OTUs belonging to the Polyporales, and exclusive associations with the Basidiomycete Order Agaricales (Neonothopanus sp.), making up 22\% of the total OTUs (Fig 10b). In contrast, a greater proportion of OM OTUs were shared among the other species, with up to ten individuals associating with the same OTU, and only eleven plants across the four species associating with only one OTU type (Fig 10b).

\section{Phylogenetic Trees Analyses}

Tree topology suggests a diverse assemblage of Ascomycetes taxa, with most sequences being related to putative plant pathogens. A total of 26 sequences were included in the Ascomycete ML tree, with 21 of these coming from a single orchid individual associated with a single distinct OTU (Fig 11). Only two OTUs were shared among different individual plants: OTU1 was identified as Fusarium oxysporum, with putative OM and pathogenic ecology, and was found in a single individual each of $C$. punctatum at FTBG, C. flavum at BT, and E. graminae at BT sites (Fig 11). Two individuals, one seedling, and one adult of $C$. punctatum at FTBG were associated with OTU2, which was identified as Plectosphaerella cucumerina, another likely root pathogen. We also detected two sister taxa of the plant pathogen Trichoderma virens (100\% bootstrap support) in two E. alta individuals at FSS (Fig 11).

We included a total of 30 sequences in the ML phylogeny, and both native and invasive species were found to associate with taxa in the NTB (Fig 12). These fungi were most commonly associated with C. flavum at the ZOO and BT sites (Fig 12). However, most of the sequences (77\%; 23 of the 30 sequences) belonged to three related Basidiomycete orders, the Agaricales, Russulales, and Polyporales (100 \% bootstrap 
support; Fig 12). Within these orders, we distinguished three distinct OTUs that were shared among the different orchid species. OTU1 was identified as a member of the Polyporales, and was only detected in protocorms at the BT and ZOO sites for the invasive orchids, and in one adult plant at CSS for the native E. alta. The OTU2 sequences were identified as belonging to the Agaricales, and closely related to Neonothopanus sp. (100\% bootstrap support; Fig 12). One seedling of E. alta (sample R41) was found to associate with the ectomycorrhizal genus Russula (100\% bootstrap support; Fig 12).

The core Tulasnellaceae tree included 35 sequences, and we identified six distinct OTUs (Fig 13). The tree topology supports two distinct clades, reported here as A and B (100\% bootstrap support; Fig 13). The least related OTU was from an adult C. punctatum at FSS (sample R-29). Clade A consisted of OTU1 and OTU2. The OTU1 group was the largest OTU group detected, and was associated with only the invasive species. It was identified in C. flavum seedlings and adults, at both the BT and ZOO sites, and with E. graminae seedlings, and adults at the BT and FTBG sites. The OTU2 group was only found to associate with four spatially restricted $C$. punctatum seedlings at the FTBG site (Fig 13). Clade B was comprised of OTU3, OTU4, OTU5, and OTU6 (Fig 13). The OTU3 group was found to only associate with adult E. graminae plants, and were restricted to a small patch of pine rockland at the FTBG site. OTU4 was identified in one protocorm of C. flavum at the ZOO site (sample R-344), and one seedling of E. graminae at BT (sample R-33). The OTU5 group was only detected in two adult E. alta plants at FSS. OTU6 was found to share the most diversity in host species, forming associations in native and invasive orchid species. It was identified in both native species, one adult $C$. 
punctatum at FSS, and one adult of E. alta at CSS. This taxon was also detected in seedlings and adults of E. graminae at FTBG.

\section{Shannon diversity Indices}

We found differences in the species richness, Shannon diversity $\left(H^{\prime}\right)$, and evenness $\left(J^{\prime}\right)$, of Ascomycete OTUs between native and invasive orchid sites. Overall species richness was over two times higher for the native orchid sites (fifteen total OTUs, min. of one and max. of six OTUs, from each site), as compared to the invasive species sites (six total OTUs, min. of one and max. of three OTUs, from each site) (Table 2). Mean $\left(H^{\prime}\right)$ for Ascomycetes OTUs was higher for the native orchids $\left(H^{\prime}=1.11\right.$, Std. error $=0.22)$ than for their invasive congeners $\left(H^{\prime}=0.28\right.$, Std. error $\left.=0.36\right)\left(F_{1,4}=8.014\right.$, $\mathrm{p}=0.031$; Table 2). There was also a difference in evenness between native and invasive orchid sites; $\left(J^{\prime}\right)=0.74$, Std. error $=0.18$, and $\left(J^{\prime}\right)=0.25$, Std. error $=0.22$, respectively (Table 2). For all species, rarefaction curves showed that overall Ascomycetes OTU richness per plant species had reached saturation, suggesting that our sample sizes were sufficient to detect a true estimate of total fungal diversity (Appendix 1a).

In contrast to the pattern of Ascomycete diversity, species richness was lower for OM (NTB and core Tulasnellaceae) OTUs at the native orchid sites (seven total OTUs, min. of one and max. of two OTUs, from each site), than at the invasive species sites (12 total OTUs, min. of three and max. of five OTUs, from each site; Table 3). The mean Shannon diversity index ( $\left.H^{\prime}\right)$ for OTUs was higher for the invasive orchid sites, although not significantly different $\left(H^{\prime}=1.2\right.$, Std. error $\left.=0.14\right)$, from the native sites $\left(H^{\prime}=0.61\right.$, 
Std. error $=0.38$ ). There was a significant difference in evenness between invasive and native orchid sites; $\left(J^{\prime}\right)=0.88$, Std. error $=0.024$, and $\left(J^{\prime}\right)=0.56$, Std. error $=0.28$, respectively $\left(\mathrm{F}_{1,4}=8.515, \mathrm{p}=0.043\right)$. As with the Ascomycete indices, rarefaction curves for the OM OTU richness per plant species had also reached saturation, thus supporting our estimates of total fungal diversity (Appendix 1b).

\section{Phylogenetic Breadth Estimations}

We did not observe any significant differences in the phylogenetic breadth (MPD values) of the different mycorrhizal communities within, or between, native and invasive orchid species, or between associated NTB and Tulasnellaceae (Table 4). The PD values were similar to those obtained from MPD estimates. Within the native species group, MPD values were 1.02 for $C$. punctatum, and 0.83 for $E$. alta (mean $=0.925)$. Withinspecies MPD values for C. punctatum (FTBG and FSS sites) were 1.02 for all associated NTB and 0.90 for all Tulasnellaceae, and for E. alta (CSS site) 0.83 for the associated NTB and 0.91 for the Tulasnellaceae. Similarly, for the invasive species within-group MPD, values were 0.91 for $C$. flavum, and 0.82 for $E$. graminae (mean $=0.865$ ). Withinspecies values for C. flavum (ZOO and BT sites) were 0.91 for associated NTB and 0.90 for the Tulasnellaceae and for E. graminae (FTBG and BT sites) were 0.82 for the associated NTB, and 0.94 for the Tulasnellaceae. Of all the study species, E. graminae associated with the narrowest breadth of NTB (0.82), and the widest breadth of associations was for $C$. punctatum (1.02), which also had the largest observed distance. For the Tulasnellaceae, the narrowest breadth fungal associations were for C. flavum 
(0.81), and the widest breadth of the Tulasnellaceae associations belonged to E. graminae (0.94).

\section{Fungi Baiting}

Fungi baiting results suggested that all of the study species exhibited generally low germination rates ( $<0.5 \%$ mean germination rate for ranking highest species; Fig 14). The germination rates differed between four orchids species $\left(F_{3,161}=3.684, P=0.013\right)$. The highest germination rates were observed for the invasive E. graminae (0.435\%), with a total of 59 protocorms recovered (30 baits total at FTBG and BT sites), the lowest rates were for C. punctatum (0.013\%) with only 4 protocorms recovered (60 baits total at FTBG and FSS sites). For E. alta all seeds failed to germinate in baits. Tukey-Kramer pair-wise comparisons showed there was a significant difference in germination between C. punctatum and E. graminae fungi baits $(\mathrm{P}=0.012)$, but not between any other pairwise comparisons (Fig 14).

\section{DISCUSSION}

To explore the role of mycorrhizal specificity in promoting orchid invasions, we investigated two pairs of congeneric species with different population abundances. We identified a total of 61 fungal OTUs from 83 individuals (5 individuals we found to have more than one OTU) at five study sites in southern Florida, and one site in southwest China. The study provides evidence both for generalist strategies and enemy release as potential mechanisms driving orchid invasions in Florida. Both native and invasive orchids utilized diverse, but closely related, OM fungal groups, while putative plant 
pathogens belonging to Ascomycetes (Dearnaley 2007) were more common among the native orchid species. Our findings show that the presence of beneficial mycorrhizal fungi can determine where, and in what abundance, orchids occur (Suarez et al. 2006, McCormick et al. 2012), and that generalist associations (low fungal specificity) alone may not be enough to explain orchid abundances and distributions (Waterman \& Bidartondo 2008, Jacquemyn et al. 2010, McCormick et al. 2012 Jacquemyn et al. 2014). For introduced orchid species, enemy release may play an important, yet overlooked, role in the invasion process. Taken together, our findings provide evidence that an introduced plant's ability to establish and spread might be influenced by the types of biotic interactions (beneficial or antagonistic) that they establish in their novel ranges (Pringle et al. 2009, Liu and Pemberton 2010).

All four orchid species were associated with fungi that belong to several genera in both the Ascomycetes and Basidiomycetes. However, the core Tulasnellaceae group of Basidiomycetes was the most common associate of all four orchid species studied. This group is an important group of $\mathrm{OM}$, and has been shown to be particularly important for germination in many species (Peterson et al. 2004). Overall OTU richness for all of the orchid species was similar, and was independent of the orchid population density or site. Yet, there were clear differences in the overall fungal community between native and invasive orchids. Most notably, the invasive orchids associated with a wider range of basidiomycetous fungi ( $>50 \%$ of total OTUs) than did the natives. These fungi are likely to promote seed germination, or be beneficial to the plant later in life (Rasmussen 2002, Dearnaley et al. 2012), making association with them adaptive (Otero et al. 2005). During seed germination, the invasive orchids also utilized a greater diversity of fungal taxa 
within non-Tulasnellaceae Basidiomycete group than the natives did. For example, the 13 OTUs recovered from C. flavum protocorms were almost entirely within the Polyporales group, particularly at the BT and ZOO sites. The invasive E. graminae and the native $E$. alta were also found associating with Polyporales at the CSS site, which is geographically separated and of different habitat type (a mixture cypress swamp and pine flatwoods) from the other sites. This suggests that the Polyporales group may be widely distributed in the region, and may comprise important symbionts for germination in multiple species. The invasive orchids were also strongly associated with another group of Basidiomycetes in the Order Agaricales at the BT and ZOO sites. Although not previously reported to occur in the new world, OTU2 shared 93-99\% sequence similarity with Neonothopanus sp., a bioluminescent fungus known from Africa and Asia. OTU2 was also found in a protocorm of $C$. flavum at the BT site, suggesting it is capable of initiating germination in this species. The core Tulasnellaceae group was also important for germinating seeds of the invasive species, as they were isolated from protocorms of both C. flavum and E.graminae. This again suggests lower specificity with respect to fungi capable of promoting germination in the invasive species, compared to the native species, and thus supports a more generalist ability for recruitment.

The evidence for specialization in OM associations among the different orchid species was mixed. When we included all of the OTUs identified for each species, we found no evidence for specialization (i.e. statistically similar diversity and evenness values; Appendix 2). As a result, we decided only to consider those OTUs that were shared among at least one other orchid taxon ( $\mathrm{n}=9$ OTUs). Here we did see a difference in the overall diversity (both OTU richness and $\left(H^{\prime}\right)$ ) between the native and invasive 
species; with diversity values $\left(H^{\prime}\right)$ for the invasive species being twice as high as the native species. This was especially true for the native C. punctatum, which had ( $\left.H^{\prime}\right)$ values ranging from 0 to 0.5 , at FSS and FTBG sites. These values were in contrast to its congener C. flavum, with $\left(H^{\prime}\right)>1.87$ over all sites, and the other native species E. alta, where $\left(H^{\prime}\right)=1.33$; values that are more similar to the observed OTU diversity in the invasive orchids. These data suggested two possible scenarios: either C. punctatum is indeed narrower in its specialized OM associations than the invasive congener, or the availability of suitable OM taxa is lower in the sites and/or micro habitats with $C$. punctatum. The latter explanation may be most likely, because the diversity of OM tends to be lower in the epiphytic rhizosphere than in the terrestrial one (McCormick et al. 2004). Furthermore, orchid species from the same genus tend to associate with similar mycorrhizal communities, if available (Jacquemyn et al. 2014). Unfortunately, a strictly epiphytic comparison cannot be made, because there are no other closely related orchids in the epiphytic realm in southern Florida. Regardless, these results do show that at least for the terrestrial orchids, some of the same OTUs were detected over geographically distant sites (large spatial segregation), and in different habitat types (garden, cypress swamps, and pine rockland). This was not the case for the C. punctatum sites, which did not share any OTUs in common. However, this still does not explain the restricted distribution in E. alta in the region. Since we observed regular fruit set in one study population, perhaps for this species populations may be more specialized in the fungi necessary for germination, and then more relaxed in later life stages. This was supported by our germination trials, where E. alta had the lowest in situ germination rates (unpublished data). One seedling sampled at CSS was associated with a Russula sp., a 
known ectomycorrhizal genus, while the adult plants were almost exclusively associated with various Tulasnellaceae fungi.

We suggest that invasive orchids show a preference for NTB fungi that may be more widely dispersed and abundant than other fungi. In addition to the evidence of preference for Polyporales, we also found both invasive species to utilize Agaricales belonging to the same OTUs at the site (BT) where they occur in close proximity. Previous studies have shown that the highest densities of orchids are often in areas that support high densities of their mycorrhizal fungi (McCormick et al. 2009 and 2012). Therefore, the invasive orchids' preference for Polyporales and Agaricales in native pine rocklands may be driven by the high densities of these Basidiomycete fungi in that community. This would differ from temperate woodland and meadowland habitats (Jacquemyn et al. 2014), where co-occurring orchid species used distinctive mycorrhizal communities, and thus were spatially segregated, with no effect of phylogeny. Other studies have shown that various species of photosynthetic orchids exhibit narrow specificity over wide geographical distributions (Shefferson et al. 2005, 2007, McCormick et al. 2004, Bonnardeaux et al. 2007). Conversely, our results show that the two Florida native orchids associated similarly with both NTB and core Tulasnellaceae, a broad specificity that does not agree with the findings for other orchid species. However, similar findings were made by Suarez et al. (2006) that identified broad specificity for the core Tulasnellaceae in tropical epiphytic orchids in the Andean cloud forests.

Although there is some evidence for specialization within the core Tulasnellaceae group for the native orchids, and preference for NTB in invasive orchids, we did not find any differences in the phylogenetic breadth of the different OM fungal groups associated 
with any of the species. The highly similar MPD values (min. of 0.81 and max. 1.02) indicate that all four species associated with closely related OM communities within and between the different study sites. This evidence does not support higher specificity by the rarer species versus the invasives, in terms of phylogenetic breadth of their associations, but may instead represent the shared evolutionary histories of these closely related orchid taxa influencing the community breadth of compatible fungi (Shefferson et al. 2005)

Our results showed that the native species had more associations with Ascomycete fungi, which may pathogens, than did their recently introduced congeners, even at the same sites. Not all of the OTUs identified were putative pathogens, but we did identify one OTU as Fusarium oxysporum, a known plant pathogen. Interestingly, this genus can also be mycorrhizal for some orchids (Těšitelová et al. 2012). If even some of the fungi that colonize orchid roots are pathogens, then ERH may be another mechanism enabling the spread of invasive orchids in Florida. Native orchids were found to be disproportionately associated with Ascomycete fungi, which comprised $50 \%$ of the total OTUs detected. If the invasive orchids have a release from pathogens in the new site, it may increase overall fecundity through the reallocation of resources from defense to growth and reproduction. For example, within $50 \mathrm{~m}$ of the E. alta individuals at the CSS site infected with Trichoderma virens, a known plant pathogen, we did not find any Ascomycetes in association with the invasive E. graminae instead it associated with a beneficial fungus belonging to the NTB group. Understanding to what extent the Ascomycetes are root pathogens or form mycorrhiza in orchids remains a highly evolving area of orchid research, and the future study of this "tangled bank" of plant-fungus 
interactions promises to reveal much about the population and community ecology of orchids.

\section{CONCLUSIONS}

Understanding the diverse fungal community in which orchids survive is critical to orchid conservation and biology. This study directly addressed the role of beneficial mycorrhizal fungi and ERH in the invasion process, and provided better resolution of the role of fungi in plant invasions. However, it remains unclear whether physiological or genetic mechanisms determine specificity and preference. Future research will compare the diversity of potential fungal partners in the surrounding environment to that of the fungi collected in the tissues of each species. These studies will provide the best insights into the role that fungal specificity plays in the population dynamics of plants (McCormick et al. 2012). The results of this project also have broader ecological implications in that orchids can be sensitive to changes in environmental conditions that may influence available fungal communities (McCormick et al. 2012). With climate change, understanding these relationships becomes more urgent, because global changes may have the most impact on taxa that are heavily dependent on other taxa (Fitter et al. 2000, Compant et al. 2010). On the other hand, those plant species that can adopt more flexible fungal requirements, or avoid pathogens, in the face of environmental changes may become more widespread in the future. 
Table 3.1 Information about the fungal ITS sequences obtained for each orchid species. Included in this table: site, habitat, life stage, sequence length (bp), closest related taxa and their GenBank accession numbers. $\left({ }^{*}\right)=$ seedlings with protocorm bodies.

\begin{tabular}{|c|c|c|c|c|c|c|c|c|}
\hline Species & Site & Habitat & Age & $\begin{array}{l}\text { Sample } \\
\text { ID }\end{array}$ & $\begin{array}{l}\text { Post- } \\
\text { Trim } \\
\text { Length } \\
\text { (bp) }\end{array}$ & Closest related taxa & $\begin{array}{c}\% \\
\text { similarity }\end{array}$ & $\begin{array}{c}\text { GenBank } \\
\text { Accession no. }\end{array}$ \\
\hline C. punctatum & FTBG & Garden & adult & F-1 & 511 & $\begin{array}{l}\text { Fusarium oxysporum isolate } \\
\text { CK-7 }\end{array}$ & 99 & KJ699122.1 \\
\hline C. punctatum & FTBG & Garden & seedling & F-10 & 640 & Fomes sp. EUM1 & 97 & HM136871.1 \\
\hline C. punctatum & FTBG & Garden & adult & F-11 & 491 & $\begin{array}{l}\text { Uncultured Basidiomycota } \\
\text { clone BASO24_UMVE5_ }\end{array}$ & 94 & JX998771.1 \\
\hline C. punctatum & FTBG & Garden & seedling & F-12 & 533 & Simplicillium sp. $M-27$ & 93 & JQ422627.1 \\
\hline C. punctatum & FTBG & Garden & seedling & F-16(a) & 522 & $\begin{array}{l}\text { Plectosphaerella cucumerina } \\
\text { MFZ19 }\end{array}$ & 99 & KC756235.1 \\
\hline C. punctatum & FTBG & Garden & adult & F-3 & 311 & $\begin{array}{l}\text { Uncultured Basidiomycota } \\
\text { clone BASO24_UMVE5 }\end{array}$ & 94 & JX998771.1 \\
\hline C. punctatum & FTBG & Garden & seedling & $\mathrm{F}-5(\mathrm{a})$ & 659 & Ascomycota sp. AR-2010 & 99 & HQ608067.1 \\
\hline C. punctatum & FTBG & Garden & seedling & F-5(b) & 659 & $\begin{array}{l}\text { Phlebia cf. floridensis } R G \text { - } \\
2014\end{array}$ & 93 & KJ831896.1 \\
\hline C. punctatum & FSS & $\begin{array}{l}\text { Cypress } \\
\text { Swamp }\end{array}$ & adult & OM-28 & 521 & Ascomycetes_Chaetosphaeria & 100 & AY699682.1 \\
\hline C. punctatum & FTBG & Garden & seedling* & $\mathrm{R}-1$ & 675 & uncultured Cantharellales & 84 & HM451666.1 \\
\hline C. punctatum & FSS & $\begin{array}{l}\text { Cypress } \\
\text { Swamp }\end{array}$ & adult & $\mathrm{R}-10$ & 437 & Uncultured Helotiales clone & 73 & JX135046.1 \\
\hline
\end{tabular}




\begin{tabular}{|c|c|c|c|c|c|c|c|c|}
\hline C. punctatum & FSS & $\begin{array}{l}\text { Cypress } \\
\text { Swamp }\end{array}$ & adult & $\mathrm{R}-11$ & 490 & $\begin{array}{l}\text { Hyaloscyphaceae sp. KO- } \\
\text { groupC } 2014\end{array}$ & 81 & AB986375.1 \\
\hline C. punctatum & FTBG & Garden & adult & R-16 & 409 & $\begin{array}{l}\text { Plectosphaerella cucumerina } \\
\text { strain A0660 }\end{array}$ & 99 & KF577909.1 \\
\hline C. punctatum & FTBG & Garden & adult & $\mathrm{R}-17$ & 639 & Gibberella intermedia & 93 & JX241655.1 \\
\hline C. punctatum & FTBG & Garden & seedling* & $\mathrm{R}-2$ & 697 & uncultured Cantharellales & 85 & HM451666.1 \\
\hline C. punctatum & FTBG & Garden & adult & $\mathrm{R}-24$ & 570 & $\begin{array}{l}\text { Doratomyces microsporus } \\
\text { strain H1 }\end{array}$ & 99 & GU566278.1 \\
\hline C. punctatum & FSS & $\begin{array}{l}\text { Cypress } \\
\text { Swamp }\end{array}$ & adult & $\mathrm{R}-27$ & 229 & $\begin{array}{l}\text { Uncultured Cantharellales } \\
\text { voucher T2 1a }\end{array}$ & 96 & DQ368697.1 \\
\hline C. punctatum & FSS & $\begin{array}{l}\text { Cypress } \\
\text { Swamp }\end{array}$ & adult & $\mathrm{R}-29$ & 287 & uncultured mycorrhizal fungi & 85 & AB506830.1 \\
\hline C. punctatum & FTBG & Garden & seedling* & $\mathrm{R}-3$ & 697 & uncultured Cantharellales & 85 & HM451666.1 \\
\hline C. punctatum & FTBG & Garden & seedling* & $\mathrm{R}-4$ & 668 & uncultured Cantharellales & 85 & HM451666.1 \\
\hline C. punctatum & FSS & $\begin{array}{l}\text { Cypress } \\
\text { Swamp }\end{array}$ & adult & $\mathrm{R}-67$ & 649 & $\begin{array}{l}\text { Tulasnella sp. } 9 \text { MM-2012 } \\
\text { isolate 5c5 }\end{array}$ & 99 & JQ247568.1 \\
\hline C. punctatum & FTBG & Garden & adult & $\mathrm{R}-69$ & 632 & $\begin{array}{l}\text { Uncultured Tulasnellaceae } \\
\text { clone FM711.1 }\end{array}$ & 94 & JF691509.1 \\
\hline E. alta & CSS & $\begin{array}{l}\text { Cypress } \\
\text { Swamp }\end{array}$ & adult & F-13 & 374 & Basidiomycota isolate & 85 & KP412475.1 \\
\hline E. alta & CSS & $\begin{array}{l}\text { Cypress } \\
\text { Swamp }\end{array}$ & adult & $\mathrm{F}-17$ & 576 & $\begin{array}{l}\text { Engyodontium clone } \\
\text { 8F77_1_14 }\end{array}$ & 99 & HM231351.1 \\
\hline E. alta & CSS & $\begin{array}{l}\text { Cypress } \\
\text { Swamp }\end{array}$ & seedling & $\mathrm{F}-20$ & 567 & Simplicillium sp. M-27 & 99 & JQ422627.1 \\
\hline E. alta & CSS & $\begin{array}{l}\text { Cypress } \\
\text { Swamp }\end{array}$ & adult & $\mathrm{F}-21$ & 491 & Oxурогus sp. MEL 2382667 & 98 & КР013030.1 \\
\hline
\end{tabular}




\begin{tabular}{|c|c|c|c|c|c|c|c|c|}
\hline E. alta & CSS & $\begin{array}{l}\text { Cypress } \\
\text { Swamp }\end{array}$ & adult & $\mathrm{R}-25$ & 619 & Tulasnella sp. XC-2015 & 98 & KF537642.1 \\
\hline E. alta & CSS & $\begin{array}{l}\text { Cypress } \\
\text { Swamp }\end{array}$ & adult & R-39 & 459 & $\begin{array}{l}\text { Trichoderma virens isolate } \\
\text { Isf-77 }\end{array}$ & 98 & КР985643.1 \\
\hline E. alta & CSS & $\begin{array}{l}\text { Cypress } \\
\text { Swamp }\end{array}$ & adult & $\mathrm{R}-40$ & 187 & $\begin{array}{l}\text { Trichoderma virens isolate } \\
\text { Isf-77 }\end{array}$ & 98 & КР985643.1 \\
\hline E. alta & CSS & $\begin{array}{l}\text { Cypress } \\
\text { Swamp } \\
\text { Cypress }\end{array}$ & seedling & $\mathrm{R}-41$ & 472 & $\begin{array}{l}\text { Uncultured Russula clone } \\
\text { L22c3 }\end{array}$ & 97 & KP866128.1 \\
\hline E. alta & CSS & Swamp & adult & $\mathrm{R}-43$ & 653 & Epulorhiza sp. S1 & 99 & AJ313439.1 \\
\hline E. alta & CSS & $\begin{array}{l}\text { Cypress } \\
\text { Swamp }\end{array}$ & adult & $\mathrm{R}-44$ & 596 & Tulasnella sp. 9 MM-2012 & 99 & JQ247568.1 \\
\hline E.alta & CSS & $\begin{array}{l}\text { Cypress } \\
\text { Swamp }\end{array}$ & adult & $\mathrm{R}-26$ & 406 & Uncultured soil fungus SK76 & 97 & JQ666593.1 \\
\hline C.flavum & $\mathrm{ZOO}$ & $\begin{array}{l}\text { Pine } \\
\text { Rockland }\end{array}$ & seedling & 851(a) & 518 & uncultured polyporales & 95 & JF691147.1 \\
\hline C. flavum & $\mathrm{ZOO}$ & $\begin{array}{l}\text { Pine } \\
\text { Rockland }\end{array}$ & seedling & 851(b) & 578 & Oxyporus sp. MEL 2382667 & 98 & KР013030.1 \\
\hline C. flavum & BT & $\begin{array}{l}\text { Pine } \\
\text { Rockland }\end{array}$ & protocorm & F-6 & 611 & uncultures Polyporales & 88 & JF691147.1 \\
\hline C. flavum & BT & $\begin{array}{l}\text { Pine } \\
\text { Rockland }\end{array}$ & protocorm & F-7 & 572 & uncultured Polyporales & 90 & JF691147.1 \\
\hline C. flavum & BT & $\begin{array}{l}\text { Pine } \\
\text { Rockland }\end{array}$ & protocorm & F-8 & 577 & Tulasnellaceae_C263 & 91 & AB506830.1 \\
\hline C. flavum & BT & $\begin{array}{l}\text { Pine } \\
\text { Rockland }\end{array}$ & protocorm & F-9 & 646 & Tulasnellaceae_C263 & 92 & AB506830.1 \\
\hline C. flavum & $\mathrm{ZOO}$ & $\begin{array}{l}\text { Pine } \\
\text { Rockland }\end{array}$ & adult & OM-24 & 584 & $\begin{array}{l}\text { Uncultured Polyporales } \\
\text { clone FM056.1 }\end{array}$ & 95 & JF691147.1 \\
\hline C. flavum & BT & $\begin{array}{l}\text { Pine } \\
\text { Rockland }\end{array}$ & protocorm & P-1 & 541 & uncultured Polyporales & 76 & JF691147.1 \\
\hline C. flavum & BT & $\begin{array}{l}\text { Pine } \\
\text { Rockland }\end{array}$ & protocorm & $\mathrm{P}-2$ & 597 & Neonothopanus sp. L4 & 93 & JX684002.1 \\
\hline
\end{tabular}




\begin{tabular}{|c|c|c|c|c|c|c|c|c|}
\hline C. flavum & BT & $\begin{array}{l}\text { Pine } \\
\text { Rockland }\end{array}$ & protocorm & P-3 & 537 & uncultured Polyporales & 75 & JF691147.1 \\
\hline C. flavum & $\mathrm{ZOO}$ & $\begin{array}{l}\text { Pine } \\
\text { Rockland }\end{array}$ & protocorm & P-344 & 643 & $\begin{array}{l}\text { Uncultured Tulasnellaceae } \\
\text { clone } 16-176-4 B\end{array}$ & 97 & KC243948.1 \\
\hline C. flavum & $\mathrm{ZOO}$ & $\begin{array}{l}\text { Pine } \\
\text { Rockland } \\
\text { Pine }\end{array}$ & protocorm & P-6 & 554 & Polyporales_Oxysporyus sp. & 98 & КР013030.1 \\
\hline C. flavum & $\mathrm{ZOO}$ & $\begin{array}{l}\text { Rockland } \\
\text { Pine }\end{array}$ & protocorm & P-7 & 504 & Polyporales_Oxysporyus sp. & 98 & КР013030.1 \\
\hline C. flavum & $\mathrm{ZOO}$ & Rockland & protocorm & P-8 & 542 & Polyporales_Oxysporyus sp. & 81 & КР013030.1 \\
\hline C. flavum & $\mathrm{ZOO}$ & $\begin{array}{l}\text { Pine } \\
\text { Rockland }\end{array}$ & protocorm & P-9 & 539 & Polyporales_Oxysporyus sp. & 81 & КР013030.1 \\
\hline C. flavum & $\mathrm{ZOO}$ & $\begin{array}{l}\text { Pine } \\
\text { Rockland }\end{array}$ & seedling & $\mathrm{R}-45$ (a) & 645 & $\begin{array}{l}\text { Simplicillium lanosoniveum } \\
\text { strain PSU-ES104 }\end{array}$ & 93 & JN116646.1 \\
\hline C. flavum & $\mathrm{ZOO}$ & $\begin{array}{l}\text { Pine } \\
\text { Rockland }\end{array}$ & seedling & R-45(b) & 520 & Tulasnella sp. M-10 & 86 & JQ713582.1 \\
\hline C. flavum & $\mathrm{ZOO}$ & $\begin{array}{l}\text { Pine } \\
\text { Rockland }\end{array}$ & adult & $\mathrm{R}-48(\mathrm{a})$ & 580 & Fomes sp. EUM1 & 99 & HM136871.1 \\
\hline C. flavum & $\mathrm{ZOO}$ & $\begin{array}{l}\text { Pine } \\
\text { Rockland } \\
\text { Pine }\end{array}$ & adult & R-48(b) & 578 & Tulasnellaceae_C263 & 92 & AB506830.1 \\
\hline C. flavum & $\mathrm{ZOO}$ & Rockland & adult & $\mathrm{R}-49$ & 594 & Neonothopanus sp. L4 & 99 & JX684002.1 \\
\hline C. flavum & $\mathrm{ZOO}$ & $\begin{array}{l}\text { Pine } \\
\text { Rockland }\end{array}$ & adult & $\mathrm{R}-50$ (a) & 644 & Neonothopanus sp. L4 & 98 & JX684002.1 \\
\hline C. flavum & $\mathrm{ZOO}$ & $\begin{array}{l}\text { Pine } \\
\text { Rockland }\end{array}$ & adult & $\mathrm{R}-50$ (b) & 580 & Tulasnellaceae_C263 & 92 & AB506830.1 \\
\hline C. flavum & $\mathrm{ZOO}$ & $\begin{array}{l}\text { Pine } \\
\text { Rockland }\end{array}$ & adult & $\mathrm{R}-53$ & 644 & Polyporales_Oxysporyus sp. & 80 & КР013030.1 \\
\hline C. flavum & BT & $\begin{array}{l}\text { Pine } \\
\text { Rockland }\end{array}$ & adult & R-54 & 570 & Tulasnellaceae_C263 & 91 & AB506830.1 \\
\hline C. flavum & $\mathrm{BT}$ & $\begin{array}{l}\text { Pine } \\
\text { Rockland }\end{array}$ & adult & $\mathrm{R}-55$ & 646 & Neonothopanus sp. L4 & 98 & JX684002.1 \\
\hline
\end{tabular}




\begin{tabular}{|c|c|c|c|c|c|c|c|c|}
\hline C. flavum & BT & $\begin{array}{l}\text { Pine } \\
\text { Rockland }\end{array}$ & adult & R-56 & 549 & Neonothopanus sp. L4 & 99 & JX684002.1 \\
\hline & & Pine & & & & Fusarium oxysporum isolate & & \\
\hline C. flavum & BT & Rockland & adult & $\mathrm{R}-60$ & 659 & Fox64 & 97 & KJ562370.1 \\
\hline C. flavum & BT & $\begin{array}{l}\text { Pine } \\
\text { Rockland }\end{array}$ & adult & $\mathrm{R}-61$ & 582 & Saccharomycete sp. jbra554 & 100 & AY796124.1 \\
\hline C. flavum & $\mathrm{ZOO}$ & $\begin{array}{l}\text { Pine } \\
\text { Rockland }\end{array}$ & protocorm & OM-32 & 443 & Polyporales_Oxysporyus sp. & 99 & KР013030.1 \\
\hline E. graminae & CSS & $\begin{array}{l}\text { Cypress } \\
\text { Swamp }\end{array}$ & seedling & F-14 & 597 & Fomes sp. EUM1 & 99 & HM136871.1 \\
\hline E. graminae & BT & $\begin{array}{l}\text { Pine } \\
\text { Rockland }\end{array}$ & seedling & F-16(b) & 413 & Uncultured Thelephoraceae & 77 & JQ616806.1 \\
\hline E. graminae & BT & $\begin{array}{l}\text { Pine } \\
\text { Rockland }\end{array}$ & seedling & F-16(c) & 660 & Tulasnella sp M-10 & 92 & JQ713582.1 \\
\hline E. graminae & FTBG & Garden & protocorm & P-10 & 614 & uncultured Polyporales & 98 & КР013030.1 \\
\hline E. graminae & FTBG & Garden & adult & $\mathrm{R}-211$ & 725 & uncultured soil fungus clone & 82 & DQ420987.1 \\
\hline E. graminae & FTBG & Garden & adult & $\mathrm{R}-212$ & 520 & uncultured Hypocreales & 77 & KР975471.1 \\
\hline E. graminae & FTBG & Garden & adult & $\mathrm{R}-215$ & 586 & uncultured mycorrhizal fungi & 94 & AB506830.1 \\
\hline E. graminae & FTBG & Garden & adult & R-216 & 587 & Tulasnella sp. $M-10$ & 92 & JQ713582.1 \\
\hline E. graminae & FTBG & Garden & adult & $\mathrm{R}-221$ & 610 & Tulasnellaceae_C257 & 92 & AB506827.1 \\
\hline E. graminae & FTBG & Garden & adult & $\mathrm{R}-222$ & 608 & Tulasnellaceae_C257 & 93 & AB506827.1 \\
\hline E. graminae & FTBG & Garden & adult & $\mathrm{R}-226$ & 658 & $\begin{array}{l}\text { Uncultured Tulasnella clone } \\
\text { RW14 }\end{array}$ & 96 & HM802312.1 \\
\hline E. graminae & FTBG & Garden & adult & $\mathrm{R}-227$ & 620 & Tulasnellaceae_C257 & 93 & AB506827.1 \\
\hline
\end{tabular}




\begin{tabular}{|c|c|c|c|c|c|c|c|c|}
\hline E. graminae & FTBG & Garden & adult & $\mathrm{R}-228$ & 616 & Tulasnellaceae_C257 & 92 & AB506827.1 \\
\hline E. graminae & FTBG & Garden & adult & R-233 & 608 & Tulasnellaceae_C257 & 93 & AB506827.1 \\
\hline E. graminae & FTBG & Garden & adult & $\mathrm{R}-234$ & 619 & Tulasnellaceae_C257 & 93 & AB506827.1 \\
\hline E. graminae & FTBG & Garden & adult & $\mathrm{R}-235$ & 515 & $\begin{array}{l}\text { uncultured Tulasnella clone } \\
\text { FM588.1 }\end{array}$ & 96 & JF691432.1 \\
\hline E. graminae & BT & $\begin{array}{l}\text { Pine } \\
\text { Rockland }\end{array}$ & seedling & $\mathrm{R}-33$ & 496 & Tulasnellaceae_C115 & 98 & AB506842.1 \\
\hline E. graminae & BT & $\begin{array}{l}\text { Pine } \\
\text { Rockland }\end{array}$ & adult & $\mathrm{R}-35$ & 511 & $\begin{array}{l}\text { Fusarium oxysporum strain } \\
\text { EECC-643 }\end{array}$ & 100 & КР942940.1 \\
\hline E. graminae & FTBG & Garden & adult & $\mathrm{R}-37$ & 214 & Fungal sp. 51630 & 99 & KP890618.1 \\
\hline E. graminae & XTBG & $\begin{array}{l}\text { Subtropic } \\
\text { Forest }\end{array}$ & adult & $\mathrm{R}-38$ & 374 & $\begin{array}{l}\text { Neocosmospora ornamentata } \\
\text { LVPEI.H1816_10 }\end{array}$ & 92 & JX868635.1 \\
\hline E. graminae & FTBG & Garden & protocorm & $\mathrm{R}-84$ & 658 & $\begin{array}{l}\text { Tulasnella sp. } 9 \text { MM-2012 } \\
\text { isolate 5c5 }\end{array}$ & 99 & JQ247568.1 \\
\hline E. graminae & FTBG & Garden & protocorm & $\mathrm{R}-85$ & 701 & $\begin{array}{l}\text { Uncultured Tulasnella clone } \\
R W 14\end{array}$ & 96 & HM802312.1 \\
\hline E. graminae & FTBG & Garden & adult & $\mathrm{R}-220$ & 657 & Tulasnella sp M-10 & 92 & JQ713582.1 \\
\hline E. graminae & BT & $\begin{array}{l}\text { Pine } \\
\text { Rockland }\end{array}$ & adult & $\mathrm{R}-31$ & 471 & Cryptococcus sp. 211 & 100 & LN997707.1 \\
\hline
\end{tabular}




\begin{tabular}{|c|c|c|c|c|c|c|c|c|c|c|c|c|c|c|c|}
\hline \multirow[b]{2}{*}{ Site } & \multirow{2}{*}{$\begin{array}{l}\text { No. of } \\
\text { plants }\end{array}$} & \multicolumn{3}{|c|}{ NTB } & \multicolumn{5}{|c|}{ Tulasnellaceae } & \multirow[b]{2}{*}{ Total } & \multirow{2}{*}{$\begin{array}{c}\text { OTU } \\
\text { richness }\end{array}$} & \multirow[b]{2}{*}{$H^{\prime}$} & \multirow[b]{2}{*}{$\mathrm{SE}\left(H^{\prime}\right)$} & \multirow[b]{2}{*}{$J^{\prime}$} & \multirow[b]{2}{*}{$\operatorname{SE}\left(J^{\prime}\right)$} \\
\hline & & OTU1 & OTU2 & OTU3 & OTU1 & OTU2 OTU3 & OTU4 & OTU5 & OTU6 & & & & & & \\
\hline Native & & & & & & & & & & & & & & & \\
\hline FTBG & 5 & & & & 1 & 4 & & & & 5 & 2 & 0.50 & & 0.72 & \\
\hline FSS & 1 & & & & & & & & 1 & 1 & 1 & 0.00 & & 0.00 & \\
\hline CSS & 5 & 1 & & & & & 1 & 2 & 1 & 5 & 4 & 1.33 & & 0.96 & \\
\hline Sub total & 11 & 1 & & & 1 & 4 & 1 & 2 & 2 & 11 & 7 & 0.61 & 0.38 & $0.56^{*}$ & 0.28 \\
\hline Invaded & & & & & & & & & & & & & & & \\
\hline FTBG & 13 & 1 & & & 2 & 7 & & & 3 & 13 & 4 & 1.16 & & 0.83 & \\
\hline $\mathrm{ZOO}$ & 10 & 5 & 2 & 2 & 4 & & 1 & & & 14 & 5 & 1.47 & & 0.91 & \\
\hline BT & & & 3 & & 4 & & 1 & & & 8 & 3 & 0.97 & & 0.89 & \\
\hline Sub total & 23 & 6 & 5 & 2 & 10 & & 2 & & 3 & 35 & 12 & 1.2 & 0.14 & $0.88^{\text {* }}$ & 0.024 \\
\hline
\end{tabular}

Table 3.2 Number of Rhizoctonia OTUs identified in non-Tulasnellaceae basidiomycete (NTB) and Tulasnellaceae groups from native orchids at three sites (FTBG, FSS, CSS), and from invasive orchids at three sites (FTBG, ZOO, BT). $H^{\prime}=$ Shannon-Weiner diversity index and $J^{\prime}=$ the evenness index, $\mathrm{SE}(x)=$ standard error. Numbers in bold represent mean diversity indices for each group. ${ }^{*}=$ statistically significant difference. 


\begin{tabular}{|c|c|c|c|c|c|c|c|c|}
\hline Species & Site & $\begin{array}{l}\text { No. of } \\
\text { plants }\end{array}$ & Ascomycetes (OTUs) & $\begin{array}{l}\text { Species } \\
\text { richness }\end{array}$ & $H^{*}$ & SE $\left(H^{\prime}\right)$ & $J^{c}$ & SE $\left(J^{\prime}\right)$ \\
\hline \multicolumn{9}{|l|}{ Native } \\
\hline C. punctatum & FTBG & 7 & 7 & 6 & 1.75 & & 0.98 & \\
\hline C. punctatum & FSS & 3 & 3 & 3 & 1.10 & & 1.00 & \\
\hline E. alta & CSS & 5 & 5 & 5 & 1.61 & & 1.00 & \\
\hline \multirow[t]{2}{*}{ E. graminae } & XTBG & 1 & 1 & 1 & 0.00 & & 0.00 & \\
\hline & & 16 & 16 & 15 & 1.11 & 0.39 & 0.74 & \\
\hline \multicolumn{9}{|l|}{ Invasive } \\
\hline C. flavum & $\mathrm{ZOO}$ & 1 & 1 & 1 & 0.00 & & 0.00 & \\
\hline C. flavum & BT & 2 & 1 & 1 & 0.00 & & 0.00 & \\
\hline E. graminae & FTBG & 3 & 3 & 3 & 1.10 & & 1.00 & \\
\hline \multirow[t]{2}{*}{ E. graminae } & $\mathrm{BT}$ & 1 & 1 & 1 & 0.00 & & 0.00 & \\
\hline & & 7 & 6 & 6 & 0.28 & 0.27 & 0.25 & \\
\hline
\end{tabular}

Table 3.3 Number of Ascomycetes OTUs identified from native and invasive orchids at three native sites in southern Florida and one native site in Yunnan Province China (XTBG), and four invasive sites in Miami-Dade County, Florida. $H^{\prime}=$ ShannonWeiner diversity index and $J^{\prime}=$ the evenness index, $\mathrm{SE}\left(x^{\prime}\right)=$ standard error. Numbers in bold represent mean diversity indices for each group. 


\begin{tabular}{|lccccc|}
\hline & & \multicolumn{5}{c|}{ Mean Pairwise Distances (MPD) } \\
\cline { 3 - 6 } Species & $\begin{array}{c}\text { No. of } \\
\text { sites }\end{array}$ & NTB & $\begin{array}{c}\text { Std. } \\
\text { error }\end{array}$ & Tulasnellaceae & $\begin{array}{c}\text { Std. } \\
\text { error }\end{array}$ \\
\hline Native & & & & & \\
C. punctatum & 2 & $\mathbf{1 . 0 2}$ & 0.073 & $\mathbf{0 . 9}$ & 0.048 \\
E. alta & 1 & $\mathbf{0 . 8 3}$ & 0.067 & $\mathbf{0 . 9 1}$ & 0.009 \\
Sub total & & $\mathbf{0 . 9 2 5}$ & 0.07 & $\mathbf{0 . 9 0 5}$ & 0.024 \\
& & & & & \\
Invasive & & & & & \\
C. flavum & 2 & $\mathbf{0 . 9 1}$ & 0.032 & $\mathbf{0 . 8 1}$ & 0.24 \\
E. graminae & 2 & $\mathbf{0 . 8 2}$ & 0.10 & $\mathbf{0 . 9 4}$ & 0.029 \\
Sub total & & $\mathbf{0 . 8 6 5}$ & 0.067 & $\mathbf{0 . 8 8}$ & 0.13 \\
\hline & & & & & \\
\hline
\end{tabular}

Table 3.4 Mean pairwise distances (MPD) were calculated based on ML consensus trees for NTB and Tulasnellaceae sequences obtained from native and invasive orchid species. Numbers shown in bold represent total breadth of associates for each fungal type. 


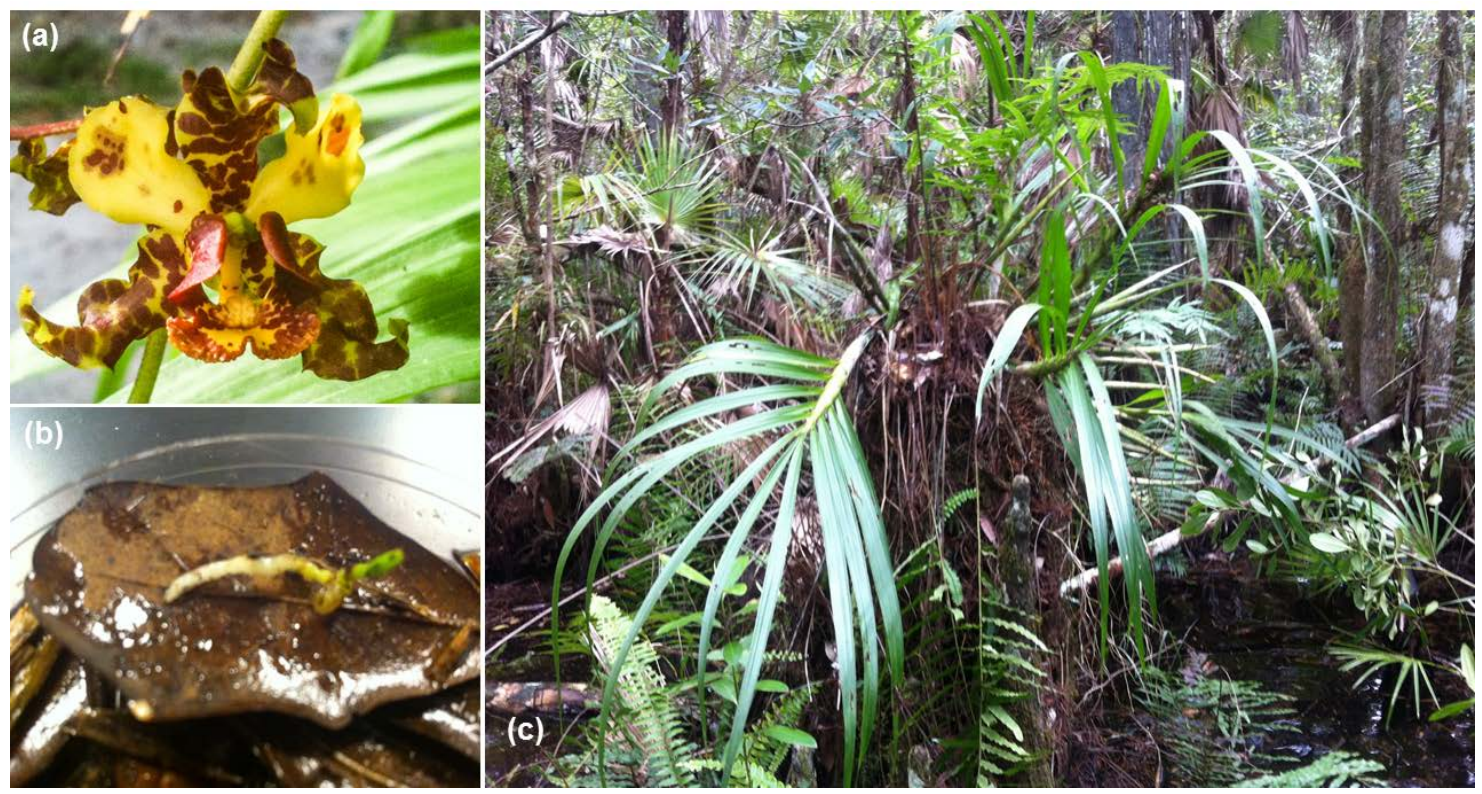

Fig. 3.1 Plates showing Cyrtopodium punctatum (a) flower, (b) seedling with protocorm body, and (c) adult at Fakahatchee Strand State Park, in southwest Florida. 

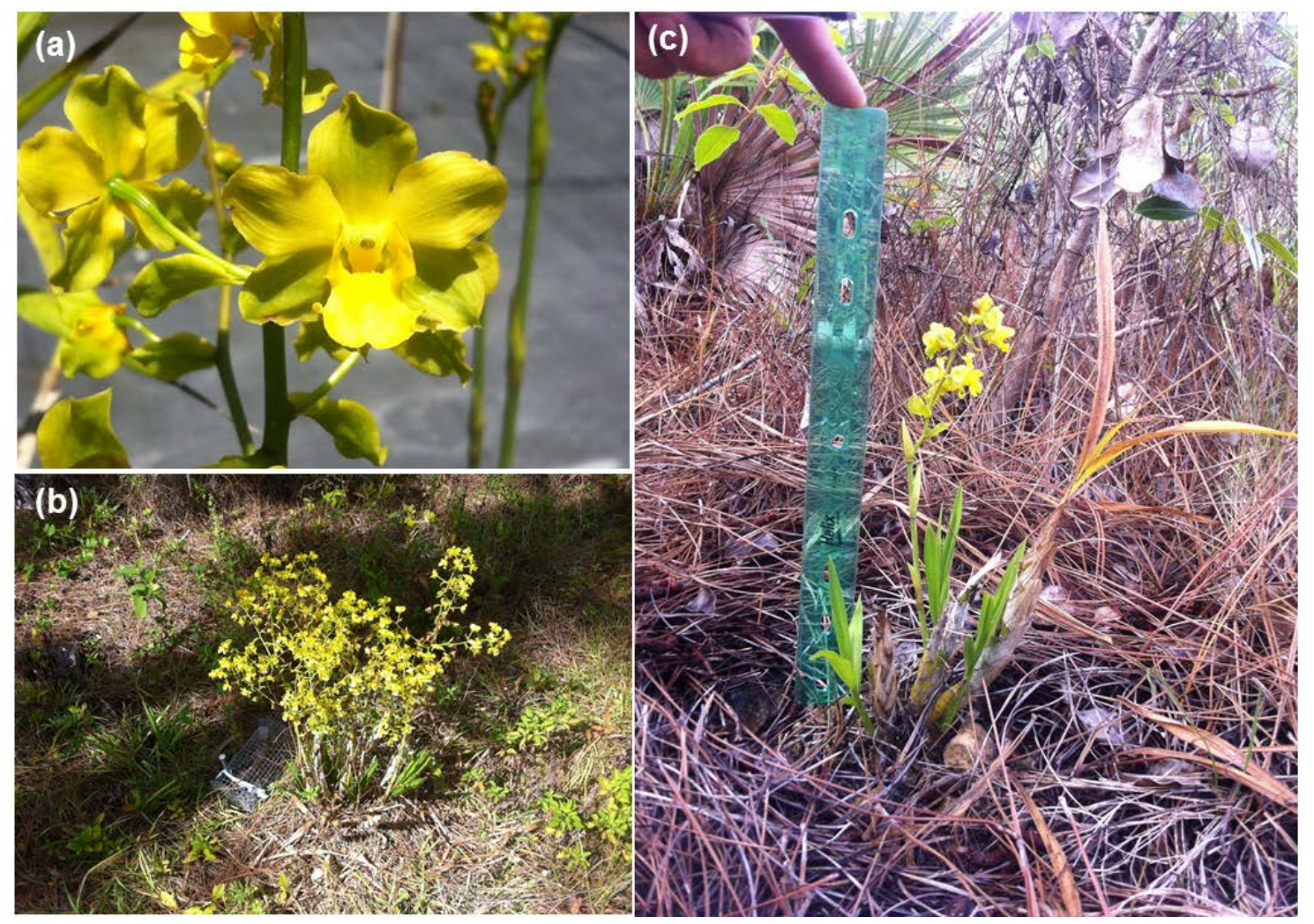

Fig. 3.2 Plates showing the invasive Cyrtopodium flavum (a) flower, (b) adult plant at Boystown Pineland, Miami-Dade County, Florida, and (c) small adult plant illustrating the prolific flowering abilities in this species. 

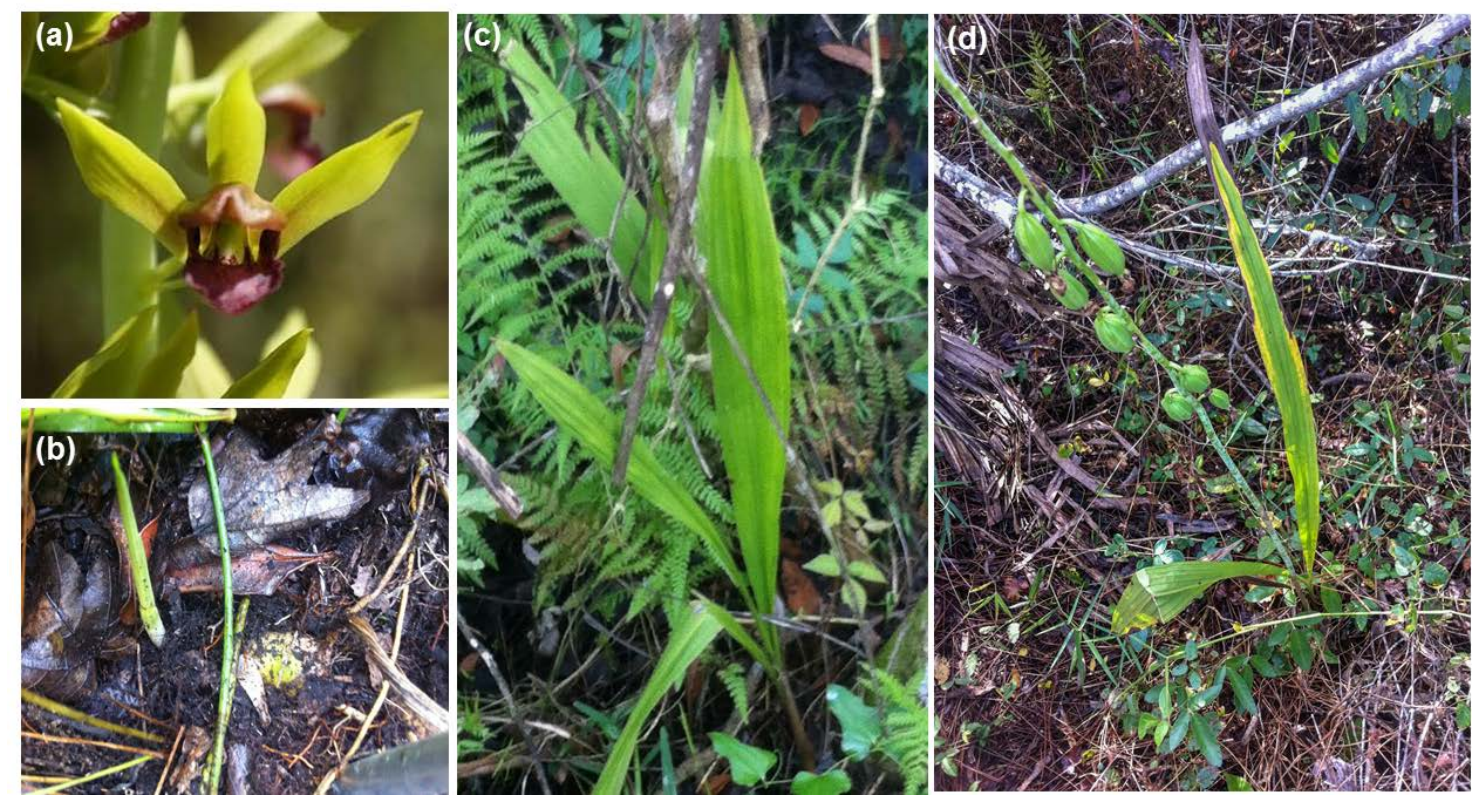

Fig 3.3 Plates showing Eulophia alta (a) flower (photo courtesy of Christine Cook), (b) seedling, (c) adult plant, and (d) adult plant with fruits. All plants were located at Corkscrew Swamp Sanctuary in southwest Florida. 

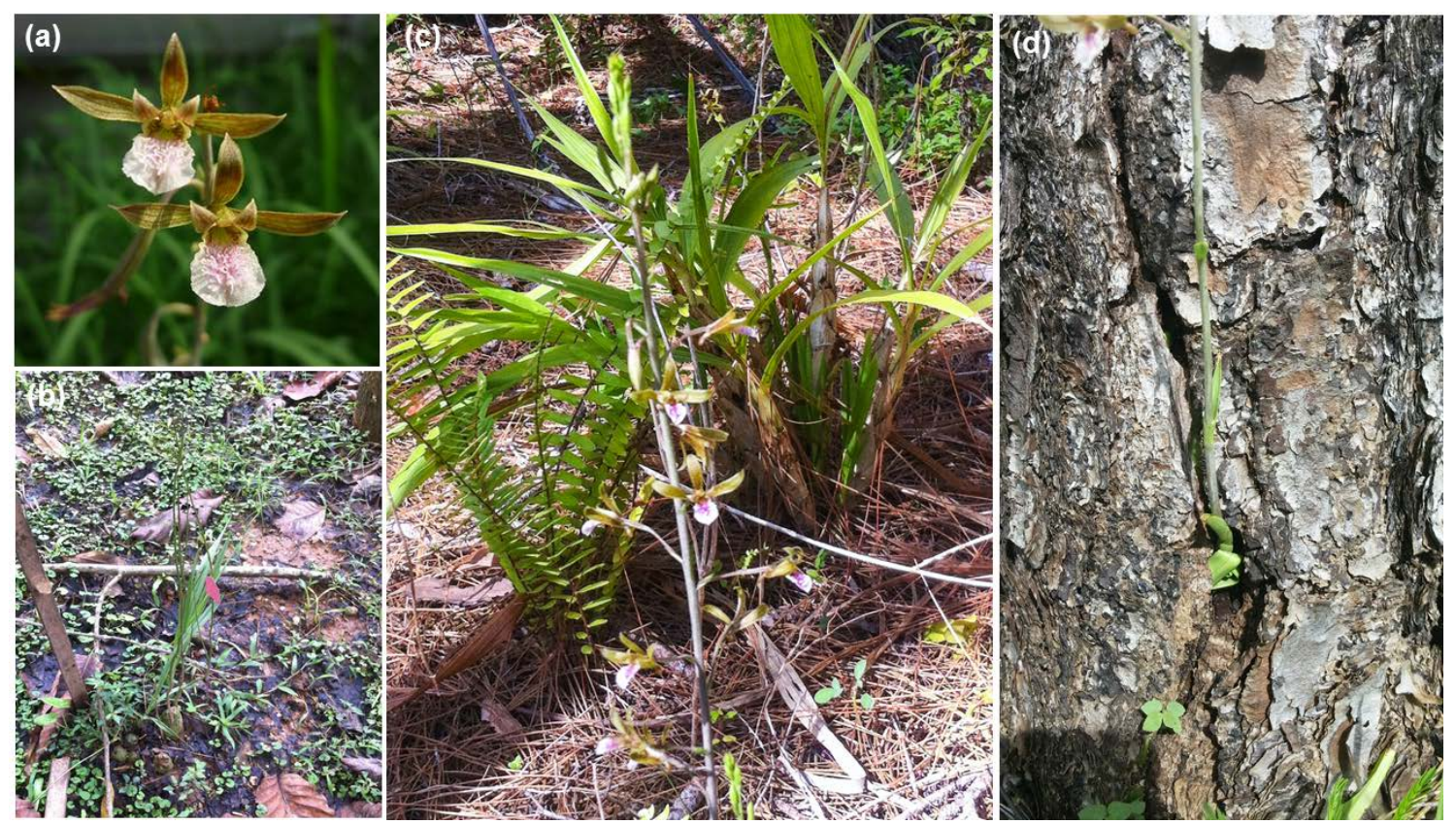

Fig 3.4 Plates showing the invasive Eulophia graminae (a) flowers (photos courtesy of Christine Cook), (b) adult plant at Xishuangbanna Tropical Botanic Garden, Yunnan Province, China (c) adult plant growing alongside C. flavum at Boystown Pineland Miami-Dade County, Florida, and (d) seedling growing epiphytically on Pinus elliotti at Fairchild Tropical Botanic Garden, Coral Gables, Florida. All plants were located at Corkscrew Swamp Sanctuary in southwest Florida. 

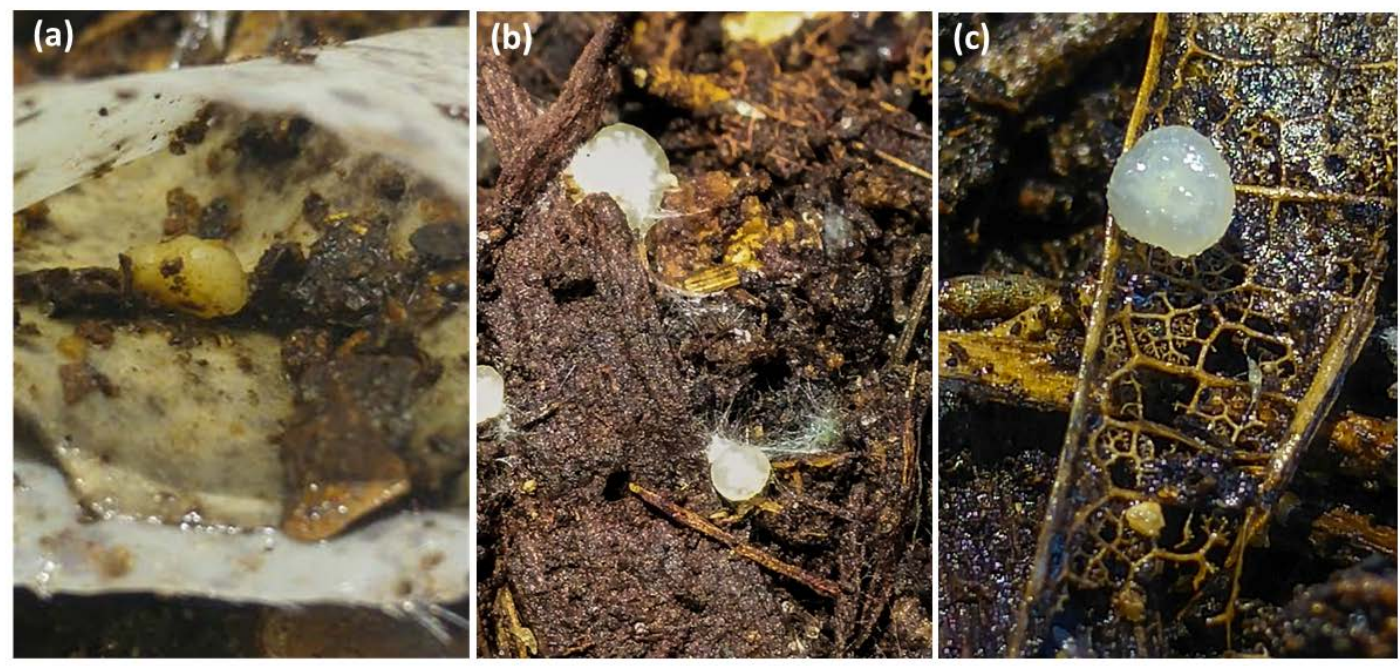

Fig. 3.5 Plates showing symbiotic seed germination for invasive orchid species; (a) shows protocorm of Cyrtopodium flavum recovered from fungal baits at the invaded Boystown Pineland site, (b) protocorms of $C$. flavum showing hyphal penetration recovered in situ in mulch near Zoo Miami, Miami-Dade County, Florida, and (c) a protocorm of E. graminae recovered in situ at Fairchild Garden site.
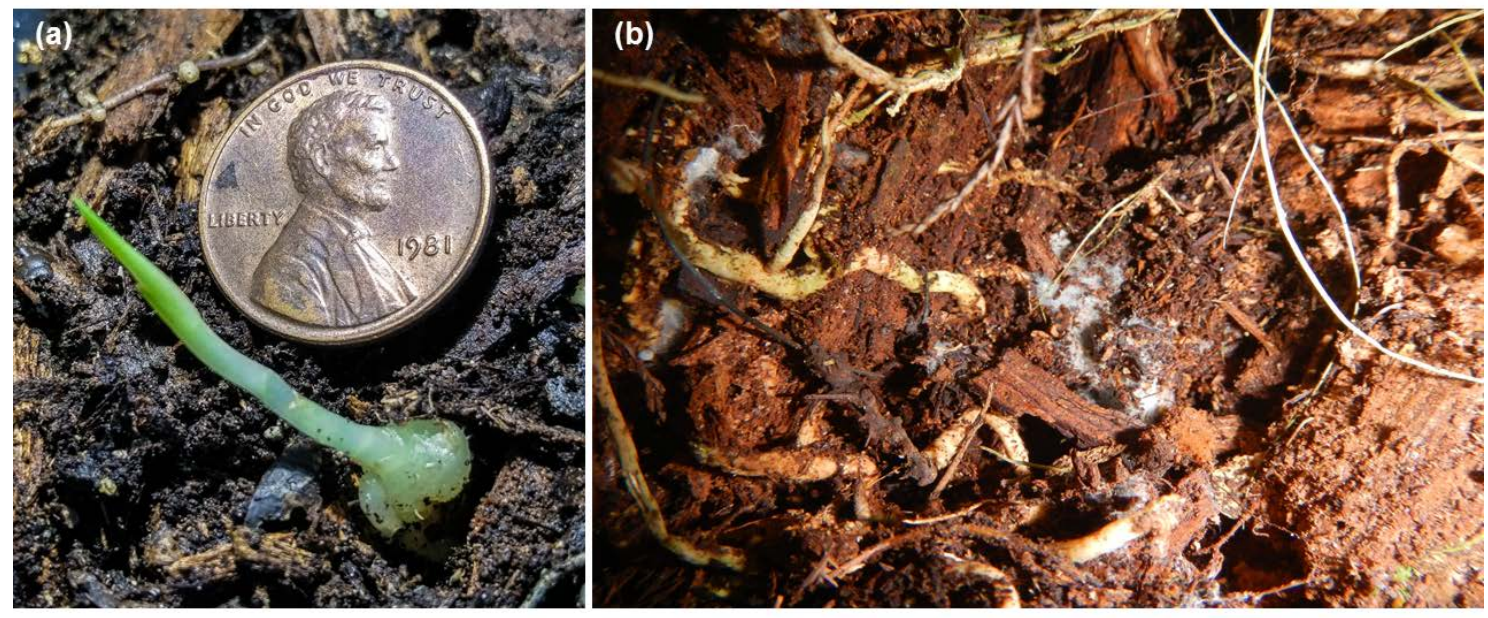

Fig 3.6 Plates showing (a) Cyrtopodium punctatum seedling with apical meristem and protocorm body, and (b) C. punctatum roots with fungal hyphae at Fakahatchee Strand State Park (photo courtesy of Dennis Giardina). 

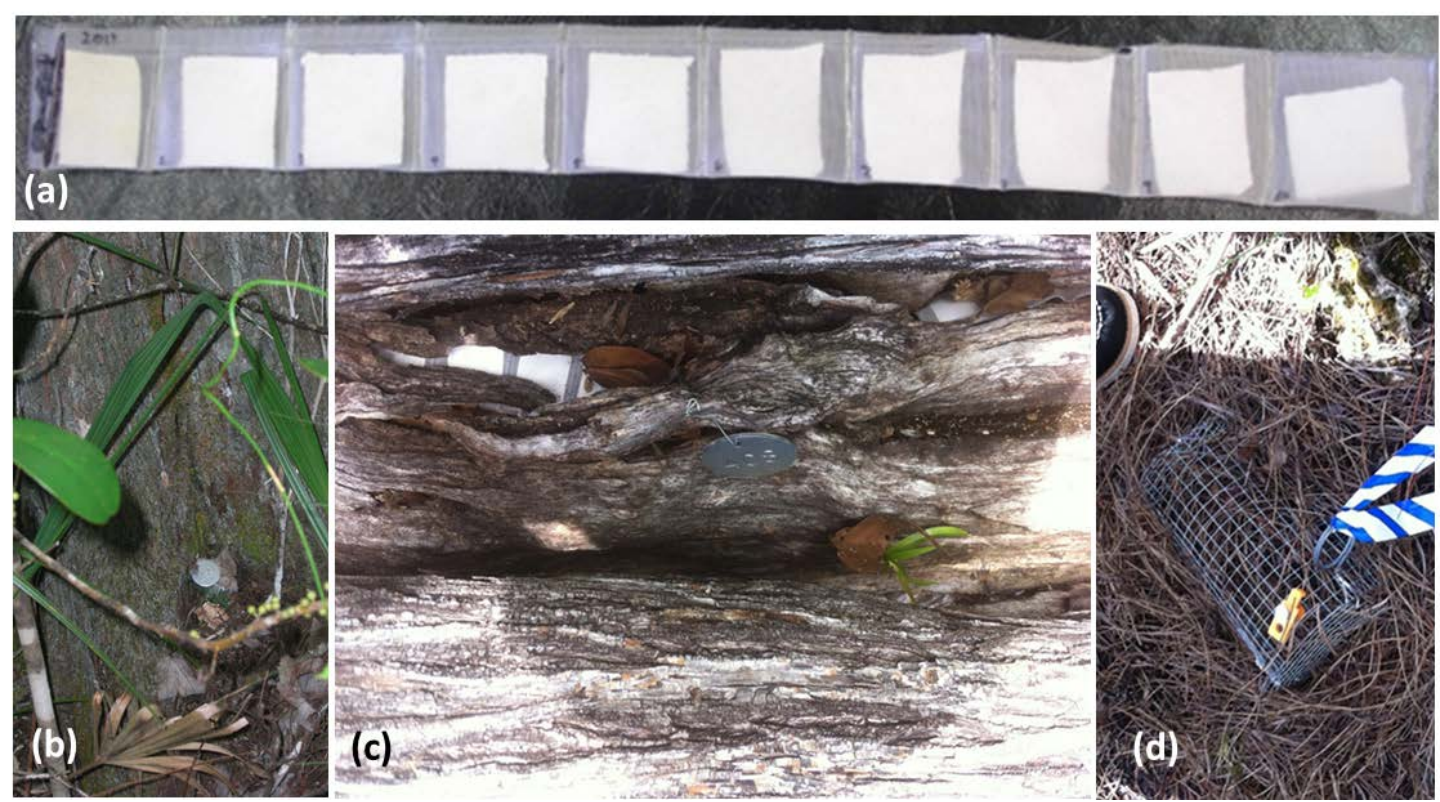

Fig. 3.7 Plates showing fungal baits; (a) nylon mesh compartments with sterile filter paper each containing 50 seeds, (b) fungal bait deployed beneath organic debris at the base of a bald cypress trunk at Fakahatchee Strand State Preserve site, (c) bait deployed in a crevice of buttonwood at Fairchild Garden site, and (d) fungal baits containing invasive orchid seeds were placed in metal cages filled with pine needle litter and decomposing organic debris. 
(a) C. punctatum $(\mathrm{N}=34, \mathrm{n}=18)$

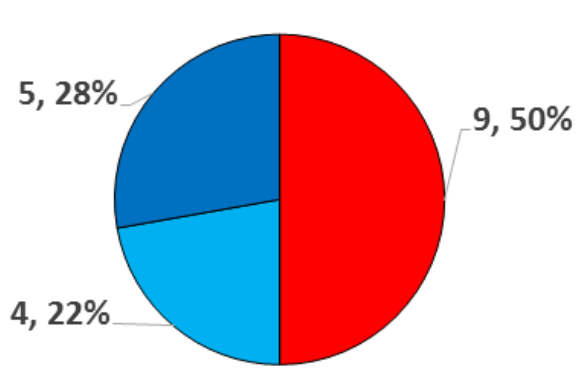

(c)

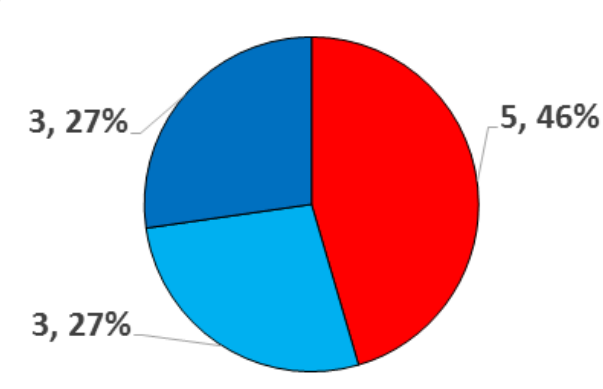

(b) C. flavum $\mathrm{N}=28, \mathrm{n}=18$

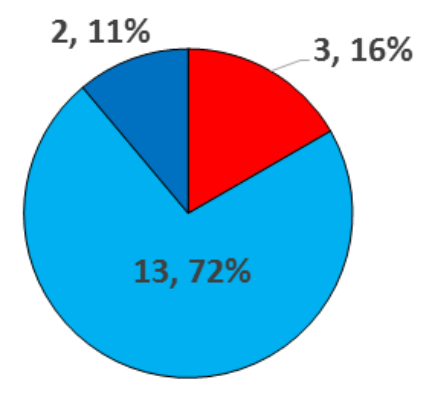

- Ascomycetes

NTB

Tulasnellaceae (d) E. graminae $(\mathrm{N}=24, \mathrm{n}=14)$

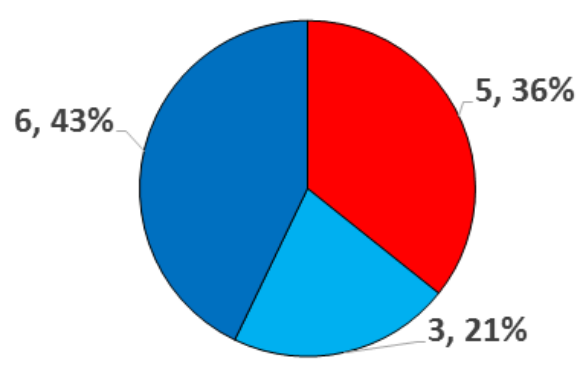

Fig 3.8 Pie charts showing the number and diversity of fungal OTUs identified in four congeneric orchid species in southern Florida; (a) and (c) are native species, (b) and (d) are invasive species. NTB = non-Tulasnellaceae basidiomycete; N = number of sequences included; $n=$ total number of OTUs detected. 
(a) Native Orchids

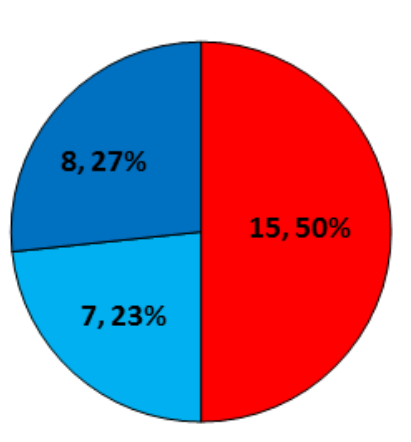

(b) Invasive Orchids

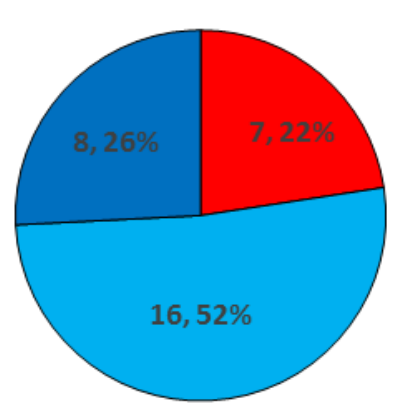

Ascomycetes

- NTB

Tulasnellaceae

Fig. 3.9 Pie charts showing the breakdown of the total number of different fungal OTUs identified between the (a) native species, and (b) invasive species. NTB = non-Tulasnellaceae basidiomycete. 
(a)

Native Orchids $(\mathrm{n}=\mathbf{1 5})$

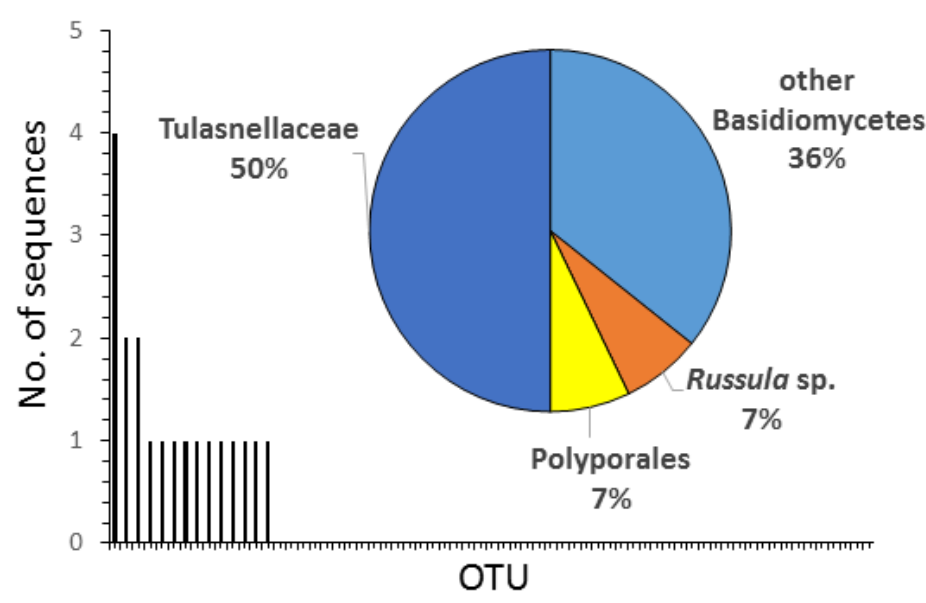

(b)

\section{Invasive Orchids $(\mathrm{n}=\mathbf{2 4})$}

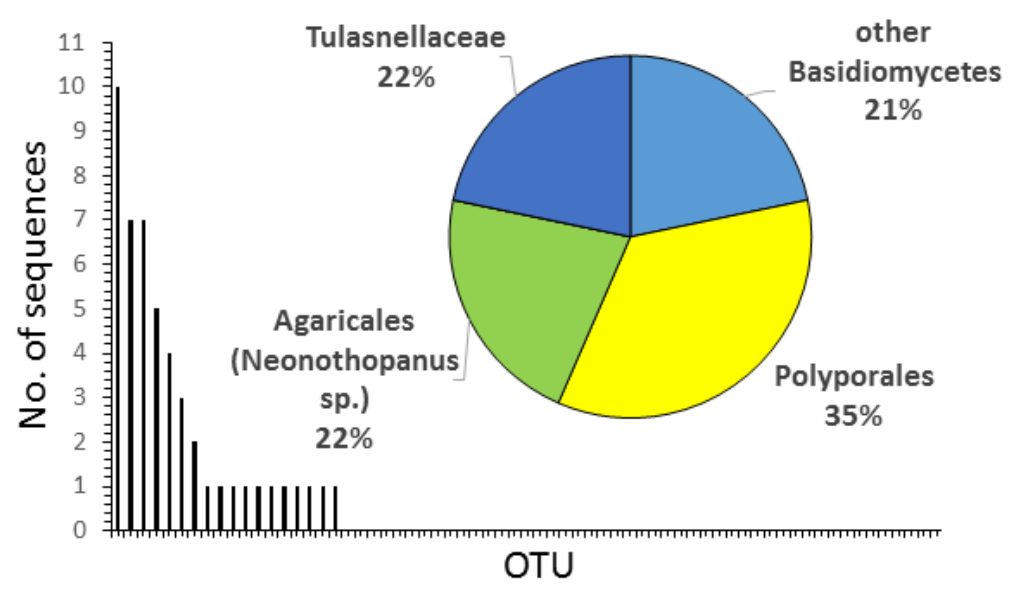

Fig. 3.10 Comparison of mycorrhizal communities associating with native and invasive orchid congeners. Native orchid sites include FTBG, FSS, and CSS. Invasive orchid sites included FTBG, BT, ZOO, and CSS. n= total no. of OTUs. 


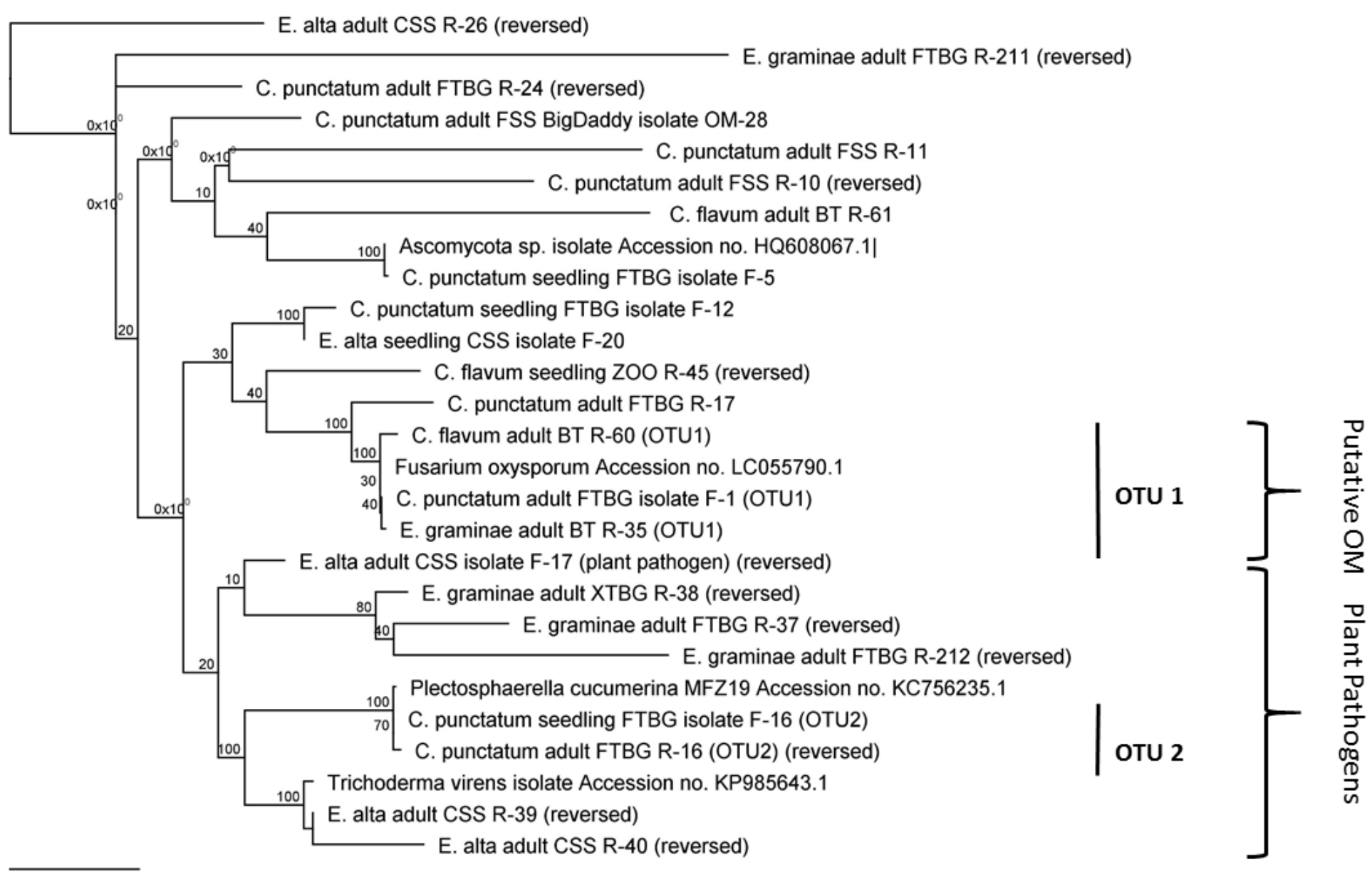


Fig. 3.11 Maximum-likelihood trees of ITS sequences of Ascomycete fungi isolated from the congeneric pairs, Cyrtopodium punctatum and Eulophia alta (natives), and Cyrtopodium flavum and Eulophia graminae (invasives) in southern Florida. Topology shows the relationships between native and invasive species and their relative associations with putative orchid mycorrhizal groups (OTU1), and plant pathogens (OTU2). Numbers indicate bootstrapping percentage supporting the branches. 


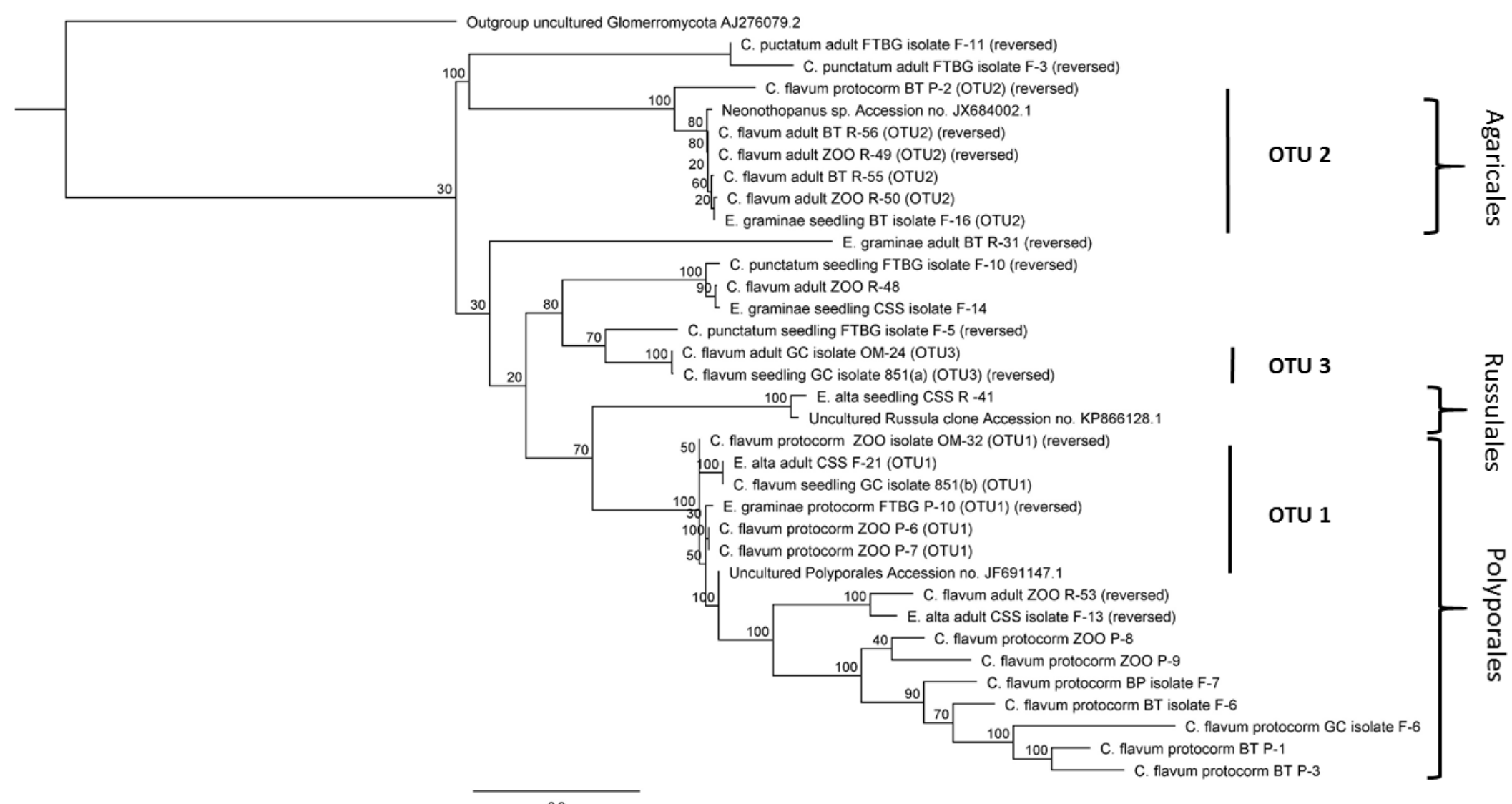

0.3

Fig. 3.12 Maximum-likelihood trees of ITS sequences of non-Tulasnellaceae basidiomycete (NTB) fungi isolated from the congeneric pairs, Cyrtopodium punctatum and Eulophia alta (natives), and Cyrtopodium flavum and Eulophia graminae (invasives) in southern Florida. 


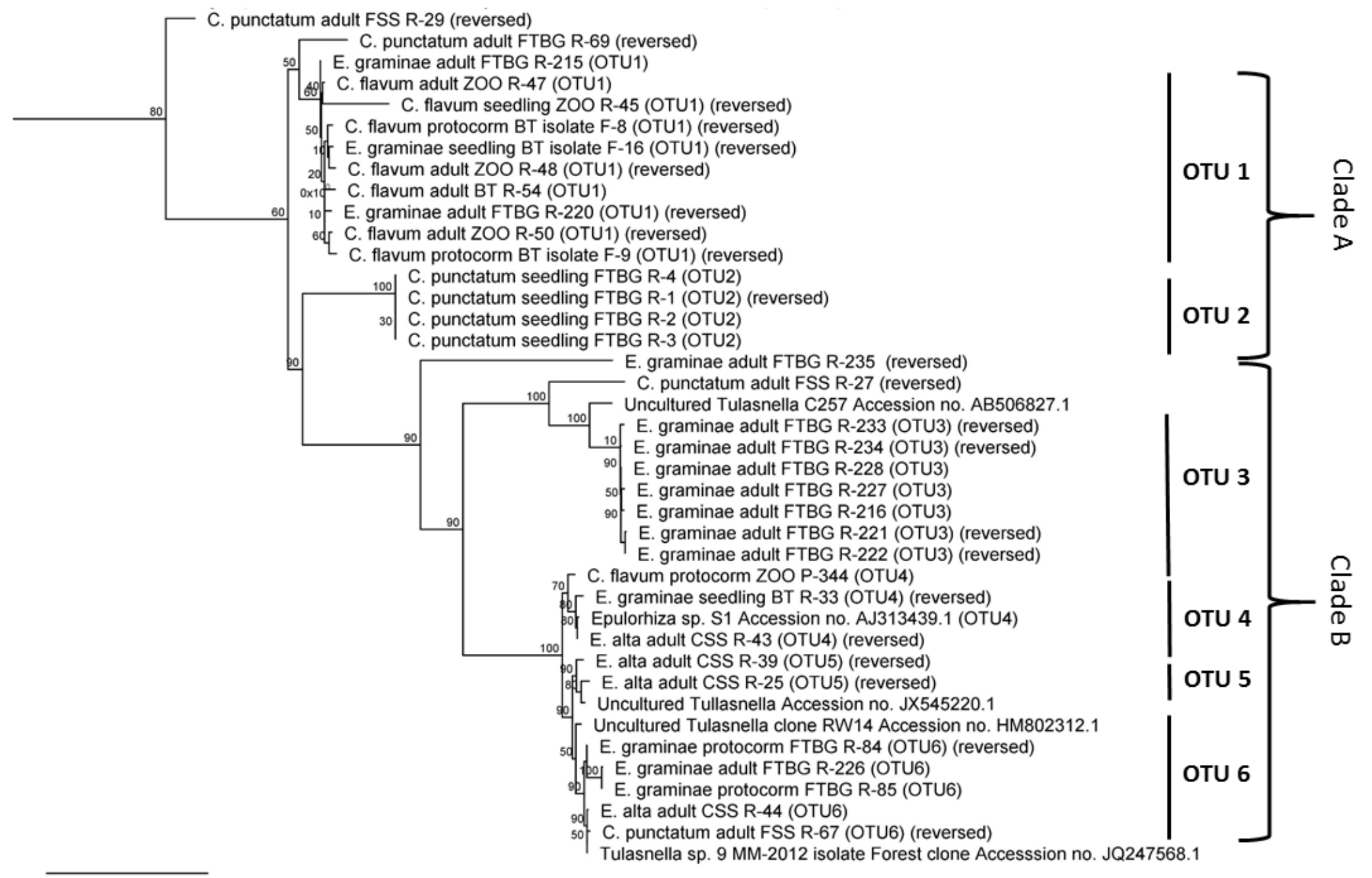


Fig 3.13 Maximum-likelihood trees of ITS sequences of Tulasnellaceae fungi isolated from the congeneric pairs, Cyrtopodium punctatum and Eulophia alta (natives), and Cyrtopodium flavum and Eulophia graminae (invasives) at FTBG, FSS, CSS, BT, and ZOO sites in southern Florida. The branches support two Clades, clade A and clade B, and OTUs 1-6. 


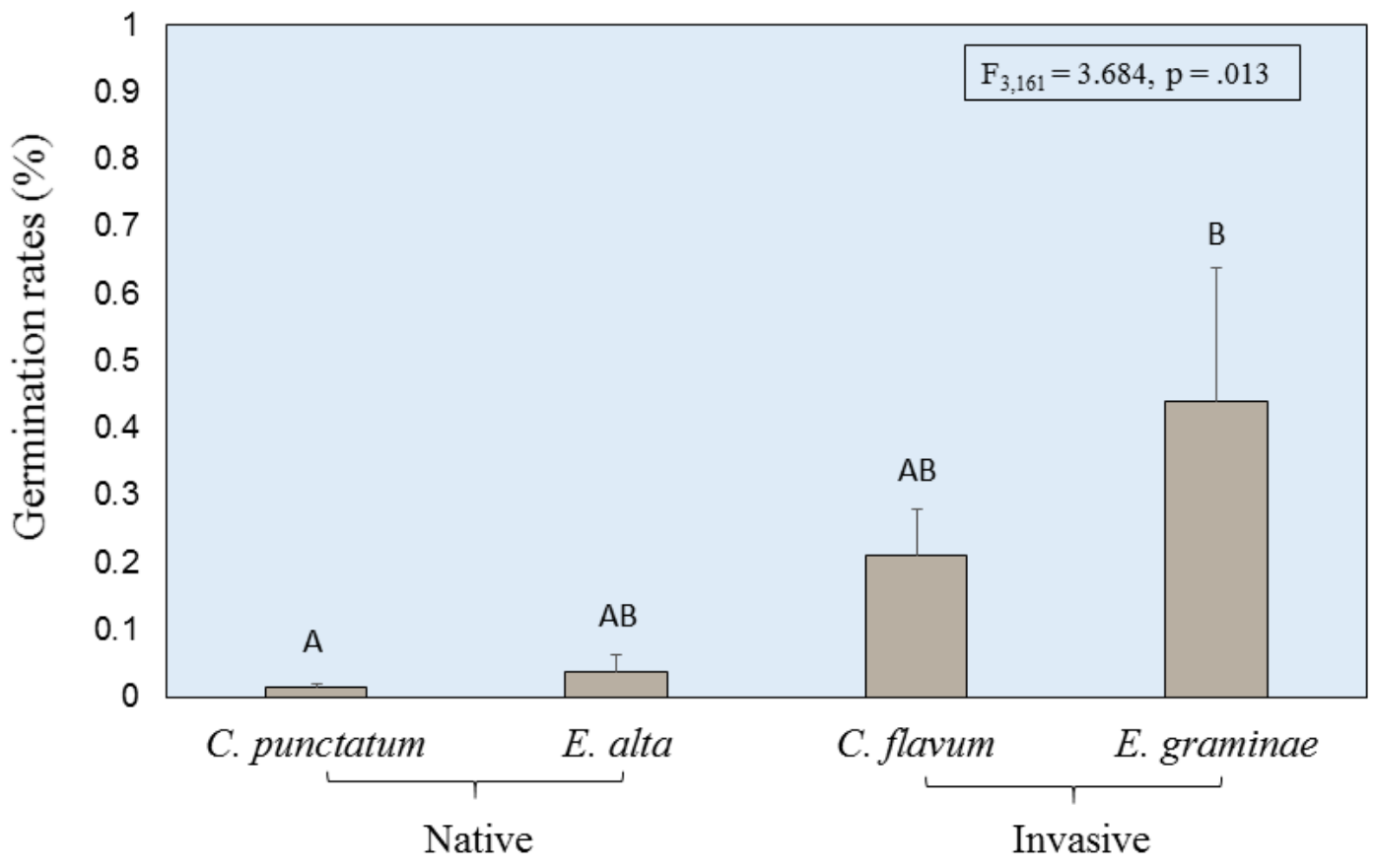

Fig. 3.14 Graph showing the mean percent germination rates for native and invasive orchid species as a result of in situ baiting techniques over five study sites (FTBG, ZOO, BT, FSS, and CSS). Different letters symbolize statistically significant differences; based on Tukey HSD posthoc comparisons. 
(a)

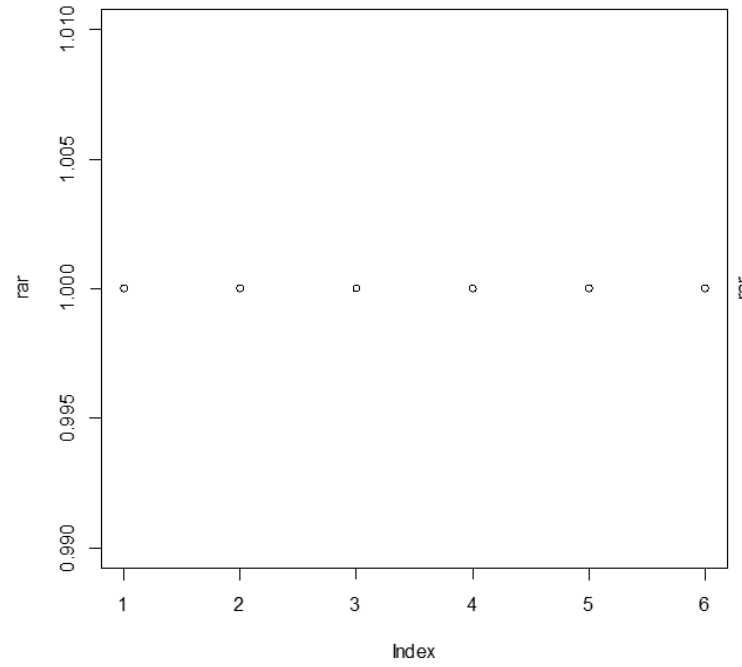

(b)

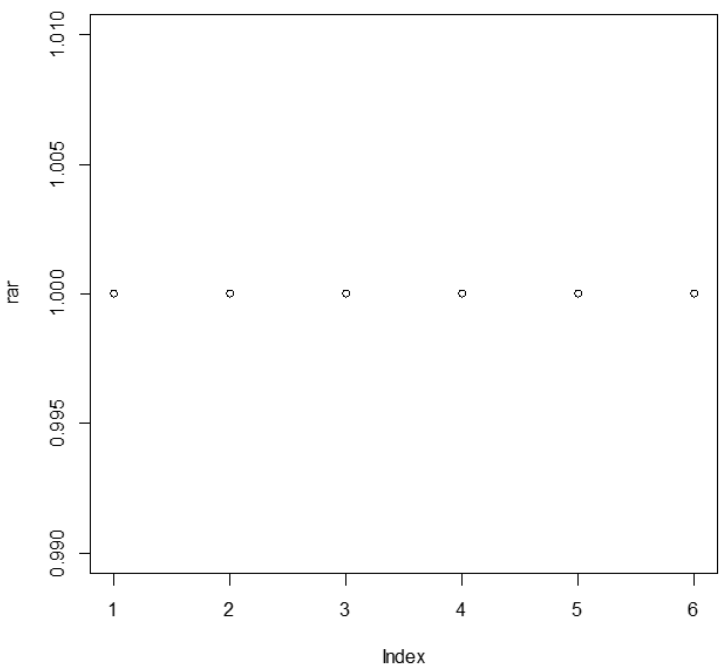

Appendix 3.1 Graphs showing rarefaction curves for Ascomycete (a) and Basidiomycete (b) Shannon-Diversity estimations. 


\section{REFERENCES}

Agrawal, A. A., Kotanen, P. M., Mitchell, C. E., Power, A. G., Godsoe, W., \&

Klironomos, J. (2005). Enemy release? An experiment with congeneric plant pairs and diverse above-and belowground enemies. Ecology, 86(11), 2979-2989.

Bailarote, B. C., Lievens, B., \& Jacquemyn, H. (2012). Does mycorrhizal specificity affect orchid decline and rarity? American journal of botany, 99(10), 16551665.

Barbosa, P., Hines, J., Kaplan, I., Martinson, H., Szczepaniec, A., \& Szendrei, Z. (2009). Associational resistance and associational susceptibility: having right or wrong neighbors. Annual review of ecology, evolution, and systematics, 40, 1-20.

Bidartondo, M.I., \& Read, D.J. (2008). Fungal specificity bottlenecks during orchid germination and development. Molecular Ecology, 17(16), 3707-3716.

Bonnardeaux. Y, Brundrett, M, Batty, A, Dixon, K. Koch, J, and Sivasithamparam, K. (2007). Diversity of mycorrhizal fungi of terrestrial orchids: compatibility webs, brief encounters, lasting relationships and alien invasions. Mycological Research 111: $51-61$.

Brundrett, M. C., Scade, A., Batty, A. L., Dixon, K. W., \& Sivasithamparam, K. (2003). Development of in situ and ex situ seed baiting techniques to detect mycorrhizal fungi from terrestrial orchid habitats. Mycological research, 107(10), 1210-1220.

Caldwell, B. A., Castellano, M. A., \& Griffiths, R. P. (1991). Fatty acid esterase production by ectomycorrhizal fungi. Mycologia, 83(2), 233-236.

Cameron, K. M., Chase, M. W., Whitten, W. M., Kores, P. J., Jarrell, D. C., Albert, V. A., \& Goldman, D. H. (1999). A phylogenetic analysis of the Orchidaceae: evidence from rbcL nucleotide sequences. American Journal of Botany, 86(2), 208-224.

Chang, C., Hu, W. H., Chen, Y. C., Su, Y. L., \& Chiu, Y. T. (2010). In vitro flowering and mating system of Eulophia graminea Lindl. Bot Stud, 51, 357-362.

Compant, S., Van Der Heijden, M. G., \& Sessitsch, A. (2010). Climate change effects on beneficial plant-microorganism interactions. FEMS microbiology ecology, 73(2), 197-214.

Dearnaley, J. D. (2007). Further advances in orchid mycorrhizal research. Mycorrhiza, 17(6), 475-486.

Dearnaley, J. D. W., Martos, F., \& Selosse, M. A. (2012). 12 Orchid Mycorrhizas: Molecular Ecology, Physiology, Evolution and Conservation Aspects. In Fungal associations (pp. 207-230). Springer Berlin Heidelberg. 
De Long, Jonathan, R., Swarts, N. D., Dixon, K. W., \& Egerton-Warburton, L. M. (2012). Mycorrhizal preference promotes habitat invasion by a native Australian orchid: Microtis media. Annals of botany.

Faith, D. P. (1992). Conservation evaluation and phylogenetic diversity. Biological conservation, 61(1), 1-10.

Fitter, A. H., Heinemeyer, A., \& Staddon, P. L. (2000). The impact of elevated CO2 and global climate change on arbuscular mycorrhizas: a mycocentric approach. New Phytologist, 147(1), 179-187.

Gardes, M., \& Bruns, T. D. (1993). ITS primers with enhanced specificity for basidiomycetes-application to the identification of mycorrhizae and rusts. Molecular ecology, 2(2), 113-118.

Jacquemyn, H., Honnay, O., Cammue, B., Brys, R., \& Lievens, B. (2010). Low specificity and nested subset structure characterize mycorrhizal associations in five closely related species of the genus Orchis. Molecular Ecology, 19(18), 40864095.

Jacquemyn, H., Brys, R., Lievens, B., \& Wiegand, T. (2012a). Spatial variation in belowground seed germination and divergent mycorrhizal associations correlate with spatial segregation of three co-occurring orchid species. Journal of Ecology, 100(6), 1328-1337.

Jacquemyn, H., Deja, A., Bailarote, B. C., \& Lievens, B. (2012b). Variation in mycorrhizal associations with tulasnelloid fungi among populations of five Dactylorhiza species. PloS one, 7(8).

Jacquemyn, H., Brys, R., Merckx, V. S., Waud, M., Lievens, B., \& Wiegand, T. (2014). Coexisting orchid species have distinct mycorrhizal communities and display strong spatial segregation. New Phytologist, 202(2), 616-627.

Johnson, T. R., Stewart, S. L., Dutra, D., Kane, M. E., \& Richardson, L. (2007). Asymbiotic and symbiotic seed germination of Eulophia alta (Orchidaceae)preliminary evidence for the symbiotic culture advantage. Plant cell, Tissue and organ culture, 90(3), 313-323.

Keane, R. M., \& Crawley, M. J. (2002). Exotic plant invasions and the enemy release hypothesis. Trends in Ecology \& Evolution, 17 (4):164-170.

Kearse, M., Moir, R., Wilson, A., Stones-Havas, S., Cheung, M., Sturrock, S., Buxton, S., Cooper, A., Markowitz, S., Duran, C., Thierer, T., Ashton, B., Mentjies, P., \& Drummond, A. (2012). Geneious Basic: an integrated and extendable desktop 
software platform for the organization and analysis of sequence data. Bioinformatics, 28(12), 1647-1649.

Kembel, S. W., Cowan, P. D., Helmus, M. R., Cornwell, W. K., Morlon, H., Ackerly, D. D., \& Webb, C. O. (2010). Picante: R tools for integrating phylogenies and ecology. Bioinformatics, 26(11), 1463-1464.

Li, A., Luo, Y. B., \& Ge, S. (2002). Note: A Preliminary Study on Conservation Genetics of an Endangered Orchid (Paphiopedilum micranthum) from Southwestern China. Biochemical Genetics, 40(5), 195-201.

Liu, H., \& Stiling, P. (2006). Testing the enemy release hypothesis: a review and metaanalysis. Biological Invasions, 8 (7):1535-1545.

Liu, H., Stiling, P., \& Pemberton, R. W. (2007). Does enemy release matter for invasive plants? Evidence from a comparison of insect herbivore damage among invasive, non-invasive and native congeners. Biological Invasions, 9 (7):773-781.

Liu, H., \& Pemberton, R. (2010). Pollination of an invasive orchid, Cyrtopodium polyphyllum (Orchidaceae), by an invasive oil-collecting bee, Centris nitida, in southern Florida. Botany, 88 (3):290-295.

Liu, H., Feng, C., Xie, X., Lin, W., Deng, Z., Wei, X., Liu, S., \& Luo, Y. (2014). Impacts of extreme weather on flowering phenology of wild orchids in southwestern China. In Darwin’s Orchids-Now and then, Bernhardt, P. and R. Meier (Eds.) University of Chicago, Chicago. 311-327.

Luer, C. A. (1972). The native orchids of Florida. New York: Botanical Garden.

McCormick M.K., Whigham D.F., \& O’Neill J. (2004). Mycorrhizal diversity in photosynthetic terrestrial orchids. New Phytologist 163, 425-438.

McCormick, M.K., Whigham, D.F., Sloan, D., O'Malley, K., \& Hodkinson, B. (2006). Orchid-fungus fidelity: A marriage meant to last? Ecology, 87(4), 903-911.

McCormick, M.K., Whigham, D.F., O’Neill, J.P., Becker, J.A., Werner, S., Rasmussen, H.N., Bruns, T.D., \& Taylor, D.L. (2009). Abundance and distribution of Corallorhiza odontorhiza reflect variations in climate and ectomycorrhizae. Ecological Monographs, 79(4), 19-635.

McCormick, M. K., Taylor, D. L., Juhaszova, K., Burnett, R. K., Jr., Whigham, D. F., \& O'Neill, J. P. (2012). Limitations on orchid recruitment: Not a simple picture. Molecular Ecology, 21(6), 1511-1523.

Mitchell, C. E., \& Power, A. G. (2003). Release of invasive plants from fungal and viral pathogens. Nature, 421(6923), 625-627. 
Nomura, N., Ogura-Tsujita, Y., Gale, S. W., Maeda, A., Umata, H., Hosaka, K., \& Yukawa, T. (2013). The rare terrestrial orchid Nervilia nipponica consistently associates with a single group of novel mycobionts. Journal of plant research, 126(5), 613-623.

Otero, J. T., Ackerman, J. D., \& Bayman, P. (2002). Diversity and host specificity of endophytic Rhizoctonia-like fungi from tropical orchids. American Journal of Botany, 89(11), 1852-1858.

Otero, J. T., Bayman, P., \& Ackerman, J. D. (2005). Variation in mycorrhizal performance in the epiphytic orchid Tolumnia variegata in vitro: the potential for natural selection. Evolutionary Ecology, 19(1), 29-43.

Otero, J. T., \& Flanagan, N. S. (2006). Orchid diversity-beyond deception. Trends in Ecology \& Evolution, 21:64-65.

Otero, J. T., Flanagan, N. S., Herre, E. A., Ackerman, J. D., \& Bayman, P. (2007). Widespread mycorrhizal specificity correlates to mycorrhizal function in the neotropical, epiphytic orchid Ionopsis utricularioides (Orchidaceae). American Journal of Botany, 94(12), 1944-1950.

Pandey, M., Sharma, J., Taylor, D., \& Yadon, V. L. (2013). A narrowly endemic photosynthetic orchid is non-specific in its mycorrhizal associations. Molecular Ecology, 22(8), 2341-2354.

Pansarin, L. M., Pansarin, E. R., \& Sazima, M. (2008). Reproductive biology of Cyrtopodium polyphyllum (Orchidaceae): a Cyrtopodiinae pollinated by deceit. Plant Biology, 10 (5):650-659.

Pemberton, R. W., Collins, T. M., \& Koptur, S. (2008). An Asian orchid, Eulophia graminea (Orchidaceae: Cymbidieae), naturalizes in Florida. Lankesteriana.

Pemberton, R. W., \& Liu, H. (2008). Potential of invasive and native solitary specialist bee pollinators to help restore the rare cowhorn orchid (Cyrtopodium punctatum) in Florida. Biological conservation, 141 (7):1758-1764.

Peterson, R.L., Massicotte, H.B., \& Melville, L.H. (2004). Mycorrhizas: Anatomy and Cell Biology. CABI Publishing. Wallingford, UK.

Phillips, R. D., Barrett, M. D., Dixon, K. W., \& Hopper, S. D. (2011). Do mycorrhizal symbioses cause rarity in orchids?. Journal of Ecology, 99(3), 858-869.

Pringle, A., Bever, J. D., Gardes, M., Parrent, J. L., Rillig, M. C., \& Klironomos, J. N. (2009).Mycorrhizal symbioses and plant invasions. Annual Review of Ecology Evolution and Systematics, 40, 699-715. 
Rasmussen, H. N. (1995). Terrestrial orchids: from seed to mycotrophic plant. Cambridge University Press.

Rasmussen, H. N. (2002). Recent developments in the study of orchid mycorrhiza. Plant and soil, 244(1-2), 149-163.

Rasmussen, H.N., \& Whigham, D.F. (1998). The underground phase: a special challenge in studies of terrestrial orchid populations. Botanical Journal of the Linnean Society, 126, 49-64.

Richardson, D., Allsopp, N., D'Antonio, C., Milton, S., \& Rejmanek, M. (2000). Plant invasions - the role of mutualisms. Biological Reviews, 75(1), 65-93.

Russell, F. L., \& Louda, S. M. (2005). Indirect interaction between two native thistles mediated by an invasive exotic floral herbivore. Oecologia, 146(3), 373-384.

Selosse, M. A., Faccio, A., Scappaticci, G., \& Bonfante, P. (2004). Chlorophyllous and achlorophyllous specimens of Epipactis microphylla (Neottieae, Orchidaceae) are associated with ectomycorrhizal septomycetes, including truffles. Microbial Ecology, 47(4), 416-426.

Shefferson, R. P., WEIß, M., Kull, T., \& Taylor, D. (2005). High specificity generally characterizes mycorrhizal association in rare lady's slipper orchids, genus Cypripedium. Molecular Ecology, 14(2), 613-626.

Shefferson, R. P., Taylor, D. L., Weiß, M., Garnica, S., McCormick, M. K., Adams, S. \& Yukawa, T. (2007). The evolutionary history of mycorrhizal specificity among lady's slipper orchids. Evolution, 61(6), 1380-1390.

Smith, S. E., \& Read, D. J. (2010). Mycorrhizal symbiosis. Academic press.

Stewart, S. L., \& Richardson, L. W. (2008). Orchid flora of the Florida Panther National Wildlife Refuge. North American Native Orchid Journal, 14(2), 70-104.

Stone, R. (2010). Home, home outside the range. Science, 329(5999), 1592-1594.

Suarez, J. P., Weiss, M., Abele, A., Garnica, S., Oberwinkler, F., \& Kottke, I. (2006). Diverse tulasnelloid fungi form mycorrhizas with epiphytic orchids in an andean cloud forest. Mycological Research, 110, 1257-1270.

Sun, M. (1997). Genetic diversity in three colonizing orchids with contrasting mating systems. American Journal of Botany, 84(2), 224-224.

Swarts, N. D., Sinclair, E. A., Francis, A., \& Dixon, K. W. (2010). Ecological specialization in mycorrhizal symbiosis leads to rarity in an endangered orchid. Molecular Ecology, 19(15), 3226-3242. 
Taylor, D. L., Bruns, T. D., Szaro, T. M., \& Hodges, S. A. (2003). Divergence in mycorrhizal specialization within Hexalectris spicata (Orchidaceae), a nonphotosynthetic desert orchid. American Journal of Botany, 90(8), 1168-1179.

Taylor, D.L. (2004). Myco-heterotroph-fungus marriages - is fidelity over-rated? New Phytologist, 163(2), 217-221.

Taylor, D. L., \& McCormick, M. K. (2008). Internal transcribed spacer primers and sequences for improved characterization of Basidiomycetous orchid mycorrhizas. New Phytologist, 177(4), 1020-1033.

Těšitelová, T., Těšitel, J., Jersáková, J, Řihová, G. Selosse, M.-A. (2012): Symbiotic germination capability of four Epipactis species (Orchidaceae) is broader than expected from adult ecology. American Journal of Botany 99: 1020-1032.

Waterman, R. J., \& Bidartondo, M. I. (2008). Deception above, deception below: linking pollination and mycorrhizal biology of orchids. Journal of Experimental Botany, 59 (5):1085-1096

Wunderlin, R. P., \& Hansen, B. F. (2012). Atlas of Florida Vascular Plants (http://www. plantatlas. usf. edu/).[SM Landry and KN Campbell (application development), Florida Center for Community Design and Research.]. Institute for Systematic Botany, University of South Florida, Tampa. 


\section{CHAPTER IV}

MYCORRHIZAL INTERACTIONS: A NEW FACTOR TO CONSIDER IN THE ASSISTED COLONIZATION OF ORCHIDS 


\section{ABSTRACT}

Assisted colonizationis the movement of a species by humans outside its native range to habitats predicted to be suitable under future climatic conditions. These conservation actions have been highly controversial and rarely attempted. This study examines the mycorrhizal associations of four rare orchid species that have been translocated to higher altitude at Yachang National Nature Reserve in Guangxi Province. Using microbiological and DNA techniques, we identified the mycorrhizal fungi associated with these species within and beyond their natural elevation ranges. The degree of mycorrhizal specificity was estimated by generating phylogenetic trees from which mycorrhizal breadth was defined as both the number of distinct fungal taxa (OTU richness) associated within each species, and the OTU diversity. The results indicated that wide-ranging orchid species were more likely to associate with a greater number (32 OTUs) and more diverse groups of fungi (Shannon diversity $\left(H^{\prime}\right)=1.28$ ) than narrow range species (22 OTUs, $H^{\prime}=0.505$ ). However, translocated orchids were able to establish mycorrhizal relationships with new fungi in the recipient ranges. Understanding how mycorrhizal interactions change between different species and natural ranges is critical to assisting Chinese orchid recovery efforts, and assessing the viability of assisted colonization in general.

\section{INTRODUCTION}

Assisted colonization, also known as managed relocation, is the movement of a species by humans to higher latitudes or elevations beyond its native range to habitats predicted to be suitable under future climatic conditions (McLachlan et al. 2007, Hunter 
2007). Assisted colonization as a viable strategy to mitigate biodiversity losses as a result of climate change remains a highly debated and rarely attempted conservation action (Hoegh-Guldberg et al. 2008, Ricciardi and Simberloff 2009, Minteer and Collins 2010, Hewitt et al. 2011). Because of the scarcity of such controversial initiatives, only a few examples of assisted colonization currently exist (see examples in Stone 2010), and a smaller portion of translocated taxa have been evaluated (Willis et al. 2009, Liu et al. 2012). Central arguments toward assisted colonization, are whether endangered species have the flexibility in their physiological and ecological requirements to survive in the recipient community, and that whether moving species under any circumstances is a good idea (Riccardi and Simberloff 2009, Reichard et al. 2012), some species introductions have led to unintended consequences-- a prime example being invasive species. Either way, these management practices are in contrast to the traditional "preservationist" beliefs upon which conservation biology is built.

While the debate continues, it is important to take advantage of special circumstances in which actions such as translocating species to higher elevation may been necessary. These opportunities can increase our understanding of the distributions and ecological requirements of the selected species, and will help in decision-making frameworks to identify which species are best fit for assisted colonization (HoeghGuldberg et al. 2008, Liu et al. 2010a, Lunt et al. 2013). Such assessments identify the best candidates with the lowest risks, while addressing the two major concerns previously mentioned. However, some argue that we still have much to learn about the impacts of introduced species, making these assessments unreliable (Riccardi and Simberloff 2009). One factor to consider for assisted colonization assessments is possible changes in the 
mutualistic interactions of the translocated species. Among other traits, the ability to form beneficial biotic interactions in a new range is essential to the establishment of many introduced species (Richardson et al. 2000, Mitchell et al. 2006, Pringle et al. 2009). The best case scenario is if the same mutualistic partners are present in the new ranges. Another is if there are similar organisms that can provide the same functions or compensate for the lack of their former partners. In these cases, flexibility in biotic interactions (generalization) of the host species will largely determine whether the species can survive or not. The worst scenario will be if there are no compatible partners within the new range and moving these species may be more complex logistically and of higher risk. Yet, these species may still be targeted for assisted colonization because of the unique ecosystem services they provide, or because they exhibit low ecological redundancy (Lunt et al. 2013).

Orchids have been identified as good candidates for testing assisted colonization strategy (see examples from Keel et al. 2011, Liu et al. 2010, Lunt et al. 2013), and serve as model organisms to test the feasibility of moving highly specialized species; because of their strong dependence on pollinators for reproduction (Tremblay et al. 2005), and their associations with mycorrhizal fungi that are necessary for seed germination and later stages in life (Rasmussen 1995, Taylor 2004, McCormick et al. 2006). Furthermore, both insect pollinators and orchid mycorrhiza are sensitive to sudden changes in temperatures and precipitation (Parmesan and Yohe 2003, Batty et al. 2001, McCormick et al. 2009, Wang et al. 2015, Liu et al. in press). However, there are obvious concerns about the movement of orchid species (Liu et al. 2010a). One such issue becomes clear when considering specialized pollinator interactions where, unlike many mycorrhizal 
associations, pollinator services can be more site and/or habitat specific (Waterman et al. 2011, see results in Chapter 3). Also, having a "cheater" pollination strategy is not uncommon in orchids, comprising about $1 / 3$ of all orchid species (Dressler 1993). In these situations, not only will the specialist pollinator need to be moved, but also the rewarding host plant species (Pemberton 2010).

The degree of specialization in mycorrhizal associations is a strong factor that determines where and in what abundance orchids can be found (Zettler et al. 2003, Swarts et al. 2010, McCormick et al. 2009, 2012, Jacquemyn et al. 2012) and a lack of appropriate fungal partners in the recipient sites could prevent the establishment of translocated individuals. Since these associations can vary from generalist and/or broad, to highly specialized and/or localized, it is necessary to determine the specificity of mycorrhizal associations on a species by species basis before assisted migration actions can take place, particularly with rare or endangered species (Liu et al. 2012). However, mycorrhizal interactions may be less of a limiting factor in the successful establishment of translocated orchids than one would expect. Evidence suggests that orchids may be more flexible in their mycorrhizal interactions than previously thought (McCormick et al. 2006), and we have documented orchid species that are rare in their native ranges successfully establishing in introduced ranges, such as Eulophia graminae (Pemberton et al. 2008, Chang et al 2010; see Chapter 3). Keel et al. (2011), demonstrated that seeds of Habenaria repens from a southern ecotype at sea-level were capable of germinating at higher latitudes using the mycorrhizal fungi already present in the recipient habitat. This important study, showed evidence of recruitment potential for translocated orchids-- a fundamental condition in creating a sustainable orchid population. Furthermore, 
translocated individuals are likely to be seedlings or adult plants and mycorrhizal associations are essential in post-seedling growth in many orchid species (Rasmussen 1995, Liu et al. 2012, Dearnaley et al. 2012). As a result of these studies, orchids with broader or more general fungal requirements may be the best candidates for assisted colonization.

In 2006, thousands of wild orchids belonging to 29 species, and 16 genera (Liu et al. 2012), were moved to higher elevation sites in anticipation of the completion of the Longtan Reservoir near the Yachang National Orchid Reserve (hereafter Yachang Reserve) in Guangxi Province, southwestern China-- a world orchid hotspot (Cribb et al. 2003; Liu et al. 2010a). The impacted area consisted of a $20 \mathrm{~km}$ stretch along the Hongshui River, and completely inundated all the low-lying areas below 400m. The recipient site in the reserve, was located less than $30 \mathrm{~km}$ southeast from the source sites, but was $600 \mathrm{~m}$ higher in elevation, and was $3.6^{\circ} \mathrm{C}$ cooler in mean annual temperature (Huang et al. 2008). Since its inception, the Yachang Reserve has been a success story for assisted colonization of orchids, with five-year survival percentages above $67 \%$ overall (Liu et al. 2012).

Here I examine the mycorrhizal associations of four of these translocated species; Cymbidium bicolor, Geodorum eulophioides, Paphiopedilum dianthum, and Paphiopedilum hirsutissimum. The first two species have narrow elevational ranges naturally, and are only found at low elevations. The latter two species have wide elevational ranges, which can be found in both low and high elevations. All species have existing populations near $\left(<50 \mathrm{~km}^{2}\right)$ or within Yachang Reserve. The subsequent upward translocations of the narrow elevational species C. bicolor and G. eulophioides, to 
elevations $>1000 \mathrm{~m}$ above sea level (a.s.l.), introduced these species outside their natural range. The project will help determine how mycorrhiza may vary between these orchid species with different past elevational ranges, and between and within habitats, both of which are critical to evaluating the viability of assisted colonization for orchid species. Here I address three research hypotheses: $\mathrm{H}_{1}=$ Natural and translocated populations of

orchids will associate with similar groups of fungi at the recipient site. $\mathrm{H}_{2}=$ Translocated orchids will associate with similar groups of fungi in their natural and recipient ranges. $\mathrm{H}_{3}=$ There will be differences in the fungal associations between translocated orchids with narrow elevational distributions (i.e. low elevation species) and those species with wide elevational distributions. I tested these hypotheses using DNA techniques and phylogenetic analyses to compare the mycorrhizal communities of conspecific populations that remain in the natural range to the individuals that have been translocated. I also estimate the overall mycorrhizal richness and diversity among the different orchid populations.

\section{METHODS}

\section{Study Species}

Narrow elevation species: Cymbidium bicolor Lindl. can be found growing at a narrow range of low elevations (350-700m a.s.l). They can be seen growing on trees and limestone cliffs in the semi deciduous forests of southern China, Vietnam, Peninsular Malaysia, Borneo, Sulawesi, Java, Sumatra and the Philippines (Liu et al. 2012; Figs 1a \& b). Geodorum eulophioides Schltr. is an extremely rare terrestrial orchid that occurs in narrow and low elevation ranges ( $<700 \mathrm{~m}$ a.s.l.; Liu et al. 2009) (Figs 2a \& b). It has an 
extremely limited global distribution with only two disjoint occurrences: one near Yachang Reserve (Liu 2010), and one location in central Myanmar (Tanaka et al. 2011). At Yachang, only two small populations consisting of a few adult individuals remain and each is confined to a single hillside. Two other endangered sympatric congeners also occur in the region; Geodorum recurvum (Roxb.) Alston and Geodorum densiflorum (Lam.) Schltr.

Wide elevation species: Paphiopedilum dianthum Tang \& F.T. Wang can occur over a wide elevational range (400-1100m a.s.l.; Liu et al. 2012). It is predominately lithophytic, but in some instances it can also be found growing epiphytically (personal observations at Yachang; Figs 3b). This narrow endemic is considered endangered by the IUCN Redlist, and has a very restricted distribution in China, Laos and Vietnam. Today only a few isolated subpopulations remain in China (Liu et al. 2009). The abundance of P. dianthum has been significantly reduced in recent decades, with the estimated number of mature individuals at less than 10,000 (data from IUCN Redlist; Rankou et al. 2015). Paphiopedilum hirsutissimum (Lindl. ex Hook. f.) Pfitzer is relatively wide spread species and occurs on shaded cliffs, or in limestone forests over wide elevational ranges (400-1100m; Liu et al. 2012). It can be found in Guangxi, SW Guizhou, SE Yunnan, NE India, Laos, Thailand, and N Vietnam (Figs 3a).

\section{Study Sites}

The translocation site was at Yachang Reserve, located in northwest Guangxi Province, China (Fig 4). The 220-acre reserve is the first of its kind and is solely devoted to the protection of orchids. The reserve can be described as a dense semi-deciduous subtropical forest, consisting of numerous hills and steep limestone outcroppings, the 
highest of which are approx. 1,200 m a.s.l. in elevation (Fig 5). It is known for its great diversity of terrestrial and lithophytic orchids, >140 species (in 44 genera), with species rich in populations of Dendrobium and Cymbidium (Shi et al. 2007, Liu et al. 2009); here orchids occur in both monotypic and mixed-species mosaics that can dominate the understory community (personal observations). Yet, most notable are the spectacularly dense stands of lady slipper orchids (Paphiopedilum spp.) that grow along the limestone cliffs. The natural population study sites were also located within Guangxi Province and included Ding Shur Village (hereafter Ding Shur), Mulun Nature Reserve (hereafter Mulun), Jingxi County (hereafter Jingxi, Fig 6), and Bangliang Natural Reserve (hereafter Bangliang). Part of the region has been designated as a World Karst Heritage Site for its vast expanses of limestone mountains and lush subtropical forests (Fig 7). Guangxi Province has a typical subtropical monsoon climate with pronounced wet and dry seasons, and supports vegetation types that vary with elevation (Huang et al. 2008).

\section{Field Sampling}

\section{Sampling of mycorrhizal fungi}

Two roots were collected from at least five individuals of each of the four target species at each study site; overall, 60 root samples were collected. I only selected roots that were in direct contact with the substrate. Roots were removed using a clean razor blade, and immediately rinsed with sterile water to remove any excess organic debris. Samples were placed on moist paper towels and in sterile plastic bags for transport to field stations within 24 hours. Due to the remoteness of the study sites, root sample were stored at $4^{\circ} \mathrm{C}$, for up to three weeks, until processing at Xishuangbanna Tropical Botanic 
Garden (XTBG), in Yunnan Province, China. Here, we were able to confirm the presence of viable pelotons and successfully isolated fungi for the oldest samples.

Yachang site- Fieldwork was conducted from June 19-21, 2014. There were two different sampling sites within Yachang: the "orchid garden”, which is in the interior reserve and rich in orchids naturally, including natural populations of $P$. hirsutissimum and $P$. dianthum (Fig 8), and "Laya" a cliff-side site with a natural population of $P$. hirsutissimum. The site name "orchid garden" was in quotation because it naturally harbors abundant orchids of more than 20 species within a small area. The "orchid garden” is, however, also the recipient site of translocated orchids. The translocated plants were $>50 \mathrm{~m}$ away from these key natural populations of orchids. At Yachang I sampled both translocated and natural individuals of $P$. dianthum and $P$. hirsutissimum. For $P$. dianthum, I sampled five naturally occurring and five translocated individuals at the "orchid garden". From the natural populations of $P$. hirsutissimum, I sampled five plants at the Laya site, seven individuals at the orchid garden site, and five translocated plants at the orchid garden. I also collected samples from one of the two translocated $G$. eulophioides plants and five translocated plants of C. bicolor.

Dingshu Site- Field work was conducted on June 20, 2014. The Dingshu sampling site is located at low elevation (>450m a.s.l) and located near the Yachang Reserve. Here I collected samples from six plants of G. eulophioides.

Mulun Site- Field work was conducted on June 23, 2014. Mulun is a low elevation site where plants were located on steep limestone outcroppings and occurred in lower densities, as compared to the Yachang populations. At Mulun, I sampled five naturally 
occurring individuals for each $P$. hirsutissimum and $C$. bicolor. One individual of C. bicolor was growing epiphytically.

Jingxi Site- Field work was conducted on June 28, 2014. Jingxi was another low elevation site made up of two sampling sites among the county lands. Here C. bicolor plants sporadically occurred along the roadside in trees and limestone outcroppings. I collected samples from three individuals growing epiphytically on Ficus trees and two individuals growing as lithophytes.

Bangliang Site- Field work was conducted on June 29, 2014. Bangliang is a low elevation site characterized by pristine subtropical rainforest, located near the border of Vietnam. The reserve is famous for harboring one of the world's rarest primates, the cao vit gibbon. At this site I sampled six P. hirsutissimum plants, as well as one $C$. bicolor individual. All of these plants were found growing lithophytically in rocky soil.

\section{Fungal isolations and DNA Identification}

Sterile laboratory work and DNA analysis was conducted at XTBG, of the Chinese Academy of Sciences (CAS), in Yunnan Province. Using a laminar flow hood and sterile microbiological techniques, I examined root samples for the presence pelotons. If present, individual pelotons were washed in a series of sterile distilled water baths, and grown in pure cultures using fungi specific nutritive agar and liquid broth (Caldwell et al. 1991, see Chapter 3 for more detailed protocols). Subcultures of all isolates remained at XTBG and will be used for germination trials when seeds become available. To determine whether additional, presumably unculturable, fungi were present in roots, DNA was extracted from the remaining root fragments using the Plant DNeasy 
kit (Qiagen). Nuclear DNA from the ITS region was amplified using the universal fungal primer pairs; ITS 1F/4, ITS 1OF/4OF, and ITS 5/4-Tul, because they are expected to work very well for amplifying DNA of orchid fungi from culture (Gardes and Bruns 1993, Taylor and McCormick 2008). The PCR reactions were performed using Redmix HI fidelity TAQ (Applied Biosystems), with the following thermocycler program: $96^{\circ} \mathrm{C}$ for $1 \mathrm{~min}$; 35 cycles of $94^{\circ} \mathrm{C}$ for $30 \mathrm{~s}, 54^{\circ} \mathrm{C}$ (ITS $1 \mathrm{~F} / 4$ and 5/4Tul) or $60^{\circ} \mathrm{C}$ (ITS $1 \mathrm{~F} / 4$ ) for $30 \mathrm{~s}, 72^{\circ} \mathrm{C}$ for $30 \mathrm{~s}$; and $72^{\circ} \mathrm{C}$ for $10 \mathrm{~min}$. Each PCR product was cleaned using ExoSAP-IT PCR Cleanup (Affymetrix). Sequencing reactions were completed using BigDye Terminator v3.1 Cycle Sequencing Kit (Applied Biosystems). All sequences were manually corrected and aligned using the MAFFT alignment plugin implemented in Geneious version 8.1.5 (Kearse et al., 2012; Biomatters). All new ITS sequences from this study will be deposited in GenBank.

\section{DNA sequence analysis}

All sequences were compared to known sequences in GenBank through a BLAST search. This work was completed at Florida International University, and Fairchild Tropical Botanic Garden. Estimations of phylogenies were made using consensus trees produced employing neighbor-joining, and maximum likelihood (ML) with 500 random addition replicates, trees were also generated in the Geneious program. Tree topologies were qualitatively similar for both estimations. Sequences were grouped into operational taxonomic units (OTUs) using the ML pairwise sequence distances from the phylogenetic trees, i.e. tree tips. Because of alignment difficulties, I designated all OTUs as belonging to either the Ascomycetes or Rhizoctonia basidiomycetes and constructed separate 
consensus trees for the two taxonomic groups. I considered the sequences with $\geq 97 \%$ similarity to constitute a single OTU for the Ascomycetes and non-Tulasnellaceae Basidiomycetes. Because of the rapid evolution in the ITS region of the Tulasnellaceae, I used a 95\% similarity cutoff for these taxa (Taylor and McCormick 2009). For each orchid species, the total number of sequences obtained from root samples and the total number of OTUs were calculated for each species and for each population type (natural or translocated). To compare the diversity of each fungal group for each orchid species, the Shannon-Weiner Index ( $H^{\prime}$ ) (Faith 1992) was calculated using counts of distinct OTUs detected at each site type. The indices were then compared using Student's $t$-tests.

\section{RESULTS}

I obtained total of 53 ITS fungal sequences (16 Ascomycetes, and 27 Basidiomycetes) from a total of 60 plants across natural and translocated sites (Table 1). The majority of sequences (approx. 70\%) were identified as belonging to the Rhizoctonia functional group; families represented were Tremellaceae, Ceratobasidiaceae, Thelephoraceae, and Tulasnellaceae. While the Ascomycete fungi represented around $30 \%$ of the total sequences obtained, and included both putative pathogens, represented by the Order Pleosporales, and potential mycorrhizal fungi from the Order Hypocreales.

Consensus tree topology for the Ascomycete sequences supported two major fungal Orders (70\% bootstrap value); the orders Pleosporales, and Hypocreales (Fig 9). The Pleosporales group was detected in translocated G. eulophioides, C. bicolor and $P$. dianthum. This type of fungus was also found in a natural individual of $P$. hirsutissimum at the Bangliang site. The Hypocreales group was strongly associated with the natural 
population of G. eulophioides (Dingshur site), where six of the seven individuals sampled associated with an unknown Fusarium sp. (100\% bootstrap support). This order was also well represented at the translocated site; associating with all of the species except $G$. eulophioides. The genus Dactylonectria (Hypocreales) was also detected in a natural and translocated individuals of $C$. bicolor, and evidence for a previously evolved relationship with this fungal genus.

The most diverse group of Rhizoctonia fungi belonged to the core Tulasnellaceae, which were found to associate with all of the study species. We only failed to detect any Basidiomycete associates in a single translocated individual of G. eulophioides. Within this group, we detected three distinct OTUs (A, B, \& C; Fig 10), which were shared among both natural and translocated populations, and are closely related to known OM previously identified from southwestern China, and Yachang Reserve (see Xing et al. 2013, Accessions no. JX545218.1 and JQ713581.1; and Fig 10). I also detected three closely related OTUs belonging to the Tremellaceae group. These three OTUs were detected in both natural and translocated individuals at Yachang (Fig 10). Of the two translocated individuals, one was a narrow range species, C. bicolor, and one was the wide range species, $P$. dianthum. A naturally occurring individual of $P$. hirsutissimum, also in Yachang Reserve, associated with this fungal group. Ceratobasidiaceae fungi were detected in two individuals of $P$. hirsutissimum, one from a natural individual at Bangliang, and the other from a translocated individual at Yachang; these sites represent two spatially separated populations. The OTUs were found to be closely related to an orchid associated Ceratobasidium sp. (see Accession no. GQ850444.1; Fig 10). The final Rhizoctonia family identified was the Thelephoraceae. Similar to the results for the 
Tremellaceae, the fungal sequences belonging to the Thelephoraceae group were exclusive to individuals at Yachang Reserve, and included both translocated and naturally occurring individuals (Fig 10).

We found differences in the fungal communities between orchid species, and between those species with narrow versus wide elevational ranges (Figs 11a-h). For $G$. eulophioides and C. bicolor in the natural populations, fungal associations were only observed with the Ascomycetes and Tulasnellaceae, and G. eulophioides plants showed fewer and/or weaker associations with the Tulasnellaceae group (Figs 11a \& c). Contrastingly, in the translocated site these species showed opposite trends in their associations (Figs 11b \& d). We did not detect any Rhizoctonia fungi in the single individual of G. eulophioides sampled (Fig 11b). In contrast C. bicolor individuals had an increase in fungal diversity, utilizing two new groups of fungi belonging to the Tremellaceae and Thelephoraceae (Fig 11d).

For the wide elevational range species from the natural populations, fungal associations were observed predominantly within the Tulasnellaceae group (>67\% for both species), and to a lesser extent with members of the other Rhizoctonia groups present in the study (Figs 11e \& g). There were also fewer associations formed with the Ascomycete group than observed in the narrow elevation species. For wide elevational species, fungal communities in the translocated populations differed from their natural populations (Fig 11e \& f). In the translocated populations of P. dianthum, I observed an increase in fungal diversity, detecting associations with Tremellaceae that were not recovered in the natural population (Fig 11f). The reverse relationship was observed for translocated $P$. hirsutissimum, which lost an association with Tremelleaceae that had 
been detected in the natural range (Fig $11 \mathbf{g} \& \mathbf{~ h}$ ), but maintained a relationship with Ceratobasidiaceae at the translocated site (Fig 11h).

Together the narrow elevational species associated with fewer and less diverse groups of fungi in both the natural and translocated sites (Figs 12a and b), and shared more mycorrhizal OTUs in common between the two site types (Figs 12). Similar to the individual species breakdowns for the narrow elevation species, the majority of sequences from the natural sites belonged to the Ascomycetes, and the rest belonged exclusively to the Tulasnellaceae, with lesser relationships gained at the translocated site with the Tremellaceae and Thelephoraceae fungi (Fig 15a). There were a total of eleven OTUs that were identified as OM for the narrow elevational species, three of which were unique to the natural sites, four unique to the translocated site, and two shared between site types (data included one Hypocreales OTU for C. bicolor that was conserved between sites; 12b). In contrast to the narrow elevational species, combined breakdowns of the fungal communities for the wide ranging species showed little difference in the types of associations between the natural and translocated populations (Fig13). We also saw a dramatic increase in the total number of mycorrhizal OTUs detected (21 total OTUs) as compared to the narrow elevational species, and a large portion of these OTUs were unique to each site, with only one shared taxon (Fig 13).

The diversity of the mycorrhizal associations for the narrow elevational species were significantly lower than for the wide ranging species, as well as for natural versus translocated populations (Tables 2 \& 3). A total of seven distinct OTUs were identified overall from all of the narrow elevational species sites, and the Shannon-diversity indices $\left(H^{\prime}\right)$ and evenness $\left(J^{\prime}\right)$ were also low; $H^{\prime}=0.505$ and $J^{\prime}=0.479$ respectively (Table 2). 
The OTU richness tripled for the widespread species, which associated with 21 distinct taxa over three study sites; diversity indices were also much higher $\left(H^{\prime}=1.28\right)$ and evenness estimates were marginally higher $\left(J^{\prime}=0.64\right.$; Table 2$)$. The greater species richness and higher diversity estimates for the wide elevational species are skewed because of the large number of OTUs sampled at the orchid garden/ translocation site. Shannon diversity values were five times as high for OTUs at the single translocated site, compared to the six natural sites (Table 3).

\section{DISCUSSION}

Our results support that the translocated orchids at Yachang were not hampered by the ability to establish mycorrhizal relationships with new fungi in the recipient ranges; this was true for both narrow and wide elevational species. Specifically, this study directly addressed how orchid-mycorrhizal interactions may be influenced by species range distributions, and how this factors into the decision-making framework of assisted colonization. Understanding how these relationships may change as a result of assisted colonization is urgent, because of the sensitivity of heavily dependent taxa to current global changes (Fitter et al. 2000, Compant et al. 2010, Liu et al. 2012). More broadly, determining the factors that contribute to population dynamics in general still remains a central goal in ecology. Our study supports the viability of assisted colonization of orchids at Yachang and satisfies the two major concerns plaguing this conservation strategy: 1) low risk of invasion--considering the extreme diversity of the orchid family, many of the species can be considered "low risk", since studies have shown that fewer than the expected number of orchids species have become established 
outside native ranges (Pemberton and Liu 2009), and 2) associations with mutualistic partners (i.e. mycorrhizal fungi) have been continued since there is a bountiful pool of compatible mycorrhizal fungi at Yachang Reserve, particularly Tulasnellaceae taxa, which are important for seed germination in many orchid species (Rasmussen 1995).

Our results support the hypothesis that wide-ranging species associate with a greater number and more diverse groups of fungi. We found the extremely rare endemic G. eulophioides associated with the fewest and least diverse groups of mycorrhizal fungi even when compared to the other narrow range species C. bicolor. However, the single G. eulophioides individual was transplanted one year prior, whereas the other species had been translocated for several years. Although we detected fewer overall taxa for $C$. bicolor, the community assemblage was more similar to the fungal communities of the wider ranging species, which utilized diverse groups of Rhizoctonia in the translocated populations. Interestingly, only one of the wide ranging species' fungal associates was present in both the natural and translocated ranges. Despite the narrow-range species associating with a lower diversity of mycorrhiza, two of their fungal taxa were shared between the native and translocated ranges. This suggests that the narrow elevational species, particularly C. bicolor, may be using a narrower group of fungi that are available over different habitats. While the wider ranging species can associate with a broader mycorrhizal breadth of fungi, and multiple taxa within the Tulasnellaceae, that may be more site or habitat specific. High rates of adaptive radiation for fungi in this warm and humid region is not implausible, particularly in core Tulasnella because of the rapid rates of evolution in these fungi (Binder et al. 2005, Moncalvo et al. 2006). Yet, all of the orchid species had a strong relationship with the Tulasnellaceae, and in particular with 
the OTU C fungus, which was detected in both species types and at both site types. Due to the broad compatibility of this distinct fungal taxon, further research to identify its life history and environmental requirements are highly recommended. Furthermore, preservation of those habitats that support the OTU C fungus is of conservation importance to Yachang Reserve; this strategy should also be applied to other fungal taxa that are shared between natural and translocated sites.

We also determined that the Yachang Reserve (also translocation) site is exceptionally rich in mycorrhizal diversity, in comparison to other natural sites sampled surrounding the reserve. Consequently, the high diversity of mycorrhiza is likely the main driver of the extreme, and highly localized, diversity of orchid species seen here. The least diverse site in terms of richness of OTUs was the Huang Jiang County Lands, where we were not able to detect any mycorrhiza in the $C$. bicolor plants we sampled. These sampling sites were in or near agricultural lands. The Dingshur site was also limited in mycorrhizal diversity, here all six species were associating with the same Ascomycete, or Tulasnellaceae OTU suggesting either high specialization or a limited abundance of compatible fungi at this site. Based on the highly disturbed conditions at Dingshur, it may be a situation where habitat alterations (i.e agricultural practices) have changed the environmental conditions necessary to support a diverse assemblage of mycorrhizal fungi. 


\section{CONCLUSION}

This research has provided the opportunity to participate in a rarely attempted assisted colonization project. The results of this project have provided a critical evaluation to the conservation program at Yachang, and support that these actions are a viable tool to mitigate orchid biodiversity losses for some Chinese orchid species. We can now apply the knowledge we obtained of the fungi needed to establish viable populations outside their natural environment or range to development of ex-situ propagation protocols. These protocols can be developed for species that are threatened due to their commercial value and relieve poaching pressure in natural populations. Currently there is increasing pressure to secure a sustainable market for orchid-based products that are used in traditional Chinese medicine. We can also begin to design PCR primers specific to each taxonomic grouping and use these to amplify mycorrhizal fungus DNA from substrate samples as a cost-efficient method to help us determine where and in what abundance the compatible fungi are within the environment, furthering the conservation mission at Yachang Reserve. The research presented here has greatly benefitted my dissertation by expounding on the role of mycorrhizal symbiosis in orchid range expansions. Together with the findings in chapter four, these studies have significantly advanced our understanding of orchid ecology, specifically concerning invasions, range expansions, and species response to environmental change. 
Table 4.1 Information about the fungal ITS sequences obtained for each orchid species. Included in this table: site, species range type (wide range or narrow (high and low ranges), sequence length (bp), two closest related taxa and their GenBank accession numbers, and percent identity.

\begin{tabular}{|c|c|c|c|c|c|c|c|}
\hline Species & Site & Range & Sample ID & $\begin{array}{l}\text { Post-Trim } \\
\text { Length (bp) }\end{array}$ & Two Closest Sequences & Accession No. & $\begin{array}{l}\text { Percent } \\
\text { Identity }\end{array}$ \\
\hline \multirow{2}{*}{ G. eulophioides } & \multirow{2}{*}{ Dingshu } & \multirow[t]{2}{*}{ Narrow } & \multirow{2}{*}{ R-45 } & \multirow{2}{*}{492} & Fusarium oxysporum & KP132221 & 100 \\
\hline & & & & & Fusarium oxysporum & KT876655 & 100 \\
\hline \multirow{2}{*}{ G. eulophioides } & \multirow{2}{*}{ Dingshu } & \multirow[t]{2}{*}{ Narrow } & \multirow{2}{*}{ R-46(a) } & \multirow{2}{*}{590} & Tulasnellaceae & AB506842 & 99 \\
\hline & & & & & Tulasnellaceae & AB506843 & 99 \\
\hline \multirow{2}{*}{ G. eulophioides } & \multirow{2}{*}{ Dingshu } & \multirow[t]{2}{*}{ Narrow } & \multirow{2}{*}{$\mathrm{R}-46(\mathrm{~b})$} & \multirow{2}{*}{598} & Epulorhiza & KJ765995 & 100 \\
\hline & & & & & Epulorhiza & KJ765994 & 100 \\
\hline \multirow{2}{*}{ G. eulophioides } & \multirow{2}{*}{ Dingshu } & \multirow[t]{2}{*}{ Narrow } & \multirow{2}{*}{ R-48(a) } & \multirow{2}{*}{484} & Fusarium solani & KР852534 & 74 \\
\hline & & & & & Fusarium solani & FJ158119 & 74 \\
\hline \multirow{2}{*}{ G. eulophioides } & \multirow{2}{*}{ Dingshu } & \multirow[t]{2}{*}{ Narrow } & \multirow{2}{*}{$\mathrm{R}-48(\mathrm{~b})$} & \multirow{2}{*}{397} & Tulasnella & HQ633056 & 100 \\
\hline & & & & & Tulasnella & JQ713581 & 99 \\
\hline \multirow{2}{*}{ G. eulophioides } & \multirow{2}{*}{ Dingshu } & \multirow[t]{2}{*}{ Narrow } & \multirow{2}{*}{$\mathrm{R}-44$} & \multirow{2}{*}{506} & Fusarium solani & KR708647.1 & 99 \\
\hline & & & & & Fusarium oxysporum & KP132218.1 & 99 \\
\hline \multirow{2}{*}{ G. eulophioides } & \multirow{2}{*}{ Translocated } & \multirow[t]{2}{*}{ Narrow } & \multirow{2}{*}{$\mathrm{R}-6$} & \multirow{2}{*}{449} & Fungal sp. & KC354538.1 & 99 \\
\hline & & & & & Phoma herbarum & KP900326.1 & 99 \\
\hline G. eulophioides & Dingshu & Narrow & $\mathrm{R}-43$ & 488 & $\begin{array}{l}\text { Uncultured fungus clone } \\
\text { Fusarium sp. P1729 }\end{array}$ & $\begin{array}{l}\text { KT122774.1 } \\
\text { KT269001.1 }\end{array}$ & $\begin{array}{l}100 \\
100\end{array}$ \\
\hline G. eulophioides & Dingshu & Narrow & $\mathrm{R}-43$ & 530 & $\begin{array}{l}\text { Tulasnella sp. XC-2015 } \\
\text { Uncultured } \\
\text { Tulasnellaceae }\end{array}$ & $\begin{array}{c}\text { KF537642.1 } \\
\text { JF691486.1 }\end{array}$ & $\begin{array}{l}98 \\
98\end{array}$ \\
\hline G. eulophioides & Dingshu & Narrow & $\mathrm{R}-47$ & 500 & Fusarium oxysporum & $\begin{array}{l}\text { KT833080.1 } \\
\text { KR232520.1 }\end{array}$ & 99 \\
\hline
\end{tabular}




\begin{tabular}{|c|c|c|c|c|c|c|c|}
\hline \multirow[t]{2}{*}{ C. bicolor } & \multirow[t]{2}{*}{ Mulun } & Narrow & \multirow[t]{2}{*}{$\mathrm{R}-40$} & \multirow[t]{2}{*}{553} & $\begin{array}{l}\text { Uncultured } \\
\text { Tulasnellaceae clone }\end{array}$ & JF691226 & 97 \\
\hline & & & & & Tulasnellaceae & AB506815 & 96 \\
\hline \multirow[b]{2}{*}{ C. bicolor } & \multirow{2}{*}{ Mulun } & Narrow & \multirow{2}{*}{ R-41 } & \multirow{2}{*}{440} & $\begin{array}{l}\text { Dactylonectria } \\
\text { estremocensis }\end{array}$ & NR_121497 & 97 \\
\hline & & & & & $\begin{array}{l}\text { Dactylonectria } \\
\text { estremocensis }\end{array}$ & KJ541683 & 97 \\
\hline C. bicolor & Translocated & Narrow & $\mathrm{R}-23$ & 515 & $\begin{array}{l}\text { Podospora sp. } \\
\text { Podospora sp }\end{array}$ & EU273519 & $\begin{array}{l}99 \\
99\end{array}$ \\
\hline \multirow[t]{2}{*}{ C. bicolor } & \multirow[t]{2}{*}{ Translocated } & Narrow & \multirow[t]{2}{*}{ R-25(a) } & \multirow[t]{2}{*}{520} & $\begin{array}{l}\text { Poaospora sp. } \\
\text { Ilyonectria destructans } \\
\text { Ilyonectria sp. Isolate }\end{array}$ & $\begin{array}{l}\text { LC109288 } \\
\text { GU934546 } \\
\text { KT264361 }\end{array}$ & $\begin{array}{l}99 \\
99 \\
99\end{array}$ \\
\hline & & Narrow & & & Tulasnella sp. & JQ713581 & 99 \\
\hline C. bicolor & Translocated & & R-25(b) & 461 & $\begin{array}{l}\text { Uncultured } \\
\text { Tulasnellaceae clone }\end{array}$ & GQ241863 & 99 \\
\hline C. bicolor & Translocated & Narrow & R-26(a) & 507 & $\begin{array}{l}\text { Uncultured Tremella } \\
\text { Uncultured fungus }\end{array}$ & $\begin{array}{l}\text { LN911375 } \\
\text { KT243415 }\end{array}$ & $\begin{array}{l}90 \\
86\end{array}$ \\
\hline \multirow[t]{2}{*}{ C. bicolor } & \multirow[t]{2}{*}{ Translocated } & Narrow & \multirow[t]{2}{*}{ R-26(b) } & \multirow[t]{2}{*}{561} & $\begin{array}{l}\text { Uncultured } \\
\text { Tulasnellaceae clone }\end{array}$ & JF691226 & 97 \\
\hline & & & & & Tulasnellaceae & AB506815 & 97 \\
\hline \multirow[t]{2}{*}{ C. bicolor } & \multirow[t]{2}{*}{ Translocated } & Narrow & R-27(a) & 529 & $\begin{array}{l}\text { Uncultured } \\
\text { Basidiomycota }\end{array}$ & LC033918 & 89 \\
\hline & & Narrow & \multirow{3}{*}{ R-27(b) } & \multirow{3}{*}{411} & $\begin{array}{l}\text { Thelephoraceae sp. } \\
\text { Uncultured }\end{array}$ & AB848634 & 88 \\
\hline \multirow{2}{*}{ C. bicolor } & \multirow{2}{*}{ Translocated } & & & & Basidiomycota & LC033918 & 97 \\
\hline & & & & & $\begin{array}{l}\text { Uncultured Tomentella } \\
\text { clone }\end{array}$ & JQ991890 & 97 \\
\hline \multirow[t]{2}{*}{ P. dianthum } & \multirow[t]{2}{*}{ Yachang } & Wide & $\mathrm{R}-15$ & 556 & $\begin{array}{l}\text { Uncultured } \\
\text { Tulasnellaceae } \\
\text { Uncultured }\end{array}$ & JX545218.1 & 99 \\
\hline & & & & & Tulasnellaceae & KF574225.1 & 97 \\
\hline P. dianthum & Yachang & Wide & R-30(a) & 481 & Uncultured fungus & KF296812.1 & 84 \\
\hline
\end{tabular}




\begin{tabular}{|c|c|c|c|c|c|c|c|}
\hline & & & & & $\begin{array}{l}\text { Uncultured } \\
\text { Tulasnellaceae } \\
\text { Uncultured } \\
\text { Tulasnellaceae }\end{array}$ & $\begin{array}{l}\text { KC243947.1 } \\
\text { GQ241863.1 }\end{array}$ & 99 \\
\hline P. dianthum & Yachang & Wide & $\mathrm{R}-14$ & 547 & $\begin{array}{l}\text { Uncultured } \\
\text { Tulasnellaceae }\end{array}$ & JX649082.1 & 97 \\
\hline P. dianthum & Yachang & Wide & R-16(a) & 579 & $\begin{array}{l}\text { Uncultured } \\
\text { Tulasnellaceae } \\
\text { Uncultured } \\
\text { Tulasnellaceae }\end{array}$ & $\begin{array}{l}\text { JX545218.1 } \\
\text { KF574225.1 }\end{array}$ & 98 \\
\hline P. dianthum & Translocated & Wide & R-30(b) & 598 & $\begin{array}{l}\text { Uncultured } \\
\text { Tulasnellaceae } \\
\text { Uncultured }\end{array}$ & JX649082.1 & 98 \\
\hline & & & & & Tulasnellaceae & KC243935.1 & 98 \\
\hline$P$. dianthum & Yachang & Wide & R-13(a) & 100 & Uncultured Ascomycota & JX998698.1 & 91 \\
\hline Р. & I actiang & vilue & $K-1$ (a) & 430 & Uncultured Ascomycota & JX998707.1 & 90 \\
\hline & & & & & Ilyonectria sp. HB 1 & KP761755.1 & 99 \\
\hline P. dianthum & Translocated & Wide & R-30 (c) & 513 & Ilyonectria sp. HB 5 & KP761761.1 & 99 \\
\hline P. dianthum & Translocated & Wide & $\mathrm{R}-32$ & 522 & $\begin{array}{l}\text { Dendryphion nanum } \\
\text { Uncultured fungus }\end{array}$ & $\begin{array}{l}\text { GU934517.1 } \\
\text { JF433009.1 }\end{array}$ & $\begin{array}{l}87 \\
87\end{array}$ \\
\hline P. dianthum & Yachang & Wide & R-13(b) & 267 & $\begin{array}{l}\text { Uncultured } \\
\text { Tulasnellaceae } \\
\text { Uncultured }\end{array}$ & DQ925644.1 & 98 \\
\hline & & & & & $\begin{array}{l}\text { Tulasnellaceae } \\
\text { Uncultured }\end{array}$ & DQ925660.1 & 93 \\
\hline P. dianthum & Translocated & Wide & R-31(a) & 521 & $\begin{array}{l}\text { Trechisporales } \\
\text { Uncultured }\end{array}$ & КР053824.1 & 93 \\
\hline & & & & & $\begin{array}{l}\text { Trechisporales } \\
\text { Uncultured }\end{array}$ & JF691340.1 & 3 \\
\hline P. dianthum & Translocated & Wide & $\mathrm{R}-29$ & 473 & Basidiomycota & HM141051.1 & 90 \\
\hline & & & & & Uncultured Tomentella & JQ991890.1 & 90 \\
\hline & & & & & Uncultured Tomentella & JQ991890.1 & 90 \\
\hline P. dianthum & Yachang & Wide & $\mathrm{R}-17$ & 519 & $\begin{array}{l}\text { Thelephoraceae sp. } \\
\text { YM3050 }\end{array}$ & AB848634.1 & 89 \\
\hline P. hirsutissimum & Yachang & Wide & $\mathrm{R}-4(\mathrm{a})$ & 543 & Uncultured fungus & JX317181.1 & 93 \\
\hline
\end{tabular}




\begin{tabular}{|c|c|c|c|c|c|c|c|}
\hline \multirow[b]{3}{*}{ P. hirsutissimum } & \multirow[b]{3}{*}{ Translocated } & \multirow[b]{3}{*}{ Wide } & \multirow[b]{3}{*}{$\mathrm{R}-20(\mathrm{a})$} & \multirow[b]{3}{*}{499} & \multirow{2}{*}{$\begin{array}{l}\text { Uncultured fungus } \\
\text { Tulasnella calospora }\end{array}$} & \multirow{2}{*}{$\begin{array}{l}\text { JX317161.1 } \\
\text { JQ713576.1 }\end{array}$} & \multirow{2}{*}{$\begin{array}{l}93 \\
99\end{array}$} \\
\hline & & & & & & & \\
\hline & & & & & $\begin{array}{l}\text { Uncultured } \\
\text { Tulasnellaceae }\end{array}$ & JX545220.1 & 99 \\
\hline \multirow{3}{*}{ P. hirsutissimum } & \multirow{3}{*}{ Laya } & \multirow{3}{*}{ Wide } & \multirow{3}{*}{$\mathrm{R}-3$} & \multirow{3}{*}{461} & Tulasnella sp. & JQ713581.1 & 99 \\
\hline & & & & & Tulasnella sp. & JN253524.1 & 99 \\
\hline & & & & & Tulasnella sp. & JQ713581.1 & 99 \\
\hline P. hirsutissimum & Yachang & Wide & $\mathrm{R}-8$ & 461 & $\begin{array}{l}\text { Tulasnella calospora } \\
\text { isolate }\end{array}$ & GU166412.1 & 99 \\
\hline \multirow[t]{2}{*}{ P. hirsutissimum } & \multirow[t]{2}{*}{ Translocated } & \multirow[t]{2}{*}{ Wide } & \multirow[t]{2}{*}{$\mathrm{R}-19(\mathrm{a})$} & \multirow[t]{2}{*}{592} & $\begin{array}{l}\text { Uncultured } \\
\text { Tulasnellaceae clone }\end{array}$ & GQ241817.1 & 99 \\
\hline & & & & & Epulorhiza sp. & HM214462.1 & 99 \\
\hline \multirow[t]{3}{*}{ P. hirsutissimum } & \multirow[t]{3}{*}{ Laya } & \multirow[t]{3}{*}{ Wide } & \multirow[t]{3}{*}{$\mathrm{R}-2$} & \multirow[t]{3}{*}{461} & $\begin{array}{l}\text { Uncultured } \\
\text { Tulasnellaceae clone }\end{array}$ & GQ241863.1 & 99 \\
\hline & & & & & Tulasnella sp. & JQ713581.1 & 99 \\
\hline & & & & & Tulasnella sp. & JQ713581.1 & 99 \\
\hline P. hirsutissimum & Laya & Wide & $\mathrm{R}-1$ & 460 & $\begin{array}{l}\text { Uncultured } \\
\text { Tulasnellaceae clone }\end{array}$ & GQ241863.1 & 99 \\
\hline$P$ hircutiscimum & Lava & Wide & $R-5$ & 459 & Tulasnella sp. & JQ713581.1 & 99 \\
\hline P. hirsutissimum & Laya & Wide & $\mathrm{R}-\mathrm{S}$ & 459 & Tulasnella sp. & JN253524.1 & 99 \\
\hline & & & & & $\begin{array}{l}\text { Tulasnella calospora } \\
\text { strain }\end{array}$ & KT164600.1 & 99 \\
\hline P. hirsutissimum & Yachang & Wide & $\mathrm{R}-21$ & 337 & $\begin{array}{l}\text { Tulasnella calospora } \\
\text { isolate Shen }\end{array}$ & EF393621.1 & 99 \\
\hline & & & & & $\begin{array}{l}\text { Tulasnella calospora } \\
\text { isolate }\end{array}$ & GU166412.1 & 99 \\
\hline P. hirsutissimum & Laya & Wide & $\mathrm{R}-4(\mathrm{~b})$ & 511 & $\begin{array}{l}\text { Uncultured } \\
\text { Tulasnellaceae clone }\end{array}$ & GQ241863.1 & 99 \\
\hline$P$ hirsutissimum & Bangliang & Wide & $R-59(a)$ & 541 & Tulasnella sp. & JQ713581.1 & 99 \\
\hline & & & & 541 & Tulasnella sp. & JN253524.1 & 99 \\
\hline P. hirsutissimum & Yachang & Wide & $\mathrm{R}-7$ & 590 & $\begin{array}{l}\text { Uncultured } \\
\text { Tulasnellaceae clone }\end{array}$ & KF574226.1 & 85 \\
\hline & & & & & Tulasnella sp. & JQ713582.1 & 97 \\
\hline P. hirsutissimum & Translocated & Wide & $\mathrm{R}-22$ & 499 & Ceratobasidium sp. & GQ850444.1 & 94 \\
\hline
\end{tabular}




\begin{tabular}{|c|c|c|c|c|c|c|c|}
\hline & & & & & Ceratobasidium sp. & GQ850394.1 & 94 \\
\hline \multirow{2}{*}{ P. hirsutissimum } & \multirow{2}{*}{ Bangliang } & \multirow{2}{*}{ Wide } & \multirow{2}{*}{$\mathrm{R}-59(\mathrm{~b})$} & \multirow{2}{*}{505} & $\begin{array}{l}\text { Dendryphion nanum } \\
\text { isolate }\end{array}$ & КС989061.1 & 83 \\
\hline & & & & & $\begin{array}{l}\text { Dendryphion europaeum } \\
\text { strain }\end{array}$ & KJ869146.1 & 83 \\
\hline \multirow{2}{*}{ P. hirsutissimum } & \multirow{2}{*}{ Translocated } & \multirow{2}{*}{ Wide } & \multirow{2}{*}{$\mathrm{R}-18(\mathrm{a})$} & \multirow{2}{*}{466} & Ilyonectria sp. Isolate & KT264362.1 & 100 \\
\hline & & & & & Ilyonectria sp. Isolate & KT264361.1 & 100 \\
\hline \multirow{3}{*}{ P. hirsutissimum } & \multirow{2}{*}{ Translocated } & \multirow{3}{*}{ Wide } & \multirow{2}{*}{$\mathrm{R}-18(\mathrm{~b})$} & \multirow{2}{*}{545} & $\begin{array}{l}\text { Uncultured mycorrhizal } \\
\text { fungus genes }\end{array}$ & AB506830.1 & 88 \\
\hline & & & & & $\begin{array}{l}\text { Uncultured } \\
\text { Tulasnellaceae clone }\end{array}$ & JF691226.1 & 78 \\
\hline & \multirow{3}{*}{ Yachang } & & \multirow{3}{*}{$\mathrm{R}-10$} & \multirow{3}{*}{510} & Tulasnella sp. & JQ713581.1 & 98 \\
\hline \multirow[t]{2}{*}{ P. hirsutissimum } & & \multirow[t]{2}{*}{ Wide } & & & $\begin{array}{l}\text { Uncultured } \\
\text { Tulasnellaceae clone }\end{array}$ & GQ241863.1 & 98 \\
\hline & & & & & Knufia tsunedae FMR & NR_132842.1 & 97 \\
\hline P. hirsutissimum & Translocated & Wide & $\mathrm{R}-19(\mathrm{~b})$ & 457 & $\begin{array}{l}\text { Knufia tsunedae genomic } \\
\text { DNA }\end{array}$ & HG003669.1 & 97 \\
\hline \multirow[t]{3}{*}{ P. hirsutissimum } & \multirow[t]{3}{*}{ Bangliang } & \multirow[t]{3}{*}{ Wide } & \multirow[t]{3}{*}{$\mathrm{R}-54(\mathrm{a})$} & \multirow[t]{3}{*}{566} & $\begin{array}{l}\text { Uncultured Tulasnella } \\
\text { clone }\end{array}$ & HM230650.1 & 79 \\
\hline & & & & & Epulorhiza sp. & DQ068773.1 & 79 \\
\hline & & & & & Cylindrocarpon sp. & KF631448.1 & 73 \\
\hline \multirow[t]{2}{*}{ P. hirsutissimum } & \multirow[t]{2}{*}{ Translocated } & \multirow[t]{2}{*}{ Wide } & \multirow[t]{2}{*}{$\mathrm{R}-20(\mathrm{~b})$} & \multirow[t]{2}{*}{471} & $\begin{array}{l}\text { Cylindrocarpon olidum } \\
\text { strain }\end{array}$ & KC427019.1 & 73 \\
\hline & & & & & Auricularia scissa & NR_125807.1 & 98 \\
\hline P. hirsutissimum & Bangliang & Wide & R-54(b) & 525 & $\begin{array}{l}\text { Uncultured } \\
\text { Basidiomycota }\end{array}$ & HM162319.1 & 98 \\
\hline P. hirsutissimum & Translocated & Wide & $\mathrm{R}-31(\mathrm{~b})$ & 537 & $\begin{array}{l}\text { Tulsnella sp. M-11 } \\
\text { Uncultured } \\
\text { Tulasnellaceae }\end{array}$ & JQ713581.1 & $\begin{array}{l}99 \\
99\end{array}$ \\
\hline
\end{tabular}




\begin{tabular}{|lccccc|}
\hline Site & $\begin{array}{c}\text { No. of } \\
\text { plants }\end{array}$ & $\begin{array}{c}\text { No. of OM } \\
\text { sequences }\end{array}$ & $\begin{array}{c}\text { Species } \\
\text { richness }\end{array}$ & $\boldsymbol{H}^{\boldsymbol{}}$ & $\boldsymbol{J}^{\boldsymbol{}}$ \\
\hline Narrow species & & & & & \\
Orchid garden & 6 & 4 & 4 & 1.386 & 0.999 \\
Dingshu & 6 & 3 & 2 & 0.636 & 0.918 \\
Mulun & 5 & 1 & 1 & 0.693 & 0.00 \\
Jingxi & 5 & 0 & 0 & 0 & 00.00 \\
& $\mathbf{2 2}$ & $\mathbf{8}$ & $\mathbf{7}$ & $\mathbf{0 . 5 0 5}$ & $\mathbf{0 . 4 7 9}$ \\
& & & & & \\
Wide species & 21 & 20 & 17 & 2.762 & 0.921 \\
Orchid garden & 5 & 5 & 1 & 0 & 0.00 \\
Laya & 6 & 3 & 3 & 1.098 & 0.999 \\
Bangliang & $\mathbf{3 2}$ & $\mathbf{2 8}$ & $\mathbf{2 1}$ & $\mathbf{1 . 2 8}$ & $\mathbf{0 . 6 4 0}$ \\
& & & & & \\
\end{tabular}

Table 4.2 Number of OM sequences identified in from narrow and wide range elevational orchid species at six sites. $H^{\prime}=$ Shannon-Weiner diversity index and $J^{\prime}=$ the evenness index. Numbers in bold represent mean $\left(H^{\prime}\right)$ and $\left(J^{\prime}\right)$ values.

\begin{tabular}{|lccccc|}
\hline Site & $\begin{array}{c}\text { No. of } \\
\text { plants }\end{array}$ & $\begin{array}{c}\text { No. of OM } \\
\text { sequences }\end{array}$ & $\begin{array}{c}\text { Species } \\
\text { richness }\end{array}$ & $\boldsymbol{H}^{\mathbf{}}$ & $\boldsymbol{J}^{\mathbf{}}$ \\
\hline Natural & & & & & \\
Orchid garden & 11 & 8 & 5 & 1.494 & 0.928 \\
Laya & 5 & 6 & 2 & 0.450 & 0.650 \\
Dingshu & 6 & 1 & 1 & 0.00 & 0.00 \\
Mulun & 5 & 2 & 2 & 0.00 & 0.00 \\
Jingxi & 5 & 0 & 0 & 0.00 & 0 \\
Bangliang & 6 & 1 & 3 & 1.099 & 1.0 \\
& $\mathbf{4 0}$ & $\mathbf{1 8}$ & $\mathbf{1 3}$ & $\mathbf{0 . 5 1 3}$ & $\mathbf{0 . 4 2 9}$ \\
Translocated & & & & & \\
Orchid garden & $\mathbf{1 5}$ & $\mathbf{1 8}$ & $\mathbf{1 6}$ & $\mathbf{2 . 6 3 0}$ & $\mathbf{0 . 9 4 8}$ \\
\hline
\end{tabular}

Table 4.3 Number of OM sequences identified from four orchid species at seven natural and one translocated sites. $H^{\prime}=$ Shannon-Weiner diversity index and $J^{\prime}=$ the evenness index. Numbers in bold represent mean $\left(H^{\prime}\right)$ and $\left(J^{\prime}\right)$ values. 


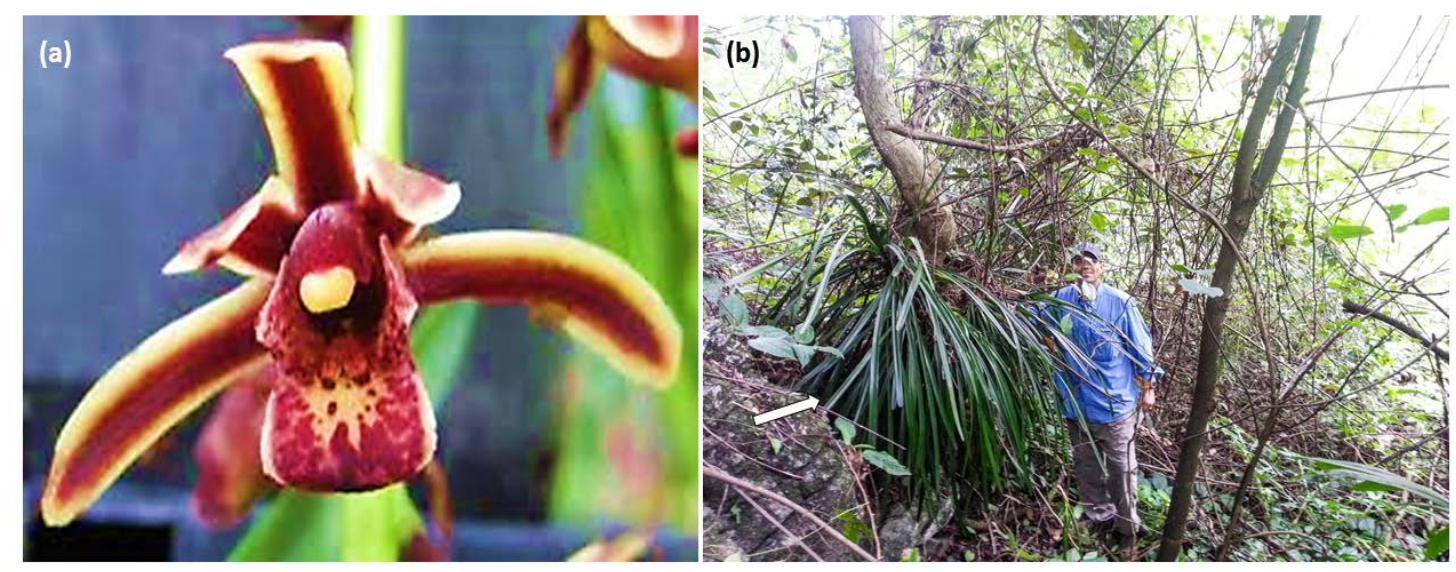

Fig. 4.1 Plates showing Cymbidium bicolor flower (a), and plate (b) shows a large plant growing epiphytically at Mulun Nature Reserve in Guangxi Province. 

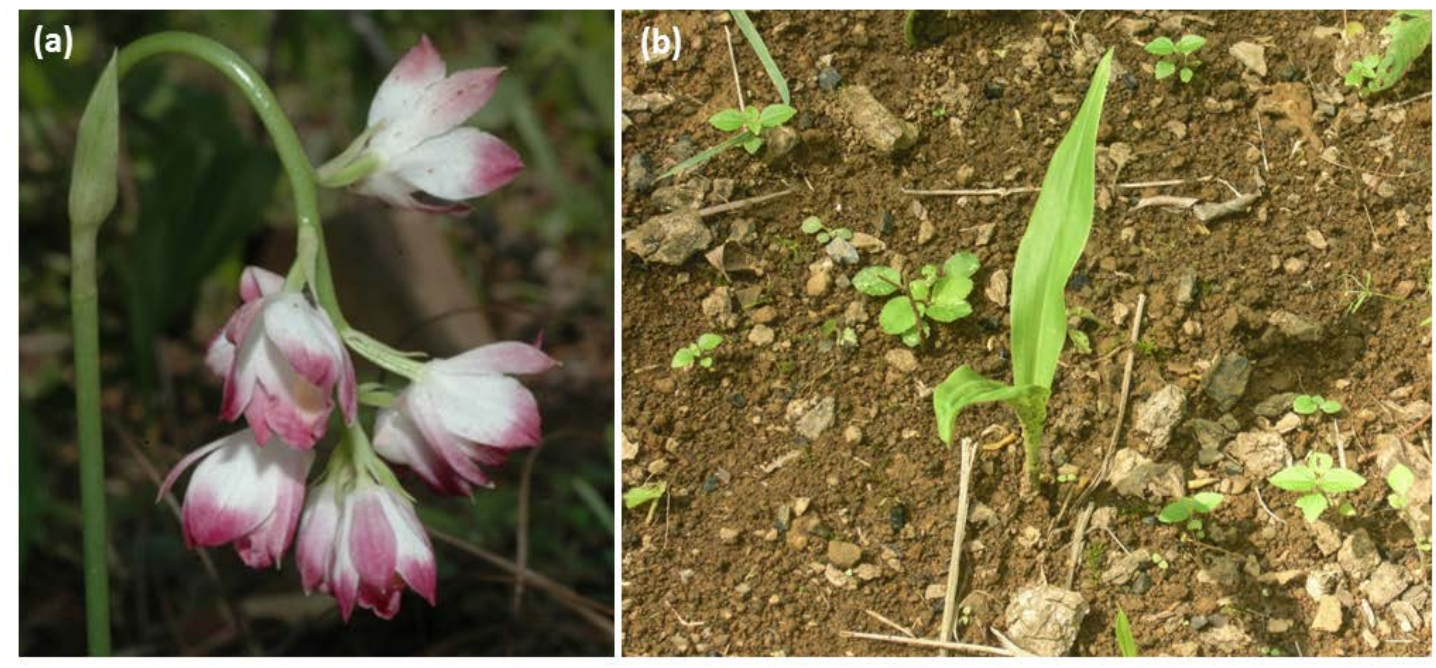

Fig. 4.2 Plates showing Geodorum eulophioides flowers (a) and translocated plant at Yachang Reserve (b). 


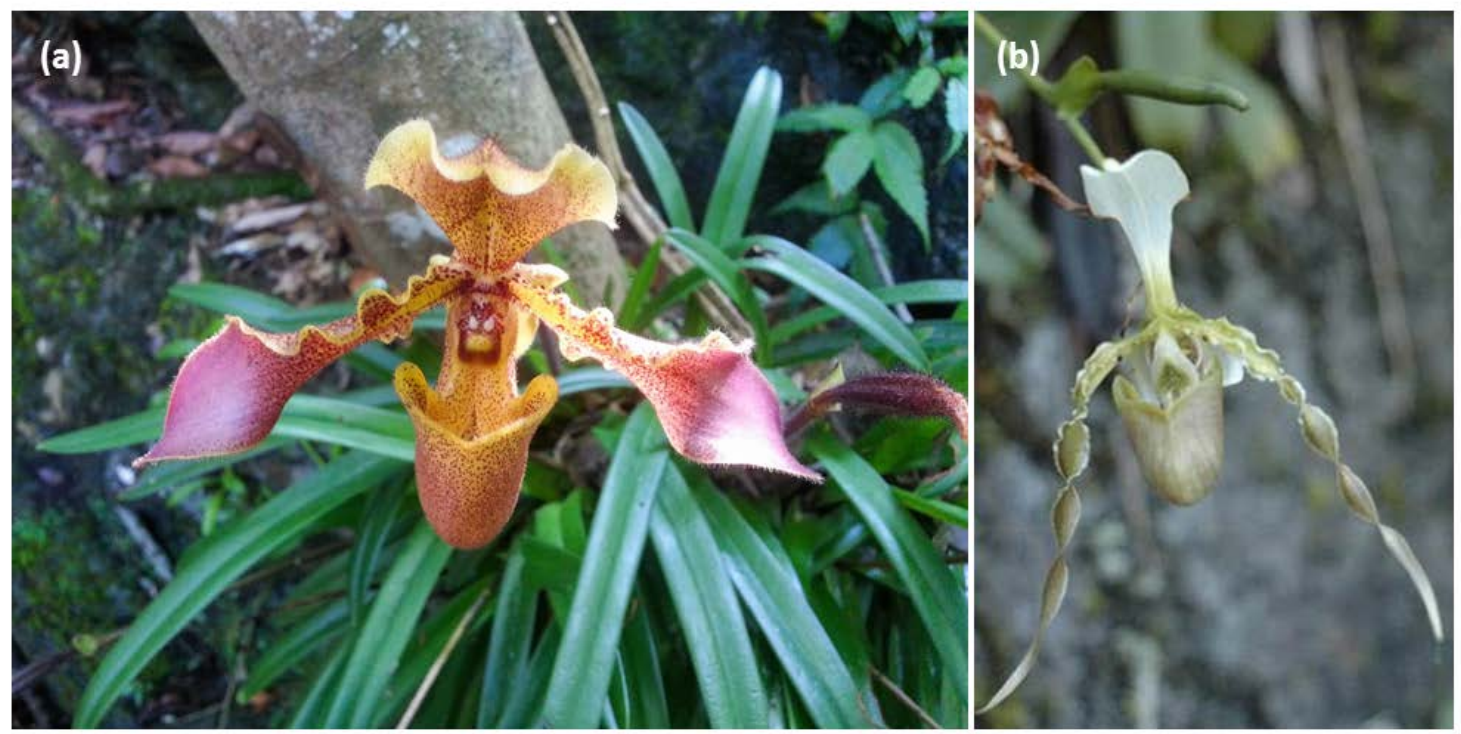

Fig. 4.3 Plates showing the flowers of Paphiopedilum hirsutissimum (a) and Paphiopedilum dianthum (b). 


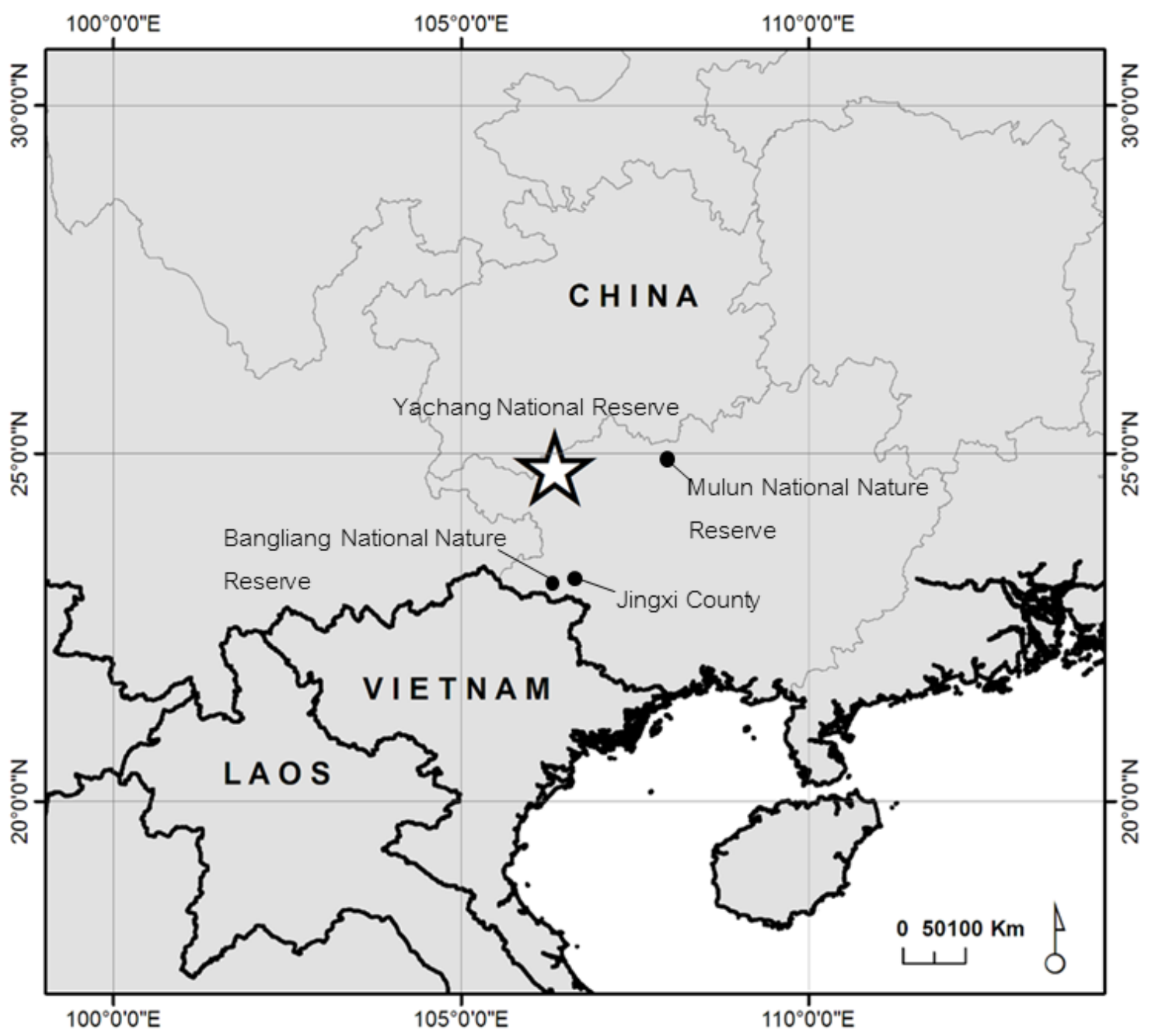

Fig. 4.4 Map showing studies site in Guangxi Province, China. Star show the Yachang National Reserve which includes the orchid garden and Laya cliffs natural sites, and the translocated site. Black dots show three low elevation natural sites sampled in the region. 


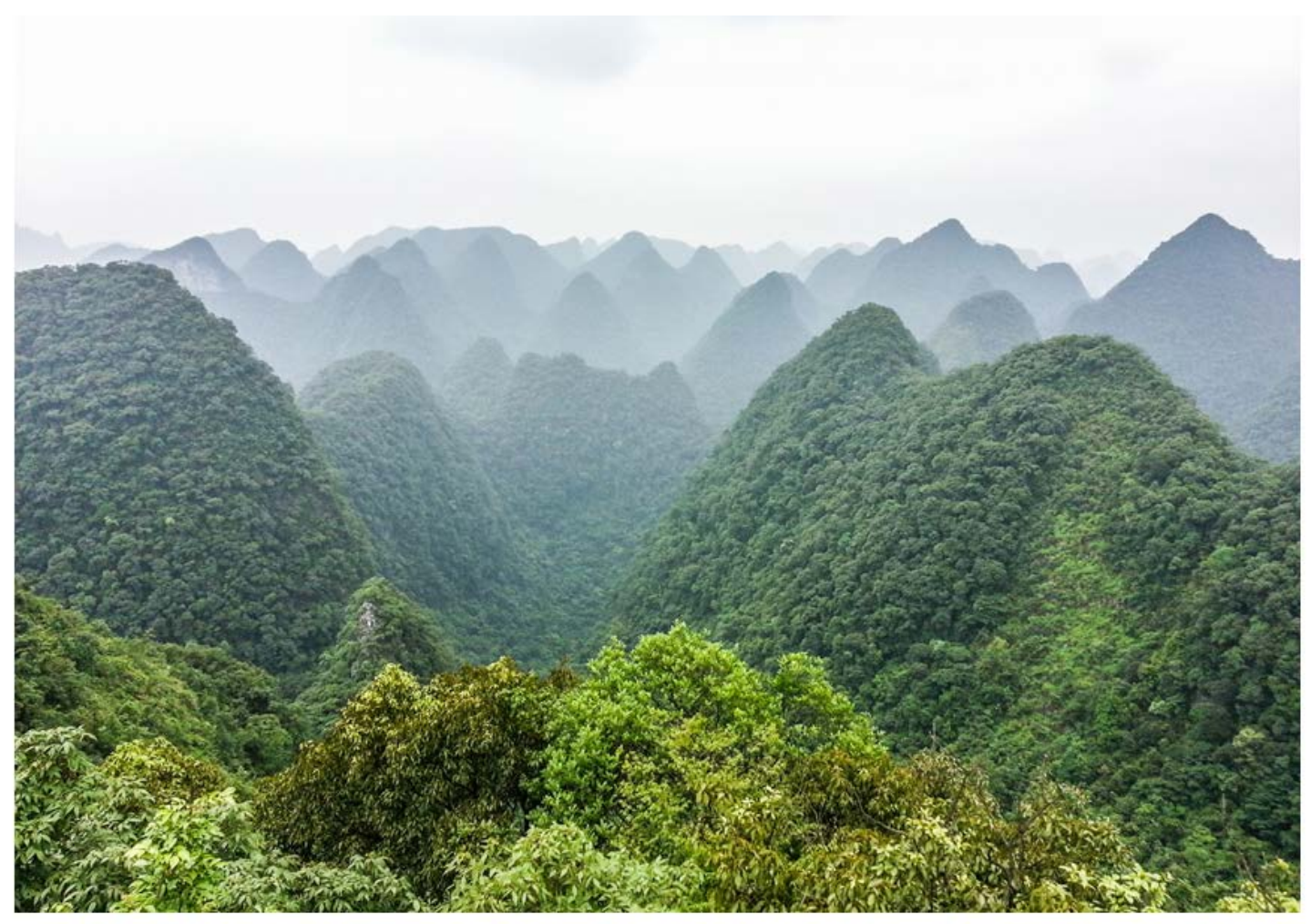

Fig. 4.5 Plate showing the limestone mountains and subtropical forests in Guangxi Province, China. Photo shows the Huanjiang Karst cluster which is part of the South China Karst formation. 


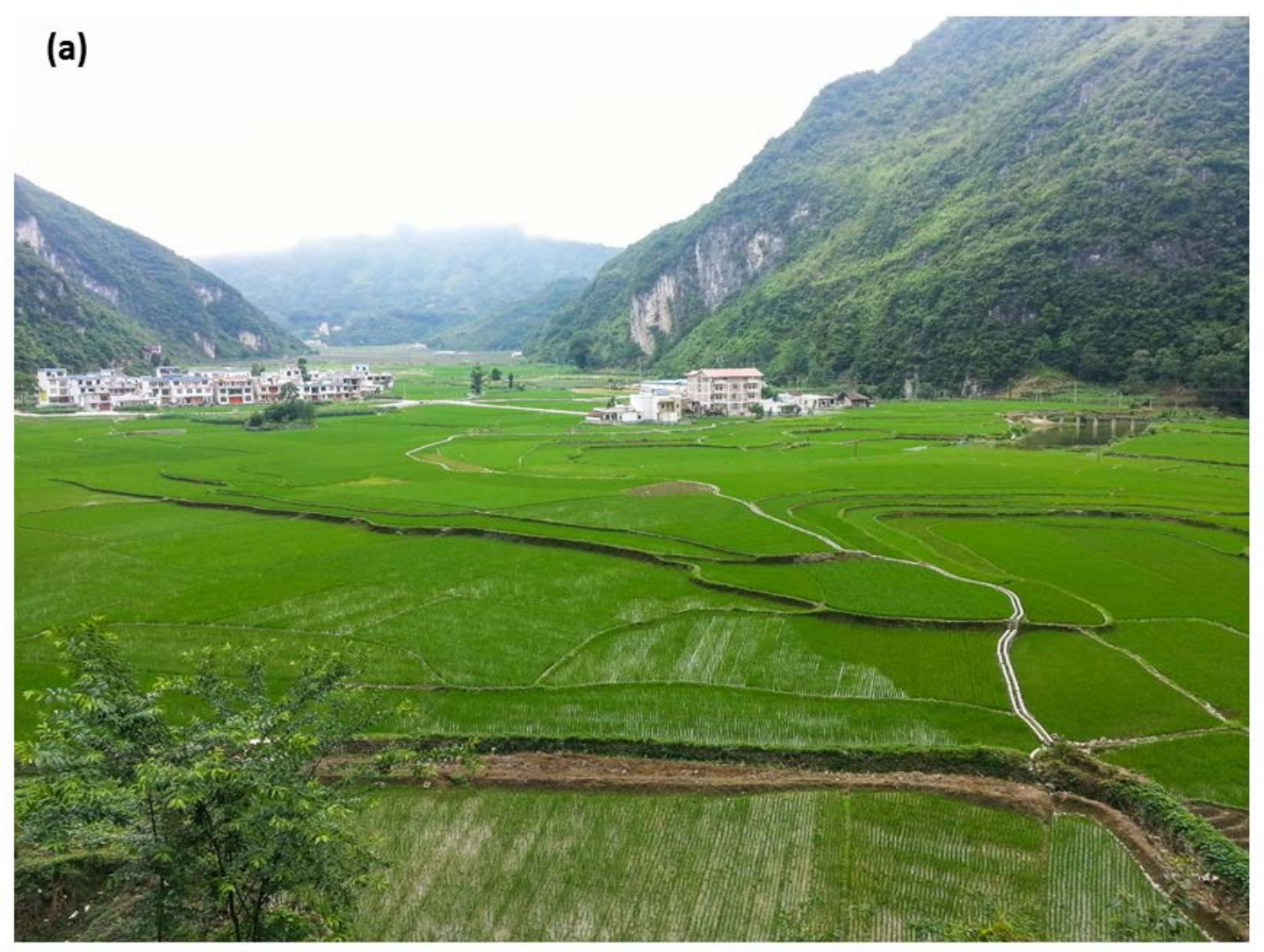

Fig. 4.6 Plate showing a village near Yachang National Nature Reserve in Leye County, Guangxi Province, China. 


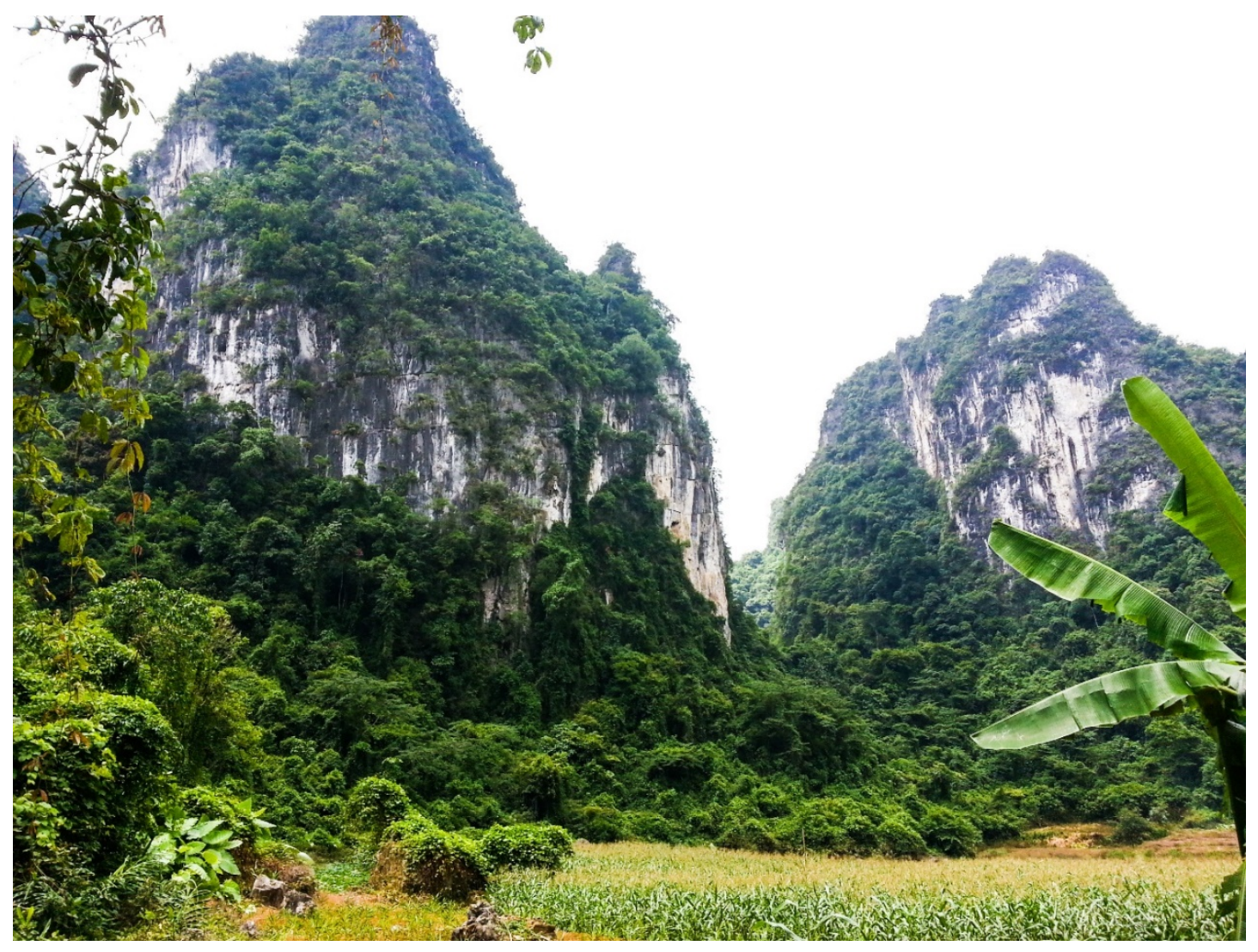

Fig. 4.7 Plate showing the Karst Formations in Guangxi Province, China; a world Karst Heritage Site. 


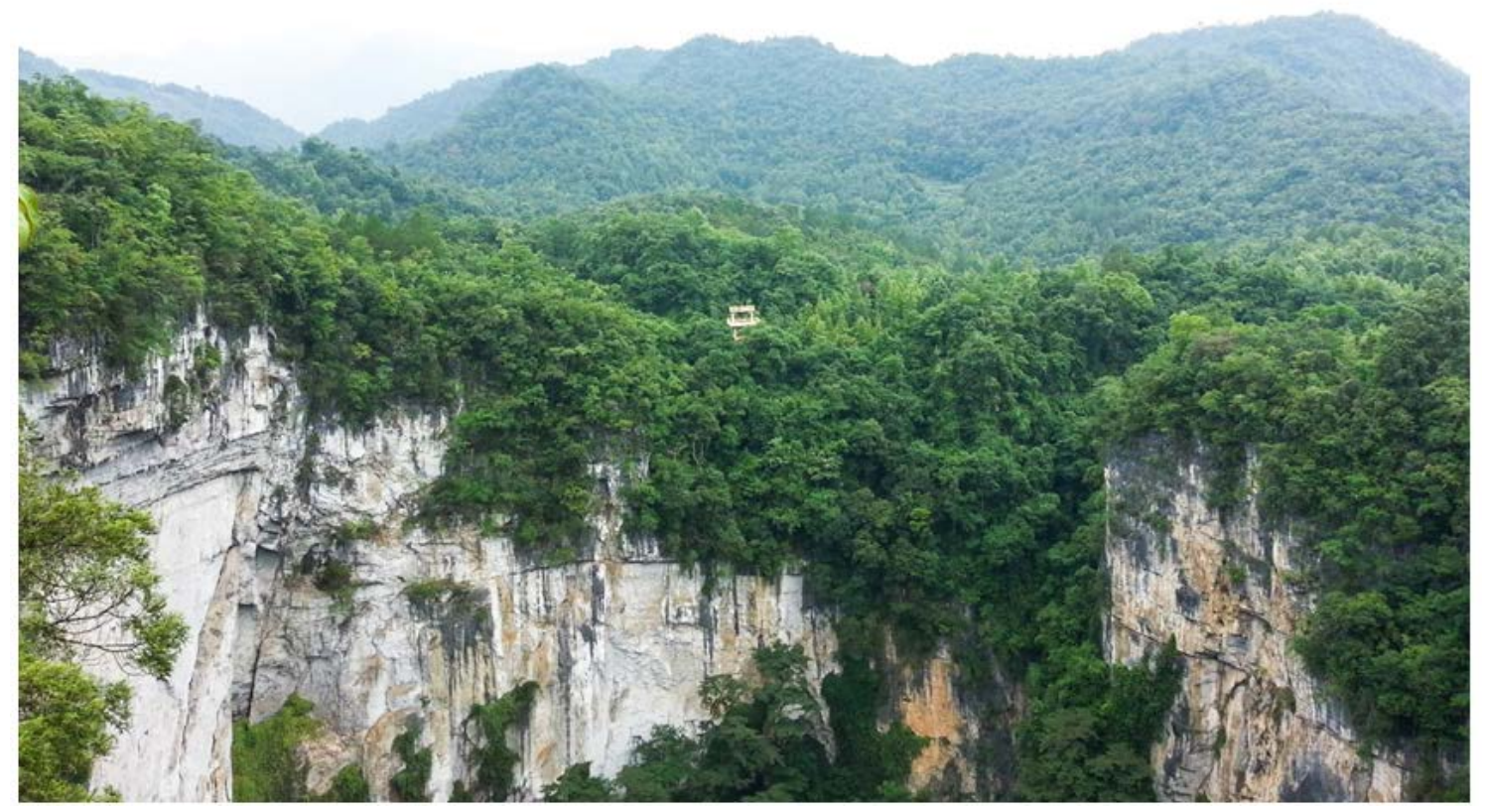

Fig. 4.8 Plate showing the limestone cliffs at the Laya site at Yachang National Nature Reserve. 
Outgroup_Asco and Basidio Trees_gi|14270349|emb|AJ276079.2|

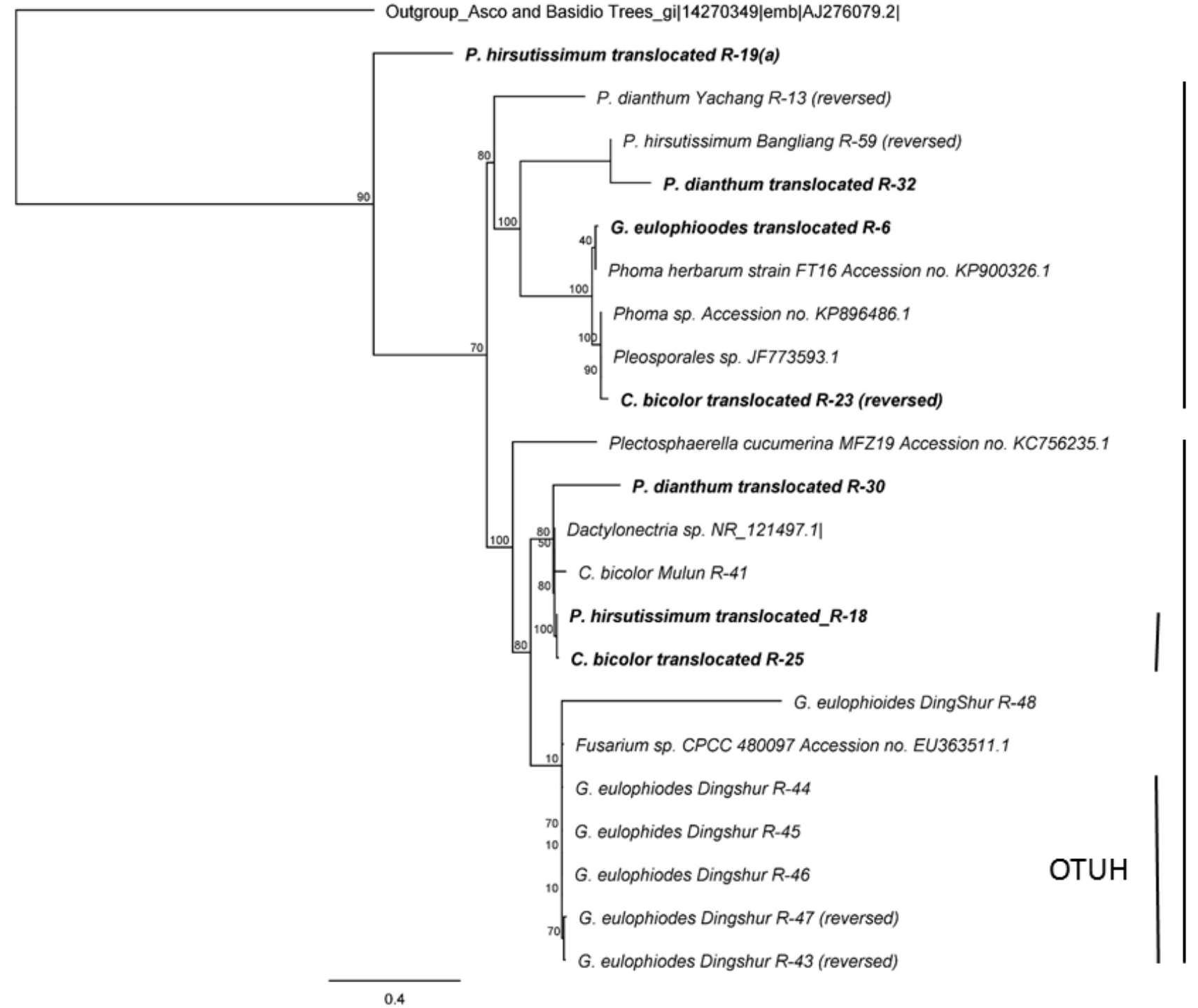

Pleosporales

Hypocreales 
Fig. 4.9 Maximum- likelihood trees (500 bootstraps) of ITS sequences of Ascomycete fungi isolated from four translocated orchid species, Geodorum eulophioides and Cymbidium bicolor (narrow elevational ranges), and Paphiopedilum dianthum and Paphiopedilum hirsutissimum (wide elevational ranges) in Guangxi Province. Topology shows the fungal relationships between these species and their relative associations with putative orchid mycorrhizal groups (OTUH). Sequences in bold an italics represent translocated plants. Numbers indicate bootstrapping percentage supporting the branches. 


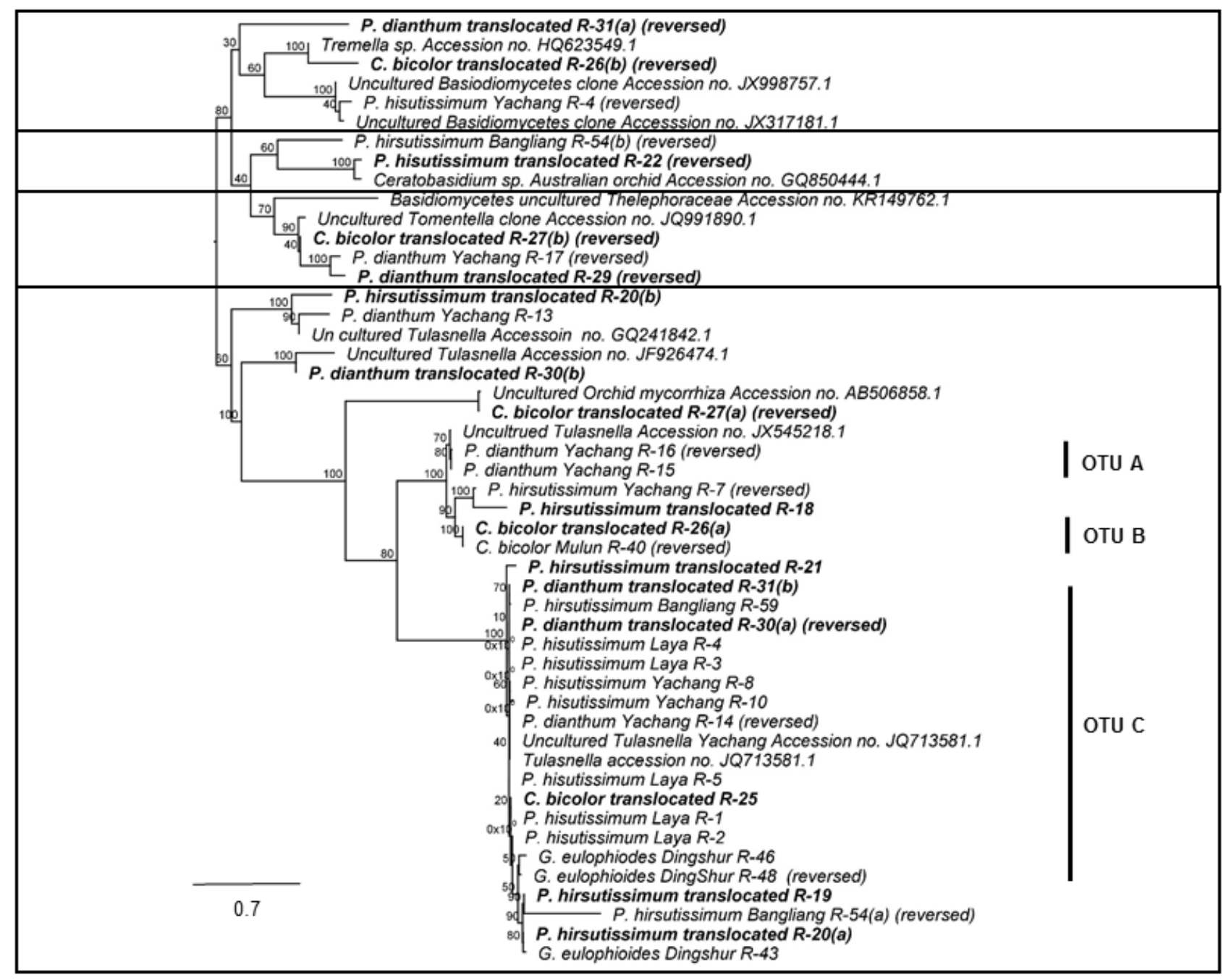

Tremellaceae

\section{Ceratobasidiaceae}

Thelephoraceae

Tulasnellaceae

Fig. 4.10 Maximum- likelihood trees (500 bootstraps) of ITS sequences of Rhizoctonia fungi isolated from four translocated orchid species, Geodorum eulophioides and Cymbidium bicolor (narrow elevational ranges), and Paphiopedilum dianthum and 
Paphiopedilum hirsutissimum (wide elevational ranges) in Guangxi Province. Topology shows the fungal relationships between these species and their relative associations with putative orchid mycorrhizal groups Tremellaceae, Ceratobasidiaceae, Thelephoraceae, and Tulasnellaceae (OTUs A, B, and C). Sequences in bold an italics represent translocated plants. Numbers indicate bootstrapping percentage supporting the branches. 
Natural Populations

a)

$\mathrm{N}=6, \mathrm{n}=9$

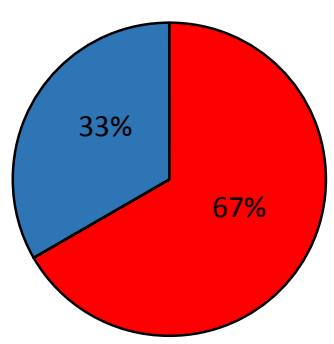

c)

$\mathrm{N}=10, \mathrm{n}=2$

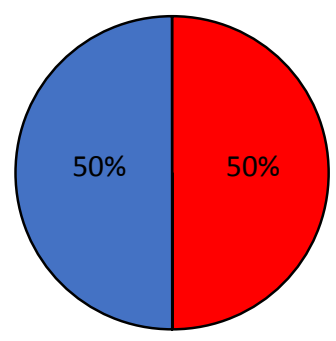

e)

$\mathrm{N}=5, \mathrm{n}=6$

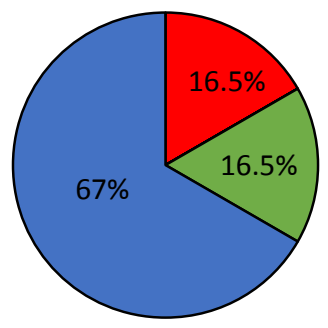

g)

$N=22, n=6$

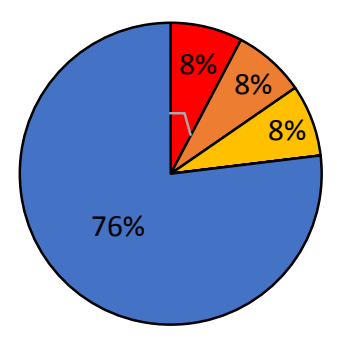

Translocated Populations

b)

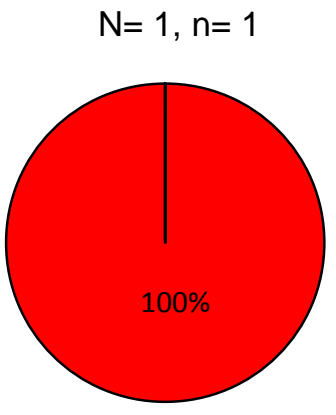

d)

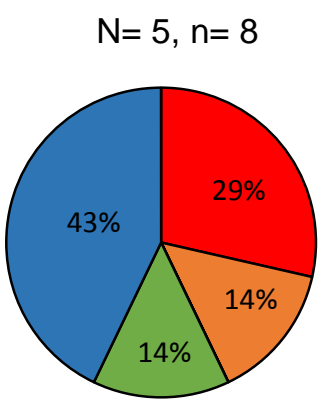

f)

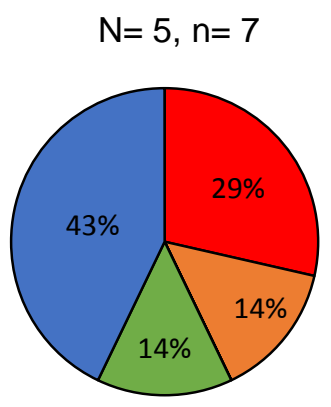

h)

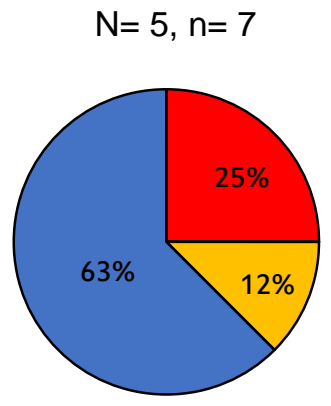


Fig. 4.11 Pie charts showing fungal sequences breakdowns for all natural (a, c, e, and g) and translocated (b, d, f, and h) populations. Species included Geodorum eulophioides (a and b) and Cymbidium bicolor (c and d), Paphiopedilum dianthum (e and f) and Paphiopedilum hirsutissimum ( $\mathrm{g}$ and $\mathrm{h}$ ). $\mathrm{N}=$ number of plants samples, and $\mathrm{n}=$ total number of sequences. 


\section{Natural Populations}

(a)

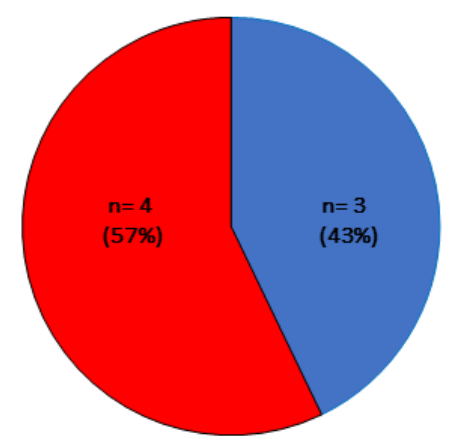

(c)

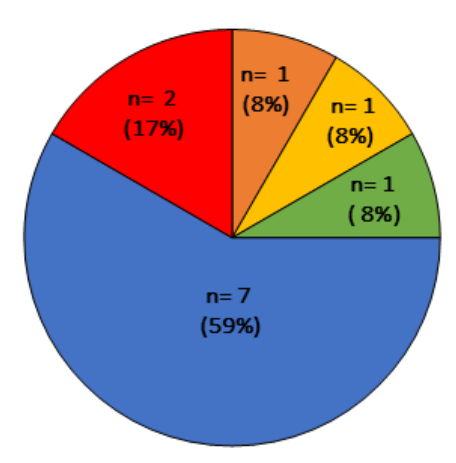

(b)

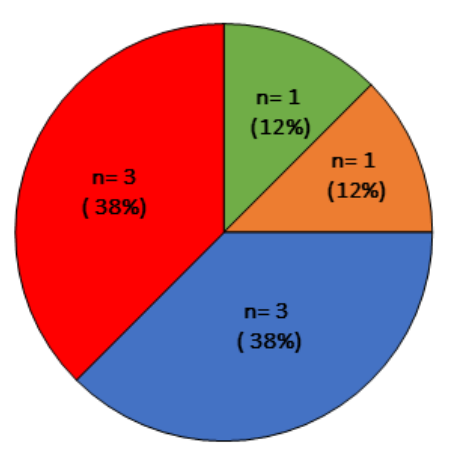

(d)

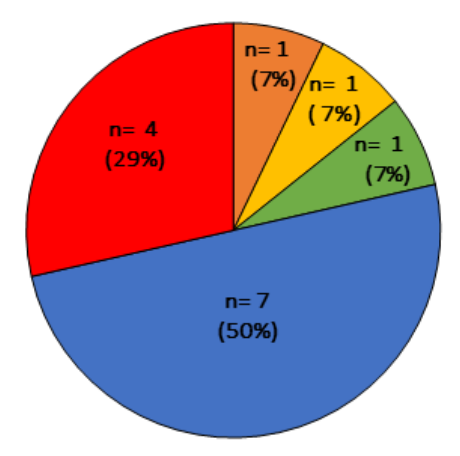

Fig. 4.12 Pie charts showing the combined differences in fungal communities for the natural and translocated poulations; narrow elevational species ( $\mathrm{a}$ and $\mathrm{b}$ ) and wide elevational species ( $\mathrm{c}$ and $\mathrm{d}$ ) populations. $\mathrm{N}=$ number of plants samples, and $\mathrm{n}=$ total number of sequences. 


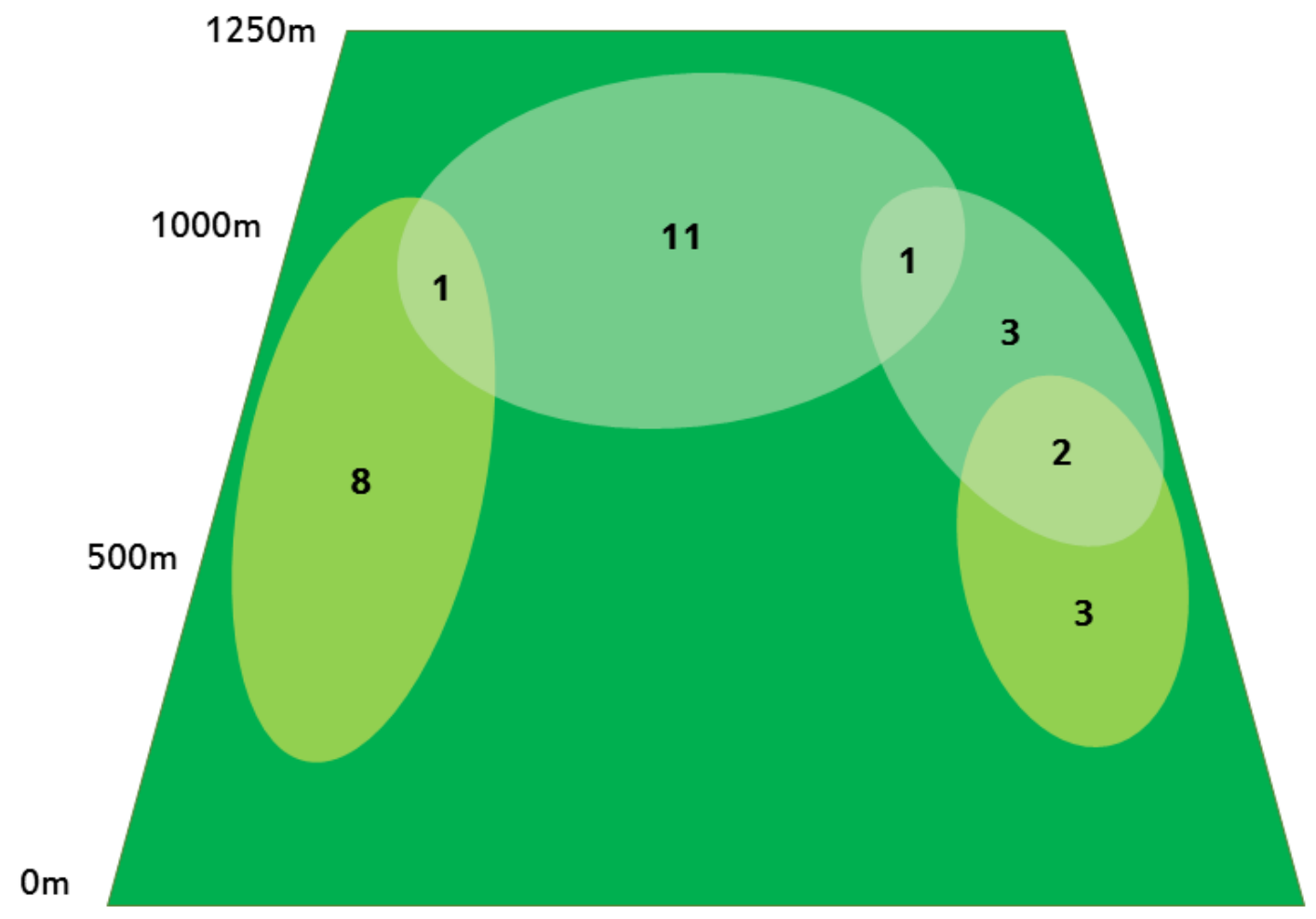

Fig. 4.13 Venn diagrams showing the total number of unique mycorrhizal OTUs detected for wide elevational species (large ovals) and narrow elevational species (small ovals). Blue-green ovals represent translocated site, and the lighter green ovals represents all natural sites combined. Numbers on y-axis repesent elevational ranges for each of the population types. 


\section{REFERENCES}

Batty, A. L., Dixon, K. W., Brundrett, M., \& Sivasithamparam, K. (2001). Constraints to symbiotic germination of terrestrial orchid seed in a Mediterranean bushland. New Phytologist, 152(3), 511-520.

Bidartondo, M.I., \& Read, D.J. (2008). Fungal specificity bottlenecks during orchid germination and development. Molecular Ecology, 17(16), 3707-3716.

Binder, M., Hibbett, D. S., Larsson, K. H., Larsson, E., Langer, E., \& Langer, G. (2005). The phylogenetic distribution of resupinate forms across the major clades of mushroom-forming fungi (Homobasidiomycetes). Systematics and Biodiversity, 3(02), 113-157.

Caldwell, B. A., Castellano, M. A., \& Griffiths, R. P. (1991). Fatty acid esterase production by ectomycorrhizal fungi. Mycologia, 83(2), 233-236.

Chang, C., Hu, W. H., Chen, Y. C., Su, Y. L., \& Chiu, Y. T. (2010). In vitro flowering and mating system of Eulophia graminea Lindl. Bot Stud, 51, 357-362.

Compant, S., Van Der Heijden, M. G., \& Sessitsch, A. (2010). Climate change effects on beneficial plant-microorganism interactions. FEMS microbiology ecology, 73(2), 197-214.

Cribb, P. J., Kell, S. P., Dixon, K. W., \& Barrett, R. L. (2003). Orchid conservation: a global perspective. In Dixon, K. W., Kell, S. P., Barrett, R. L., and Cribb P. J. Eds. Orchid Conservation. Natural History Publications, Kota Kinabalu, Sabah, 124.

Dearnaley, J. D. W., Martos, F., \& Selosse, M. A. (2012). 12 Orchid Mycorrhizas: Molecular Ecology, Physiology, Evolution and Conservation Aspects. In Fungal associations (pp. 207-230). Springer Berlin Heidelberg.

Dressler, R. L. (1993). Phylogeny and classification of the orchid family. Cambridge University Press.

Faith, D. P. (1992). Conservation evaluation and phylogenetic diversity. Biological conservation, 61(1), 1-10.

Fitter, A. H., Heinemeyer, A., \& Staddon, P. L. (2000). The impact of elevated CO2 and global climate change on arbuscular mycorrhizas: a mycocentric approach. New Phytologist, 147(1), 179-187. 
Gardes, M., \& Bruns, T. D. (1993). ITS primers with enhanced specificity for basidiomycetes-application to the identification of mycorrhizae and rusts. Molecular ecology, 2(2), 113-118.

Hewitt, N., Klenk, N., Smith, A. L., Bazely, D. R., Yan, N., Wood, S., \& Henriques, I. (2011). Taking stock of the assisted migration debate. Biological Conservation, 144(11), 2560-2572.

Hoegh-Guldberg, O., Hughes, L., McIntyre, S., Lindenmayer, D. B., Parmesan, C., Possingham, H. P., \& Thomas, C. D. (2008). Assisted colonization and rapid climate change. Science, 321(5887), 345-346.

Huang, B. Q., Yang, X. Q., Yu, F. H., Luo, Y. B., \& Tai, Y. D. (2008). Surprisingly high orchid diversity in travertine and forest areas in the Huanglong valley, China, and implications for conservation. Biodiversity and conservation, 17(11), 2773-2786.

Huang, C.-B., Chen, J.-L., Feng, C.-L., Lu, Z.-F., Li, J.-X., 2008. Characteristics of climatevertical distribution in Yachang Orchid Nature Reserve. J. Northwest Forestry University 23 (5), 39-43 (in Chinese with English abstract).

Hunter, M. L. (2007). Climate change and moving species: furthering the debate on assisted colonization. Conservation Biology, 21(5), 1356-1358.

Jacquemyn, H., Brys, R., Lievens, B., \& Wiegand, T. (2012). Spatial variation in belowground seed germination and divergent mycorrhizal associations correlate with spatial segregation of three co-occurring orchid species. Journal of Ecology, 100(6), 1328-1337.

Kearse, M., Moir, R., Wilson, A., Stones-Havas, S., Cheung, M., Sturrock, S., Buxton, S., Cooper, A., Markowitz, S., Duran, C., Thierer, T., Ashton, B., Mentjies, P., \& Drummond, A. (2012). Geneious Basic: an integrated and extendable desktop software platform for the organization and analysis of sequence data. Bioinformatics, 28(12), 1647-1649.

Kembel, S. W., Cowan, P. D., Helmus, M. R., Cornwell, W. K., Morlon, H., Ackerly, D. D., \& Webb, C. O. (2010). Picante: R tools for integrating phylogenies and ecology. Bioinformatics, 26(11), 1463-1464.

Liu, H., \& Stiling, P. (2006). Testing the enemy release hypothesis: a review and metaanalysis. Biological Invasions, 8 (7):1535-1545.

Liu, H., Stiling, P., \& Pemberton, R. W. (2007). Does enemy release matter for invasive plants? Evidence from a comparison of insect herbivore damage among invasive, non-invasive and native congeners. Biological Invasions, 9 (7):773-781. 
Liu, H., \& Pemberton, R. (2010). Pollination of an invasive orchid, Cyrtopodium polyphyllum (Orchidaceae), by an invasive oil-collecting bee, Centris nitida, in southern Florida. Botany, 88 (3):290-295.

Liu, H., Feng, C. L., Luo, Y. B., Chen, B. S., Wang, Z. S., \& Gu, H. Y. (2010). Potential challenges of climate change to orchid conservation in a wild orchid hotspot in southwestern China. The Botanical Review, 76(2), 174-192.

Liu, H., Feng, C., Chen, B., Wang, Z, Xie, X., Deng, Z., Wei, X., Liu, S., Zhang, Z., \& Luo, Y. (2012). Overcoming extreme weather challenges: Successful but variable assisted colonization of wild orchids in southwestern china. Biological Conservation. 150 (1):68-75.

Liu, H., Feng, C., Xie, X., Lin, W., Deng, Z., Wei, X., Liu, S., \& Luo, Y. (2014). Impacts of extreme weather on flowering phenology of wild orchids in southwestern China. In Darwin's Orchids—-Now and then, Bernhardt, P. and R. Meier (Eds.) University of Chicago, Chicago. 311-327.

Liu, H., Feng, C. L., Chen, B. S., Wang, Z. S., Xie, X. Q., Deng, Z. H., \& Luo, Y. B. (2012).

Overcoming extreme weather challenges: Successful but variable assisted colonization of wild orchids in southwestern China. Biological Conservation, 150(1), 68-75.

Luo, Y., Jia, J., \& Wang, C. (2002). A general review of the conservation status of Chinese orchids. Chinese Biodiversity, 11(1), 70-77.

McCormick M.K., Whigham D.F., \& O'Neill J. (2004). Mycorrhizal diversity in photosynthetic terrestrial orchids. New Phytologist 163, 425-438.

McCormick, M.K., Whigham, D.F., Sloan, D., O'Malley, K., \& Hodkinson, B. (2006). Orchid-fungus fidelity: A marriage meant to last? Ecology, 87(4), 903-911.

McCormick, M.K., Whigham, D.F., O’Neill, J.P., Becker, J.A., Werner, S., Rasmussen, H.N., Bruns, T.D., \& Taylor, D.L. (2009). Abundance and distribution of Corallorhiza odontorhiza reflect variations in climate and ectomycorrhizae. Ecological Monographs, 79(4), 19-635.

McCormick, M. K., Taylor, D. L., Juhaszova, K., Burnett, R. K., Jr., Whigham, D. F., \& O'Neill, J. P. (2012). Limitations on orchid recruitment: Not a simple picture. Molecular Ecology, 21(6), 1511-1523.

McLachlan, J. S., Hellmann, J. J., \& Schwartz, M. W. (2007). A framework for debate of assisted migration in an era of climate change. Conservation Biology, 21(2), 297302. 
Minteer, B. A., \& Collins, J. P. (2010). Move it or lose it? The ecological ethics of relocating species under climate change. Ecological Applications, 20(7), 18011804.

Mitchell, C.E., Agrawal, A.A., Bever, J.D., Gilbert, G.S., \& Hufbauer, R.A. (2006). Biotic interactions and plant invasions. Ecology Letters, 9, 726-40.

Moncalvo, J. M., Nilsson, R. H., Koster, B., Dunham, S. M., Bernauer, T., Matheny, P. B., \& Danell, E. (2006). The cantharelloid clade: dealing with incongruent gene trees and phylogenetic reconstruction methods. Mycologia, 98(6), 937-948. Pemberton, R. W. (2010). Biotic resource needs of specialist orchid pollinators. The Botanical Review, 76(2), 275-292.

Pemberton, R. W., Collins, T. M., \& Koptur, S. (2008). An Asian orchid, Eulophia graminea (Orchidaceae: Cymbidieae), naturalizes in Florida. Lankesteriana.

Pringle, A., Bever, J. D., Gardes, M., Parrent, J. L., Rillig, M. C., \& Klironomos, J. N. (2009). Mycorrhizal symbioses and plant invasions. Annual Review of Ecology Evolution and Systematics, 40, 699-715.

Rasmussen, H. N. (1995). Terrestrial orchids: from seed to mycotrophic plant. Cambridge University Press.

Rasmussen, H.N., \& Whigham, D.F. (1998). The underground phase: a special challenge in studies of terrestrial orchid populations. Botanical Journal of the Linnean Society, 126, 49-64.

Ricciardi, A., \& Simberloff, D. (2009). Assisted colonization is not a viable conservation strategy. Trends in Ecology \& Evolution, 24(5), 248-253.

Reichard, S., H. Liu, and C. Husby. 2012. Is managed Relocation another pathway of biological invasion? In Managing Eden: Plant Reintroduction’s Promises, Perils, and Uses in a Changing Climate. J. Maschinski and K. E. Haskins (editors) Island Press, Washington D.C. pp243-262.

Richardson, D., Allsopp, N., D'Antonio, C., Milton, S., \& Rejmanek, M. (2000). Plant invasions - the role of mutualisms. Biological Reviews, 75(1), 65-93.

Shi, J., J. Cheng, D. Luo, S.Y. Liu, H.S. Tan, \& Y.B. Luo. (2007). An orchid paradise: The Yachang Orchid Nature Reserve, in Guangxi, China. Orchid Review, 115:188-195.

Stone, R. (2010). Home, home outside the range. Science, 329(5999), 1592-1594. 
Suarez, J. P., Weiss, M., Abele, A., Garnica, S., Oberwinkler, F., \& Kottke, I. (2006). Diverse tulasnelloid fungi form mycorrhizas with epiphytic orchids in an Andean cloud forest. Mycological Research, 110, 1257-1270.

Suarez, J.P., Weiss, M., Abele, A., Oberwinkler, F., \& Kottke, I. (2008). Members of Sebacinales subgroup B form mycorrhizae with epiphytic orchids in a neotropical mountain rain forest. Mycological Progress, 7(2), 75-85.

Swarts, N. D., Sinclair, E. A., Francis, A., \& Dixon, K. W. (2010). Ecological specialization in mycorrhizal symbiosis leads to rarity in an endangered orchid. Molecular Ecology, 19(15), 3226-3242.

Taylor, D.L. (2004). Myco-heterotroph-fungus marriages - is fidelity over-rated? New Phytologist, 163(2), 217-221.

Taylor, D. L., \& McCormick, M. K. (2008). Internal transcribed spacer primers and sequences for improved characterization of Basidiomycetous orchid mycorrhizas. New Phytologist, 177(4), 1020-1033.

Wang X., Liu H., Gu M., Boucek R., Wu Z., Zhou G. (2015). Greater impacts from an extreme cold spell on tropical than wide ranging butterflies in southern China. Ecosphere.

Willis, S. G., Hill, J. K., Thomas, C. D., Roy, D. B., Fox, R., Blakeley, D. S., \& Huntley, B. (2009). Assisted colonization in a changing climate: a test-study using two UK butterflies. Conservation Letters, 2(1), 46-52.

Zettler, L. W., J. Sharma, \& F. N. Rasmussen. (2003). Mycorrhizal diversity. Pages 205226 in K. W. Dixon, S. P. Kell, R. L. Barrett and P. J. Cribb (eds.) Orchid Conservation. 


\section{CHAPTER V}

CONCLUSION 


\section{DISCUSSION}

This dissertation research shows that biotic interactions involving plants will be strongly affected, either positively or negatively, by predicted global change. It demonstrates that orchids make ideal study systems to better understand responses to anthropogenic change, because orchids are inordinately dependent on their biotic interactions. In the face of rapid global change, this heavy dependence on other organisms may put orchids at more risk than other, more generalist, plant species.

On the other hand, most orchids are tropical, and tropical species in general may benefit from range expansions on a warming planet, especially at the limit of their ranges in the sub-tropics. For tropical species, one can expect range expansions to continue poleward into the temperate zones, but with periodic and stochastic interruption by extreme cold events. Range expansion will be enhanced if the frequency of extreme cold weather events decreases, as predicted by global warming trends. In addition, results presented here suggest that climate change will alter interactions among species within the community and thus affect community composition; such community-level studies will provide the most realistic assessment of the potential impacts of climate change.

Results of this research also show that plant species range correlates with the breadth of community interactions. Orchids with wide range distributions (i.e. geographic or elevational) were more generalized in their mycorrhizal fungi requirements than cooccurring rare and/or narrow ranging species; the rarer species were also more likely to be affected by antagonistic fungal interactions. Overall, these findings advance the study of species invasions, range expansions, and species response to environmental change by 
addressing the potentially strong role of biotic interactions in governing species distribution, in both native and introduced ranges.

\section{FUTURE DIRECTIONS}

This research identified some of the critical mycorrhizal fungi needed to establish viable orchid populations outside their natural environment or range. Using the fungal DNA sequences, we can now begin to design PCR primers specific to each taxonomic grouping, and use these to amplify mycorrhizal fungus DNA from substrate samples. This cost-efficient method can help us determine the location and abundance of the compatible fungi within the environment, thus greatly furthering the conservation and management of orchid populations. Demographic data can then be used to create spatial

distribution maps to guide both rare species reintroductions and the mitigation of invasive species. We can also apply the horticultural knowledge we obtained to develop ex-situ propagation protocols. These protocols can enhance the availability of species that are threatened due to their commercial value, and thus relieve poaching pressure in natural populations.

\section{CONCLUSIONS}

With the current acceleration in human population growth, habitat loss, and introduction of alien species; coupled with global climate change, the prospects for conserving biodiversity can seem grim. Research such as that presented here helps to elucidate the role of community interactions in the evolution and maintenance of biodiversity. However, such knowledge will be of limited utility on a rapidly changing 
planet, unless there is a groundswell of public engagement and support for biodiversity conservation. Bridging the gaps between the scientific communities and the public will be critical to generating this support and facing the daunting challenges. While presenting a model system for studying ecological complexity and dynamics, orchids also possess the power to captivate and engage the general public. They are charismatic and powerful symbols of the wild that should be harnessed to advocate for actions to reduce human impacts and promote conservation. The research value of orchids, coupled with their broad outreach potential, make work such as that detailed in this dissertation a promising tool to combat anthropogenic pressures in the crucial years ahead. 
VITA

JASON LAMAR DOWNING

Born, Springfield, Massachusetts

2002

B.S., Organismal Biology

University of Kansas

Lawrence, Kansas

2007-2008

Post-Bachelor's

University of Miami

Coral Gables, Florida

2011

M.S., Environmental Studies

Florida International University

Miami, Florida

2011-2016

Doctoral Candidate

Florida International University

Miami, Florida

\section{PUBLICATIONS}

Downing, JL, Borrero, H, and Liu, H (2016). Differential impacts from an extreme cold spell on subtropical vs. tropical specialist bees in southern Florida. Ecosphere, accepted for publication, (MS\#: ES15-00340R1).

Weremijewicz, J, Almonte, JI, Hilaire, VS, Lopez, FD, Lu, SH, Marrero, SM, Martinez, CM, Zarate, EA, Lam, AK, Ferguson, SAN, Petrakis, Peeples, KA, Taylor, ED, Leon, NM, Valdes, C, Hass, M, Reeve, AB, Palow, D, Downing, JL (2015). Microsatellite primers for two commercially exploited and threatened orchids in Florida; Encyclia tampensis and Cyrtopodium punctatum (Orchidaceae). Applications in Plant Sciences, accepted for publication, (MS\#: APPS-D-15-00094R1).

Wuying L, Downing, JL, Liu, H., Ma, X., Ying, Zi-Bin Zhang, Z., Sheng Wang, Z. and Luo, YB. (2015) Reproductive Biology and Conservation Implications for the Endangered Orchid Geodorum eulophiodes and its Sympatric

Congeners in Southwestern China. Orchids, September: 562-569.

Downing, JL and Liu, H (2013). Self-incompatibility in Byrsonima lucida

(Malpighiaceae), a threatened pine rockland specialist. Castanea, (78): 95-102.

Downing, JL and Liu, H (2012). Friend or foe? Impacts of the introduced 
tropical oil bee Centris nitida on a threatened and specialized native mutualism in southern Florida. Biological Invasions, 14(10): 2175-2185. 